\title{
Design and testing of an independently controlled urea-SCR system for marine diesel applications
}

Derek Johnson

West Virginia University

Follow this and additional works at: https://researchrepository.wvu.edu/etd

\section{Recommended Citation}

Johnson, Derek, "Design and testing of an independently controlled urea-SCR system for marine diesel applications" (2008). Graduate Theses, Dissertations, and Problem Reports. 1909.

https://researchrepository.wvu.edu/etd/1909

This Thesis is protected by copyright and/or related rights. It has been brought to you by the The Research Repository @ WVU with permission from the rights-holder(s). You are free to use this Thesis in any way that is permitted by the copyright and related rights legislation that applies to your use. For other uses you must obtain permission from the rights-holder(s) directly, unless additional rights are indicated by a Creative Commons license in the record and/ or on the work itself. This Thesis has been accepted for inclusion in WVU Graduate Theses, Dissertations, and Problem Reports collection by an authorized administrator of The Research Repository @ WVU. For more information, please contact researchrepository@mail.wvu.edu. 
Design and Testing of an Independently Controlled Urea-SCR System for Marine Diesel Applications

by

Derek Johnson

Thesis submitted to the College of Engineering and Mineral Resources

at West Virginia University

in partial fulfillment of the requirements

for the degree of

Master of Science

in

Mechanical Engineering

Approved by

Dr. Nigel Clark, Committee Chairperson

Dr. Scott Wayne

Dr. Hailin Li

Mechanical and Aerospace Engineering Department

Morgantown, West Virginia 2008

Keywords: Urea-SCR, NOx Reduction, Marine Diesel

Copyright 2008 Derek Johnson 


\section{Abstract \\ Design and Testing of an Independently Controlled Urea-SCR System for Marine Diesel Applications}

\section{Derek Johnson}

Diesel engine emissions for on-road, stationary and marine applications are regulated through new EPA standards. The most difficult species of exhaust gas constituents to reduce are oxides of nitrogen, $\mathrm{NO}_{\mathrm{x}}$. The use of urea selective catalytic reduction (SCR) is promising for $\mathrm{NO}_{\mathrm{x}}$ abatement as a retrofit application. This work focused on the reduction of $\mathrm{NO}_{\mathrm{x}}$ by use of a stand alone urea injection system, applicable to marine diesel engines. Most current systems communicate with engine controls to predict $\mathrm{NO}_{\mathrm{x}}$ emissions based on signals such as torque and engine speed. Many marine engines employ mechanical injection technology and lack communication abilities. This system estimated $\mathrm{NO}_{\mathrm{x}}$ and measured exhaust flow independent of engine parameters. The system used independent exhaust sensor inputs to estimate $\mathrm{NO}_{\mathrm{x}}$ levels and exhaust gas flow rate. These sensor inputs were used in an independent controller and an open loop model to estimate the necessary amount of urea needed. The controller then used pulse width modulation (PWM) to power an automotive style injector for urea delivery. The goal of this work was to reduce the engine out $\mathrm{NO}_{\mathrm{x}}$ levels by 50 percent. Emissions tests were conducted at the West Virginia University's Engine Research Center. The data were analyzed to determine the $\mathrm{NO}_{\mathrm{x}}$ reduction ability of the system. NOx reduction capabilities of $41-67 \%$ were shown on the Non Road Transient Cycle (NRTC) and ICOMIA E5 Steady State cycles. The system was optimized during testing to minimize the dilute ammonia slip to cycle averages of 5-7 ppm. The goal of 50\% reduction of NOx can be achieved dependent upon cycle. Further research with control optimization and possible use of oxidation catalysts is recommended to further improve the systems NOx reduction capabilities while minimizing ammonia slip. 


\section{Dedication}

This thesis is dedicated to my parents, my family, my friends and my girlfriend; they have all supported me and told me I could do whatever I sought to do in life. It may be odd but I would lastly like to dedicate this to the old family dog Frannie. Even though she is no longer with us, she will always be in our hearts. She had the ability to bring people together and show everyone that what mattered most were the small things in life. 


\section{Acknowledgements}

I thank my advisor, Dr. Nigel Clark, for his support from my days in Challenge X to accepting me as a graduate student for this research. I would also like to thank my other committee members, Dr. Scott Wayne and Dr. Hailin Li for their time.

I would like to thank the staff of the MAE machine shop for their assistance, as well as Dave McKain for his assistance and input during testing at the laboratory. I would also like to thank everyone at MJ Bradley \& Associates for funding this research. I am also grateful for the support, donated materials and knowledge of companies which allowed me to use their products. The preparation of this thesis is based on work supported by the State of Texas through a Grant from the Texas Environmental Research Consortium and the Texas Commission on Environmental Quality and I thank them for their support.

I would like to thank my parents, Clark and Brenda Johnson for always being supportive of my engineering endeavors. They have always had words of encouragement throughout the past six years. Thank you for dealing with me through all of the reports and finals.

I would like to thank all of those friends that I have had the chance to know along this road of life, and Jared Moore, whose road ended too soon.

I never participated in sports in my youth, but I finally found my team in engineering. I am grateful for my undergraduate and graduate experiences, both good and bad, with the Challenge $\mathrm{X}$ team. I would like to mention those who have walked the road with me the past six years: Ben Smith, Howard Mearns, DJ Lenhart, Colin Hultengren, 
Clint Beddick, Josh Lantz, Jim Davis and the 2006/2007 team members. I have grown with these friends over the past few years to become the person I am today.

I would also like to thank Jeremy Sigley for the past 12 years. From working on cars in our yards during high school to becoming the best engineers of tomorrow. The stories we have could have filled this thesis alone. It has been one hell of ride the past 12 years and I hope that we continue to ride life for all its worth in the years to come.

I would finally like to thank my newest engineering peer friend, Melissa. She has stroked my ego like no other, and I think that's what allows me to continue on this path today. I am so thankful that you were there through all of these graduate years. I wouldn't have had it any other way. I love you. If I could stop time, I would stop it now and share forever with you and everyone mentioned in this thesis. I am so thankful to have everyone walking along side me down the road of life. 


\section{Table of Contents}

Design and Testing of An Independently Controlled Urea-SCR in Marine Applications .. i

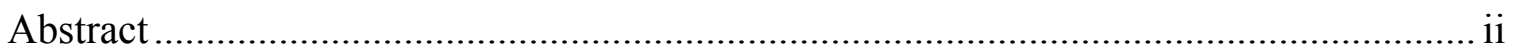

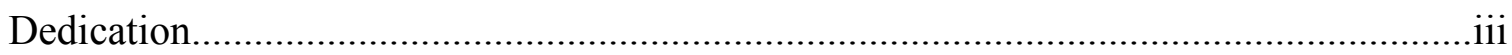

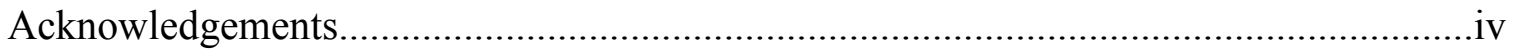

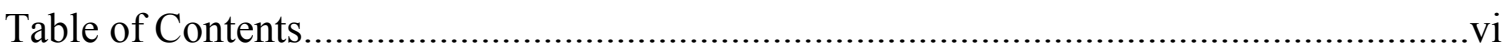

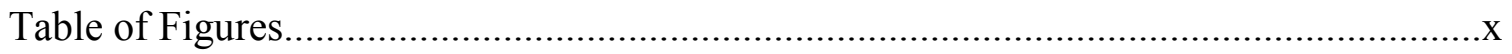

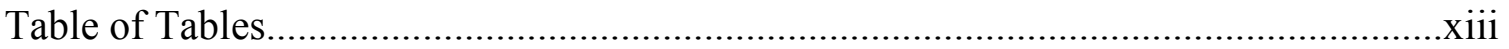

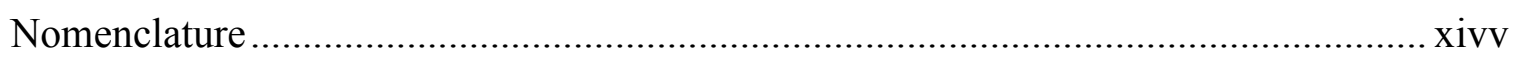

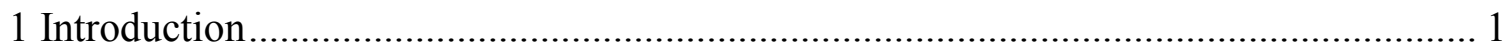

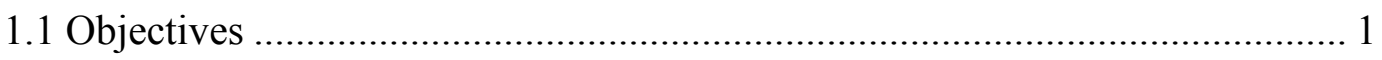

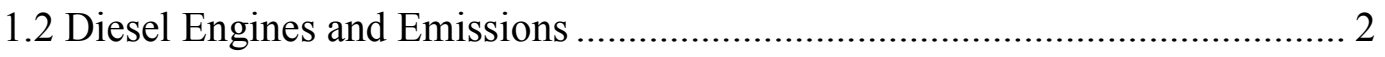

1.3 Health and Environmental Effects ............................................................. 2

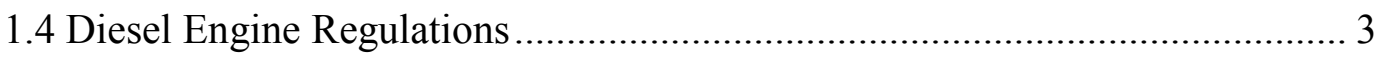

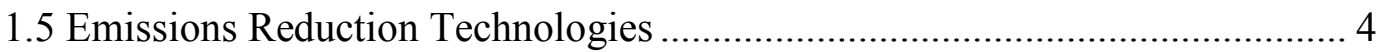

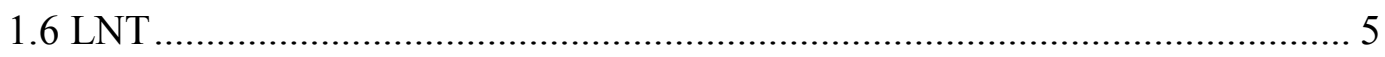

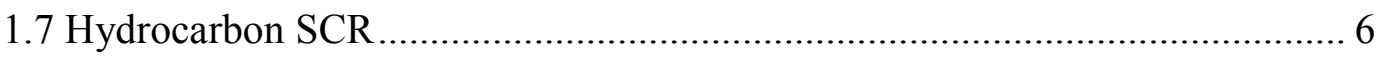

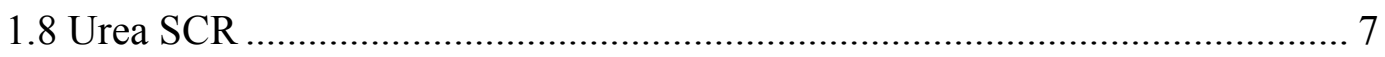

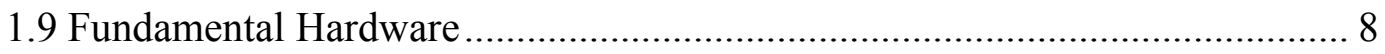

1.10 Advantages and Disadvantages................................................................. 12

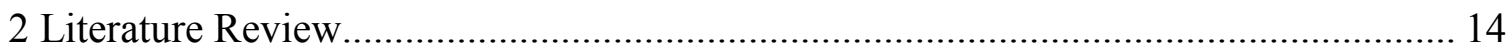

2.1 Improved SCR Systems for Heavy Duty Diesel Engine Applications ........... 14

2.2 Development of Urea DeNOx Catalyst Concept for European Ultra-Low

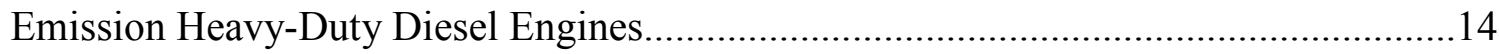


2.3 Urea-SCR Catalyst System Selection for Fuel and PM Optimized Engines and Demonstration of a Novel Urea Injection System ...................................................... 15

2.4 RJM Corporation (Production Systems) ...................................................... 16

2.5 Off-Highway Exhaust Gas After-Treatment: Combining Urea-SCR, Oxidation Catalysis and Traps 17

2.6 Thick Film $\mathrm{ZrO}_{2} \mathrm{NOx}$ Sensor for the Measurement of Low NOx

Concentration 17

2.7 Development of Urea-SCR for Heavy-Duty Trucks Demonstration Update.. 18

2.8 The Development and Performance of the Compact SCR-Trap System: A 4-

Way Diesel Emission Control System 18

2.9 Development of Urea-SCR System for Heavy-Duty Commercial Vehicles .. 19

2.10 Simulation on the Optimum Shape and Location of Urea Injector for Urea-

SCR System of Heavy-duty Diesel Engine to Prevent $\mathrm{NH}_{3}$ Slip..................................... 20

2.11 Diesel Emission Control Technology -2003 in Review.............................. 20

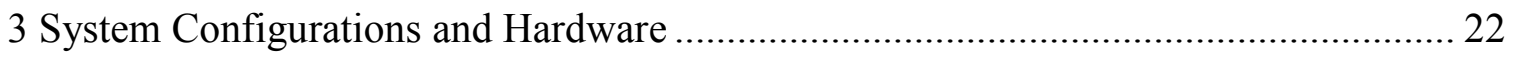

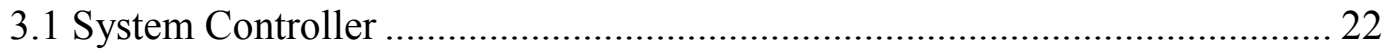

3.2 Urea

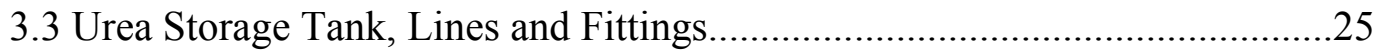

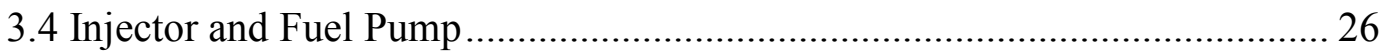

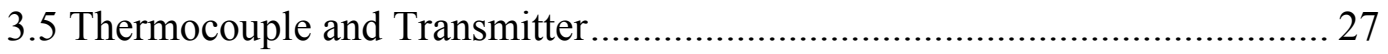

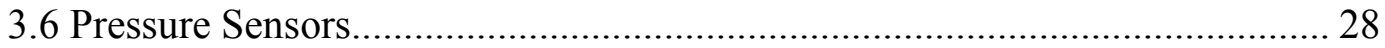

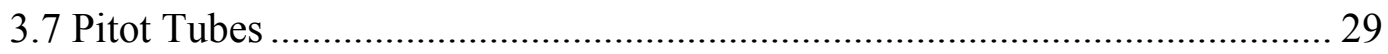

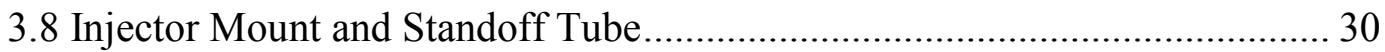

vii 


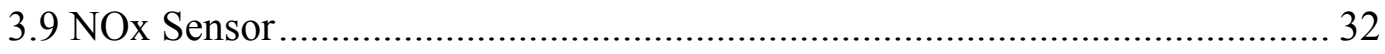

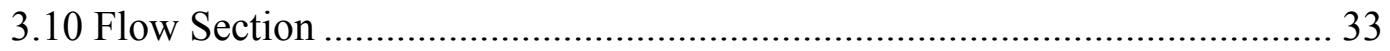

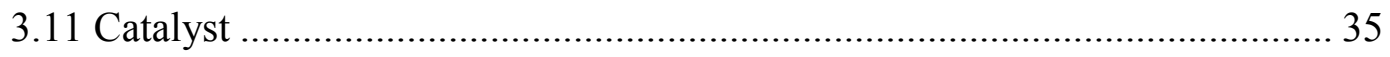

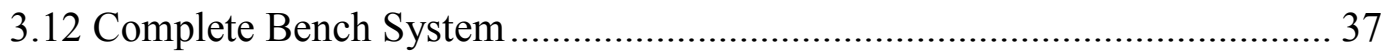

4 System Model and Control Logic ...............................................................................

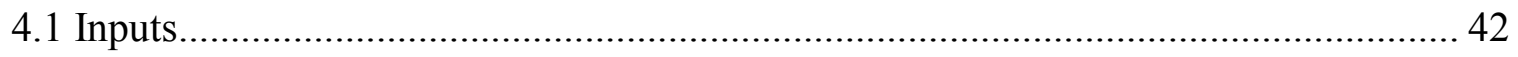

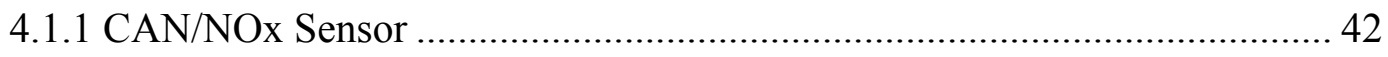

4.1.2 Differential Pressure Sensor ................................................................... 43

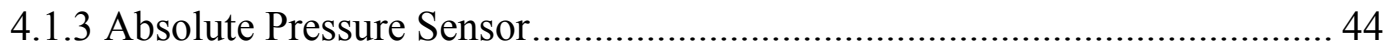

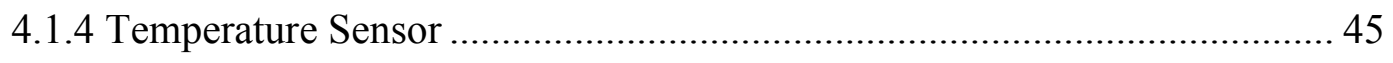

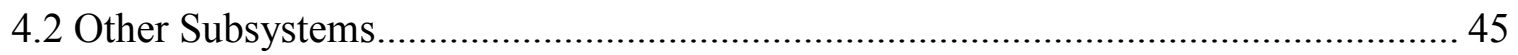

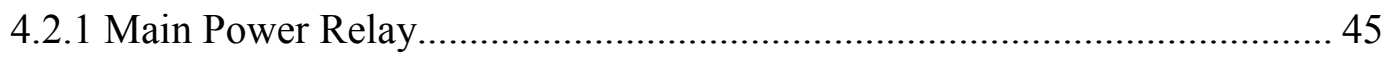

4.2.2 Temperature Conversion for Ideal Gas Law.............................................. 46

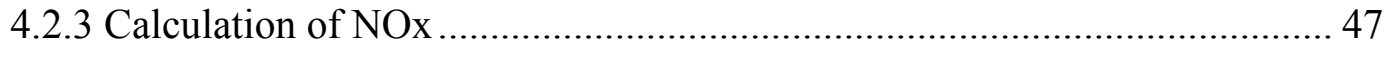

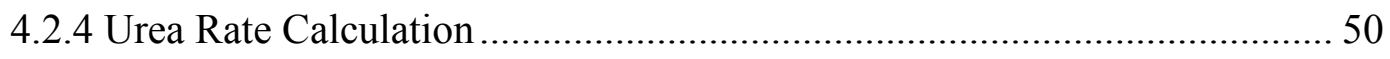

4.2.5 Boolean Switch Logic............................................................................. 51

4.2.6 Secondary Subsystem for Temperature Estimation..................................... 52

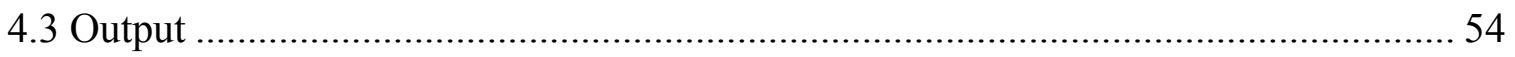

4.3.1 Duty Cycle for Urea Injector .................................................................... 54

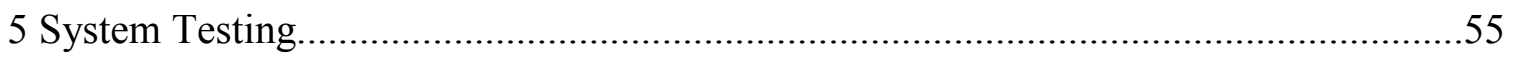

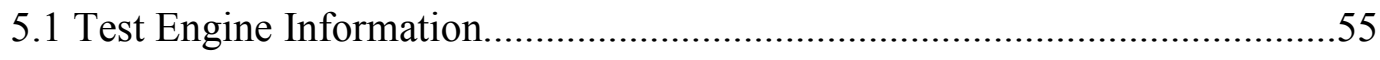

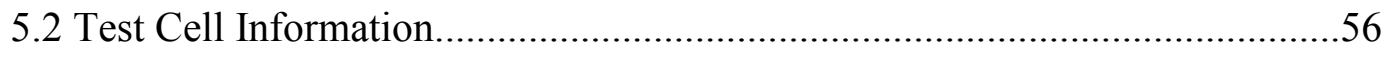

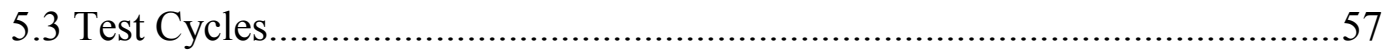

viii 


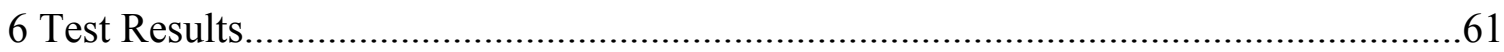

6.1 System Correlation Results....................................................................61

6.2 NRTC with varied Duty Cycle............................................................. 70

6.3 ICOMIA E5 with 50\% Duty Cycle.............................................................. 76

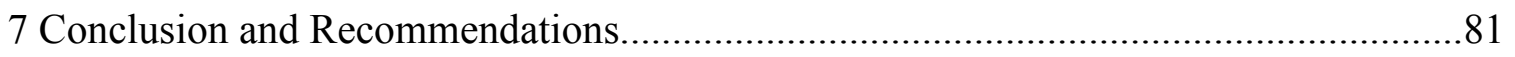

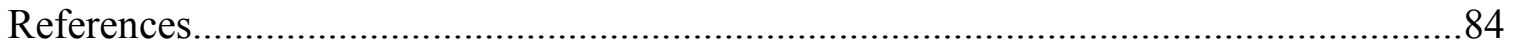

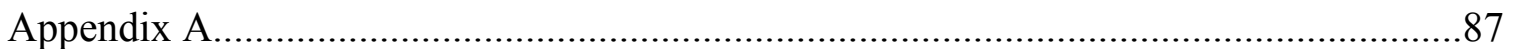




\section{Table of Figures}

Figure 1.1 Typical Diesel Exhaust System..........................................................

Figure 1.2 Possible Exhaust System Components....................................................10

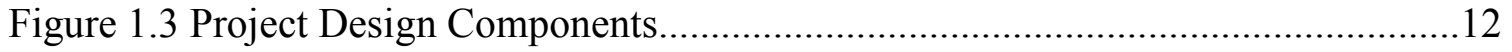

Figure 3.1 MotoHawk 80-Pin Controller and Wiring Harness.......................................24

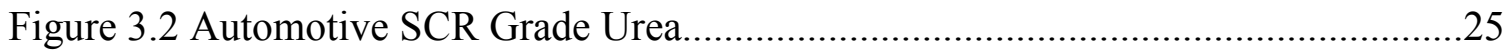

Figure 3.3 Urea Storage Tank with Fuel Line and Pressure Gauges..............................26

Figure 3.4 Injector with Upper and Lower Mounts Attached to Stainless Steel Standoff

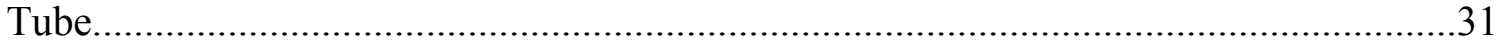

Figure 3.5 Differential Pressure for Various Diameter Flow Tubes...............................35

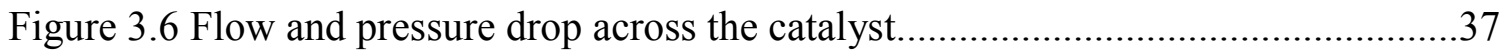

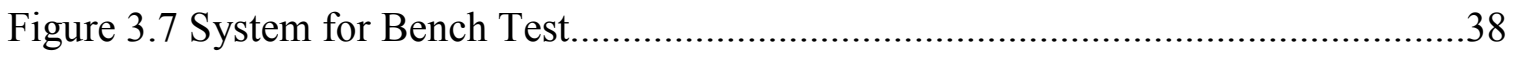

Figure 4.1 Complete System Model as Viewed in Simulink.......................................40

Figure 4.2 100ms Foreground Model Layout........................................................41

Figure 4.3 Standard MotoHawk CAN Read and Send Message Blocks........................42

Figure 4.4 Differential Pressure Subsystem with Analog Input and PSI Output..............44

Figure 4.5 Absolute Pressure Subsystem in the Simulink Environment..........................45

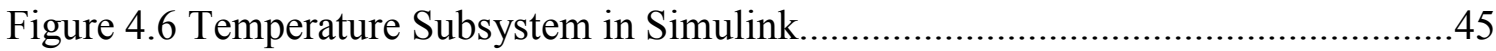

Figure 4.7 Main Power Relay Subsystem for Software Control of System....................46

Figure 4.8 Conversion From Celsius to Rankine and Gas Constant for Air.....................47

Figure 4.9 NOx Mass Flow Rate Estimation Subsystem............................................50

Figure 4.10 Subsystem to Convert NOx Rate into Injector Duty Cycle..........................51

Figure 4.11 Software Switch for Lower Temperature Limit for Urea Injection...............52 
Figure 4.12 Temperature Estimation Subsystem to Account for Thermal Inertia. .53

Figure 4.13 Motohawk PWM Output for Urea Injector. .54

Figure 5.1 Engine Map for John Deere engine. .55

Figure 5.2 Test Cell Set Up Showing, Urea Injection System, SCR catalyst, John Deere Engine and Test Cell Dynamometer. .57

Figure 5.3 NRTC Engine Speed and Torque Set Points.............................................58

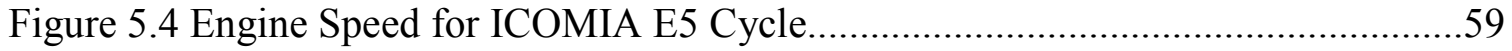

Figure 6.1 EcoPhysics and Siemens NOx Sensor Comparison for NRTC cycle.............62

Figure 6.2 Correlation of Siemens NOx Data with Respect to EcoPhysics NOx Data.....63

Figure 6.3 9-Pt Average of NOx Readings from EcoPhysics and Siemens NOx Sensor..64

Figure 6.4 Correlations of the Two Data Sets with a 9-Pt Average ..............................65

Figure 6.5 Comparison of Flow Tube and LFE for NRTC.........................................66

Figure 6.6 Correlation of Flow Tube Against Intake LFE........................................66

Figure 6.7 Temperature Plot for EERL and UIS Thermocouple Outputs......................67

Figure 6.8 NOx Comparisons for the EcoPhysics and Siemens Sensor During the

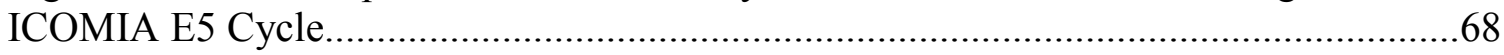

Figure 6.9 Flow Comparison of LFE and UIS Flow Tube for ICOMIA E5 Cycle..........69

Figure 6.10 Temperature Plot for EERL and UIS Thermocouple Outputs for ICOMIA E5

Cycle.

Figure 6.11 Run to Run Reduction in NOx (ppm) Based on Varied Duty Cycle..............71

Figure 6.12 Urea Injection Rate Based on DC Requested and Flow Tube Temperature..72

Figure 6.13 NRTC CO Emissions for Various Cycles with and Without Urea

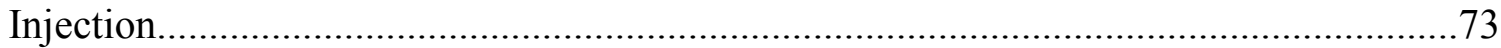

Figure 6.14 Dilute Ammonia Levels for NRTC 100\% DC.........................................74

Figure 6.15 NRTC with 50\% DC NOx Results and Continuous Reduction Percentage...75 
Figure 6.16 Dilute Ammonia Results for NRTC with 50\% DC..................................75

Figure 6.17 ICOMIA E5 Test Results with NOx Reduction Percentage for 50\% DC......77

Figure 6.18 Dilute Ammonia Slip Results for E5 50\% DC....................................... 78

Figure 6.19 E5 Carbon Monoxide Results............................................................... 


\section{Table of Tables}

Table 1.1: Tier 2 Standards for Marine Diesel Engines ................................................ 4

Table 3.1: Typical Physical Properties of 32.5\% Aqueous Urea Solution: DeNOx Grade Meets Specifications of DIN 70070:2005 and ISO 22242-1:2005 for NOx Abatement

Technologies............................................................24

Table 3.2: Pressure Ranges for Maximum Flow of 2000 CFM and Minimum Flow of 150

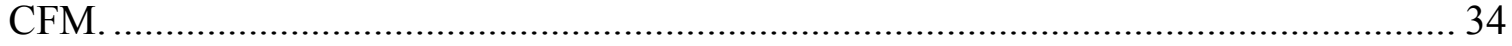

Table 5.1: ICOMIA E5 Cycle Mode Data and Set Points...........................................59

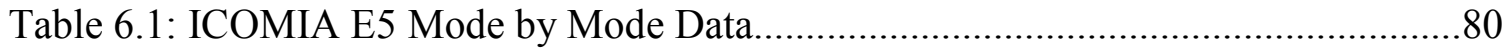




\section{Nomenclature}

ARIS Advanced Reagent Injection System

CAN Controller Area Network

CARB California Air Resource Board

CO Carbon Monoxide

$\mathrm{CO}_{2} \quad$ Carbon Dioxide

cpi cells per square inch

CR-DPF Continuously Regenerating Diesel Particulate Filter

${ }^{\circ} \mathrm{C} \quad$ Degrees Celsius

DOC Diesel Oxidation Catalyst

DPF Diesel Particulate Filter

ECU Engine Control Unit

EGR Exhaust Gas Recirculation

EPA Environmental Protection Agency

ESC European Stationary Cycle

FTP $\quad$ Federal Test Procedure

g/bhp-hr grams per brake horsepower hour

$\mathrm{g} / \mathrm{kWh} \quad$ grams per kilowatt hour

HC Hydrocarbons

$\mathrm{HCNO} \quad$ Isocyanic Acid

HDDE Heavy Duty Diesel Engine

hp horsepower

H-SCR Hydrocarbon Selective Catalytic Reduction

$\mathrm{H}_{2} \mathrm{O} \quad$ Water 


$\begin{array}{ll}\mathrm{ICCT} & \text { International Council On Clean Transportation } \\ \mathrm{K} & \text { Temperature in Kelvin } \\ \mathrm{kW} & \text { kilowatt } \\ \mathrm{L} & \text { liters of displacement } \\ \mathrm{LNT} & \text { Lean } \mathrm{NO}_{\mathrm{x}} \text { Trap } \\ \mathrm{NH}_{3} & \text { Ammonia } \\ \mathrm{NO}_{\mathrm{x}} & \text { Oxides of Nitrogen } \\ \mathrm{NO} & \text { Nitrogen Monoxide } \\ \mathrm{NO}_{2} & \text { Nitrogen Dioxide } \\ \mathrm{N}_{2} & \text { Diatomic Nitrogen } \\ \mathrm{O}_{2} & \text { Diatomic Oxygen } \\ \mathrm{PM}_{\mathrm{PM}} & \text { Particulate Matter } \\ \mathrm{ppm}_{\mathrm{SCR}} & \text { parts per million } \\ \mathrm{SCC} & \text { Selective Catalytic Reduction } \\ \mathrm{TVU}_{2} & \text { Top Dead Center } \\ & \text { West Virginia University } \\ \end{array}$




\section{Introduction}

Diesel engines are known for their durability and high fuel economy. They are used in small displacement generators and light duty automotive applications all the way up to heavy duty trucks, machinery and marine applications. Their longevity and power makes them perfect for marine applications where the vessels may be in service for thirty years or more. Diesel engines, especially older diesel engines, produce substantial regulated pollutants. These include oxides of nitrogen (NOx), particulate matter (PM), hydrocarbons $(\mathrm{HC})$ and carbon monoxide $(\mathrm{CO})$. This research focused on the reduction of NOx from diesel engines in marine applications. The vessels targeted were in the Environmental Protection Agency's (EPA) C1 marine class. The displacement of C1 engines was up to 5 liters per cylinder. Engines indicative of $\mathrm{C} 1$ class were used for testing. However, the technology developed may be adapted for use in all arenas of diesel engine applications. The emission reduction system of this project was a urea SCR exhaust after treatment system. Following is a review of technologies that reduce the regulated emissions from diesel engines as well as an in depth review of the current state of SCR applications.

\subsection{Objectives}

The objective of this research was to design, implement and test a urea injection system applicable to marine diesel applications. The goal was to reduce the NOx levels at the stack by $50 \%$ while minimizing or preventing ammonia slip. The system was to be stand-alone, in that it was not to communicate with the engine. The system was also to be independently controlled, so as to be applicable to any marine engine without intensive engineering per application. 


\subsection{Diesel Engines and Emissions}

Diesel engines may be found in a variety of applications and various states of technology due to their longevity. The engines are powered by diesel fuel that is injected electronically or mechanically into the cylinder near top dead center (TDC). The high compression ratio of the engines, on the order of 15:1 or greater, auto ignites the fuel charge. These engines may be naturally aspirated or turbocharged. Diesel engines may be on the order of $35-50 \%$ more efficient than gasoline engines of similar sizes due to throttling at part load operation (1). This high efficiency comes from their high thermal efficiencies, constant pressure heat addition and the complete combustion of diesel. However, these engine characteristics lead to unwanted and harmful emissions. The high compression leads to combustion temperatures above 2000K. Above this level, dissociation of diatomic nitrogen into monatomic nitrogen occurs. This monatomic nitrogen combines with oxygen to form NOx. The lean burn also leads to excess oxygen and with localized incomplete combustion still occurring, carbon monoxide forms. Partially oxidized hydrocarbons from the fuel and from engine lubricants lead to hydrocarbon and PM emissions (2).

\subsection{Health and Environmental Effects}

Health and environmental effects of diesel exhausts have been studied for decades. Health problems range from acute responses to chronic effects from long term exposure. Acute exposure to diesel exhaust may cause irritation of the eyes, nose, throat and neurological effects such as lightheadedness: while, long term exposure may cause chronic lung inflammation. Studies have shown that some exhaust constituents may be carcinogenic (3). Diesel emissions also negatively influence the environment. Oxides of 
nitrogen contribute to smog and acid rain (4). Due to these negative health and

environmental effects, regulations have decreased the allowable production of regulated emissions.

\subsection{Diesel Engine Regulations}

Due to the effects on health and ambient air quality, diesel emission regulations continue to become stringent. New standards have been enacted in America to meet various Environmental Protection Agency (EPA) Tier and Bin levels. Similar systems of regulations occur in Europe with Euro emissions standards. On-road diesel regulations decreased emissions in 2007 and will do so again in 2010. Stringent marine regulations have also followed suite. The currently regulated emissions from diesel engines are NOx, PM, CO and HC. The marine emissions levels for $\mathrm{C} 1$ engines with displacements of 0.9 to 1.2 liters per cylinder were lowered to $7.2 \mathrm{~g} / \mathrm{kW}-\mathrm{hr}$ for $\mathrm{HC}+\mathrm{NOx}$ in 2004 . The California Air Resources Board (CARB) has projected that without new regulations for marine diesel engines, their emissions would account for $9 \%$ of NOx and $25 \%$ of PM statewide for California (5). The International Council on Clean Transportation (ICCT) has released reports stating that air pollution from ships has overtaken all produced by road traffic. Ocean going ships produce $17 \%$ of the total NOx, which can jump to $25 \%$ in most port cities (6). While it may be difficult to lower emissions from international ships in port cities, offsetting the emissions levels by using new technologies on passenger ferries and local tugboats would help. Table 1 shows the Tier 2 emissions standards for engines covering the marine applications of ferries and tugboats. These standards applied to new engines only and the research conducted was to apply to older engines as retrofit applications. 
Table 1.1: Tier 2 Standards for Marine Diesel Engines (7)

\begin{tabular}{|c|c|c|c|c|c|c|}
\hline Category & $\begin{array}{l}\text { Displacement } \\
\text { (liter/cylinder) }\end{array}$ & $\begin{array}{l}\text { Power } \\
(\mathrm{kW})\end{array}$ & $\begin{array}{l}\text { Tier } 2 \\
\text { Model } \\
\text { Year }\end{array}$ & $\begin{array}{l}\mathrm{HC}+\mathrm{NOx} \\
(\mathrm{g} / \mathrm{kW}- \\
\mathrm{hr})\end{array}$ & $\begin{aligned} & \mathrm{PM} \\
&(\mathrm{g} / \mathrm{kW}- \\
&\mathrm{hr})\end{aligned}$ & $\begin{array}{l}\mathrm{CO} \\
(\mathrm{g} / \mathrm{kW}- \\
\mathrm{hr})\end{array}$ \\
\hline Small & $\begin{array}{l}- \\
- \\
-\end{array}$ & $\begin{array}{l}<8 \mathrm{~kW} \\
8 \leq \mathrm{kW} \leq 19 \\
8 \leq \mathrm{kW} \leq 19\end{array}$ & $\begin{array}{l}2005 \\
2005 \\
2004\end{array}$ & $\begin{array}{l}7.5 \\
7.5 \\
7.5\end{array}$ & $\begin{array}{l}0.80 \\
0.80 \\
0.60\end{array}$ & $\begin{array}{l}8.0 \\
6.6 \\
5.5\end{array}$ \\
\hline $\begin{array}{l}\text { Commercial } \\
\text { C1 }\end{array}$ & $\begin{array}{l}\text { disp. }<0.9 \\
0.9 \leq \text { disp. }<1.2 \\
1.2 \leq \text { disp. }<2.5 \\
2.5 \leq \text { disp. }<5.0\end{array}$ & $\begin{array}{l}\geq 37 \mathrm{~kW} \\
- \\
- \\
-\end{array}$ & $\begin{array}{l}2005 \\
2004 \\
2004 \\
2007\end{array}$ & $\begin{array}{l}7.5 \\
7.2 \\
7.2 \\
7.2 \\
\end{array}$ & $\begin{array}{l}0.40 \\
0.30 \\
0.20 \\
0.20\end{array}$ & $\begin{array}{l}5.0 \\
5.0 \\
5.0 \\
5.0\end{array}$ \\
\hline $\mathrm{C} 2$ & $\begin{array}{l}5.0 \leq \text { disp. }<15 \\
15 \leq \text { disp. }<20 \\
15 \leq \text { disp. }<20 \\
20 \leq \text { disp. }<25 \\
25 \leq \text { disp. }<30\end{array}$ & $\begin{array}{l}- \\
<3300 \mathrm{~kW} \\
\geq 3300 \mathrm{~kW} \\
- \\
-\end{array}$ & $\begin{array}{l}2007 \\
2007 \\
2007 \\
2007 \\
2007\end{array}$ & $\begin{array}{l}7.8 \\
8.7 \\
9.8 \\
9.8 \\
11.0\end{array}$ & $\begin{array}{l}0.27 \\
0.50 \\
0.50 \\
0.50 \\
0.50\end{array}$ & $\begin{array}{l}5.0 \\
5.0 \\
5.0 \\
5.0 \\
5.0\end{array}$ \\
\hline Recreation $\mathrm{Cl}$ & $\begin{array}{l}\text { disp. }<0.9 \\
0.9 \leq \text { disp. }<1.2 \\
1.2 \leq \text { disp. }<2.5 \\
2.5 \leq \text { disp. }<5.0\end{array}$ & $\begin{array}{l}\geq 37 \mathrm{~kW} \\
\geq 37 \mathrm{~kW} \\
\geq 37 \mathrm{~kW} \\
\geq 37 \mathrm{~kW}\end{array}$ & $\begin{array}{l}2007 \\
2006 \\
2006 \\
2009\end{array}$ & $\begin{array}{l}7.5 \\
7.5 \\
7.2 \\
7.2\end{array}$ & $\begin{array}{l}0.40 \\
0.30 \\
0.20 \\
0.20\end{array}$ & $\begin{array}{l}5.0 \\
5.0 \\
5.0 \\
5.0\end{array}$ \\
\hline
\end{tabular}

\subsection{Emissions Reduction Technologies}

There are many options in emissions reduction technologies to apply to marine diesel engines. Many engines have been in service for 30 years; EPA modeling reports show the estimated engine life for marine engines of testing size to be 7,000 hours at maximum power (8). Depending upon service, the engine life before rebuild can become substantial. West Virginia University previously tested emissions reduction systems on the Alice Austen Ferry in New York. With a commission date of 1986, the vessel and its Caterpillar engines have been in service for over 20 years (9). Engines of this era and older do not use many of the new technologies that allow for lower emissions.

Electronically controlled fuel injection, exhaust gas recirculation (EGR), lower fuel sulfur content and water injection systems are technologies that may be implemented to reduce NOx emissions significantly. These methods are difficult to employ because of the 
necessary down time of the engines. These systems also have large cost penalties associated with physical engine rebuild or retrofit. The Carl Moyer Program is a financial assistance program in California that helps owners of older diesel engines to rebuild or replace them with Tier 2 engines (10). This program has helped to make 190 vessels cleaner burning using a variety of technologies but is only applicable to California. Similar incentives have also been implemented else where such as the Texas Emissions Reduction Plan (TERP) (11).

Without large scale assistance programs and the need to minimize downtime, stand-alone exhaust after treatment systems are a more attractive technology. NOx reduction after-treatment methods include, but are not limited to, the following: lean NOx traps (LNT), hydrocarbon selective catalytic reduction (H-SCR) and urea selective catalytic reduction (urea-SCR). Each of these systems may be used in conjunction with other emissions control devices such as diesel oxidation catalysts (DOCs) or diesel particulate filters (DPFs). Urea SCR was chosen for the reduction system for this research. A brief discussion follows on LNT and H-SCR systems including their downfalls.

\subsection{LNT}

Lean NOx traps are made of a honeycomb system that contains a precious metal such as platinum. The function of the precious metal is to oxidize the engine out NO to NOx. Another pivotal component of the LNT is an alkali metal salt that is used to form and store a nitrate during the common lean burn scenario of the diesel cycle. NOx is not easily oxidized in the $\mathrm{O}_{2}$ rich environment. If the engine is run in a rich burn mode or secondary injection of fuel into the exhaust occurs, the nitrate releases the NOx that is 
then reduced to $\mathrm{N}_{2}$ and $\mathrm{H}_{2} \mathrm{O}$ (2). Diesel engines run lean to produce their power, torque and efficiency. Therefore, in order for the LNT to work, an engine ECU or other controller must inject more fuel for a given time to create rich burn conditions allowing the oxidation of $\mathrm{NO}_{2}$. This condition creates a fuel penalty. A study done on a 1.7L A170 engine at Argonne National Laboratory showed NOx conversion efficiency approximately 89 percent with a fuel penalty of just over 11 percent (1). These numbers are promising for LNT technology but mainly for light duty applications as tested. A fuel penalty on the order of 10 percent would be too costly to implement in marine applications. LNTs are highly sensitive to the sulfur content of fuels. Conversion efficiency drops with both catalyst aging and increasing sulfur content (12).

\subsection{Hydrocarbon SCR}

Hydrocarbon SCR (H-SCR) systems use a hydrocarbon fuel such as ethanol to reduce NOx emissions. This system requires a secondary injection system for the ethanol injection into the exhaust system. The catalyst is alumina supported, highly loaded with silver. At temperatures in the range from $350-400{ }^{\circ} \mathrm{C}$, the ethanol quickly converts to acetaldehyde for $\mathrm{NO}_{\mathrm{x}}$ reduction. Conversion efficiencies for such systems have been as high as $80-90$ percent. This system's fuel penalty is approximated at about two to three percent, significantly lower than the penalty for a LNT. A disadvantage of an H-SCR system is the increased $\mathrm{HC}$ emissions slipping past the catalyst. This problem is addressed with the use of catalyzed diesel particulate traps. Oakridge National Laboratories and Caterpillar conducted tests on a Cummins ISB 5.9 liter engine used in light duty trucks. The test showed NOx conversion efficiency as high as 95 percent. However, as catalyst core temperatures dropped to $250^{\circ} \mathrm{C}$ the converter efficiency fell to 
25 percent. Further research must be done in the area of HC-SCR before it can reach the wide range of efficiencies achieved by urea SCR (13).

\subsection{Urea SCR}

Selective catalytic reduction systems utilizing urea as a reducing agent are one of the most promising means of meeting the new stringent diesel emissions standards. When compared to other reduction methods, urea-SCR shows substantial NOx reduction and a wider operational temperature range (14). Urea SCR systems have been used on stationary power plant applications for years. This stationary technology now faces the challenge of becoming a mobile, transient application.

The main goal of the system is to reduce NOx by ammonia injection. SCR catalyst cores are made of mainly metal zeolite compounds. Research is also being done with combined catalysts. These compounds react with ammonia to convert $\mathrm{NO}_{\mathrm{x}}$ into $\mathrm{N}_{2}$ and $\mathrm{H}_{2} \mathrm{O}$. The reducing agent solution is eutectic with 32.5 percent urea in water (15). The ammonia needed for the reaction comes from the high temperature hydrolysis of urea with the exhaust flow. The equation for hydrolysis is given below and yields both ammonia $\left(\mathrm{NH}_{3}\right)$ and isocyanic acid $(\mathrm{HCNO})$. The second equation shows the further reduction of $\mathrm{HCNO}$ with water vapor in the exhaust.

$$
\begin{array}{ll}
\left(\mathrm{NH}_{2}\right)_{2} \mathrm{CO} \rightarrow \mathrm{NH}_{3}+\mathrm{HCNO} & \text { Equation 1 } \\
\mathrm{HNCO}+\mathrm{H}_{2} \mathrm{O} \rightarrow \mathrm{NH}_{3}+\mathrm{CO}_{2} & \text { Equation 2 }
\end{array}
$$

The majority of these systems utilize an upstream oxidation catalyst to optimize the $\mathrm{NO}_{2}$ /NO ratios. Once this ratio is optimized, three main equations describe how the urea SCR works to reduce $\mathrm{NO}_{\mathrm{x}}$. They are: 


$$
\begin{array}{ll}
6 \mathrm{NO}_{2}+8 \mathrm{NH}_{3} \rightarrow 7 \mathrm{~N}_{2}+12 \mathrm{H}_{2} \mathrm{O} & \text { Equation 3 } \\
4 \mathrm{NH}_{3}+4 \mathrm{NO}+\mathrm{O}_{2} \rightarrow 4 \mathrm{~N}_{2}+6 \mathrm{H}_{2} \mathrm{O} & \text { Equation 4 } \\
4 \mathrm{NH}_{3}+2 \mathrm{NO}+2 \mathrm{NO}_{2} \rightarrow 4 \mathrm{~N}_{2}+6 \mathrm{H}_{2} \mathrm{O} & \text { Equation 5 }
\end{array}
$$

As can be seen from the last equation, the $\mathrm{NO}_{2} / \mathrm{NO}$ ratio is pivotal because this reaction occurs at a rate ten times faster than the second, converting as much $\mathrm{NO}$ as $\mathrm{NO}_{2}(16)$. Typically NO constitutes $90 \%$ of the NOx level while $\mathrm{NO}_{2}$ is $10 \%$ or less. When hardware and control are properly sized and optimized urea SCR systems can achieve NOx reduction efficiencies greater than 90 percent. Therefore the physical design and implementation are important to ensure that the fundamental chemistry dominating a urea SCR system can occur.

\subsection{Fundamental Hardware}

The exhaust systems of heavy duty diesel applications are usually similar when not equipped with after treatment devices. The components of a simple diesel exhaust system are show in Figure 1.1. The exhaust exits the cylinders into the exhaust manifold. From the manifold it flows through the exhaust-gas turbine and then exits into an exhaust piping system. The main component post turbocharger is the sound attenuator. After the sound attenuators, there may be more exhaust piping used to direct exhaust flow from the vehicle or into the water for marine applications. 


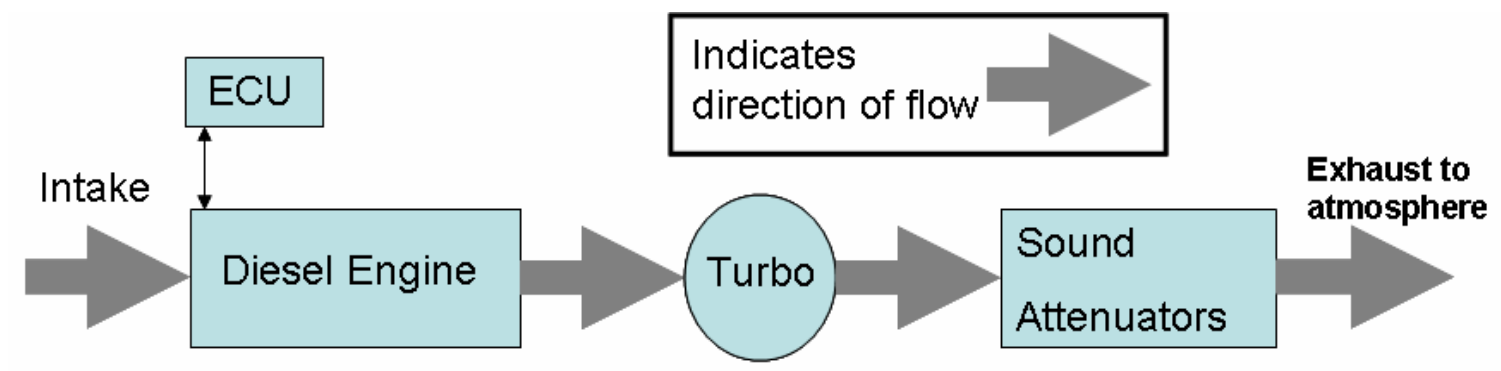

Figure 1.1 Typical Diesel Exhaust System

The hardware that forms the after-treatment system for a typical urea SCR system is complex. Most urea SCR systems utilize a DOC before the injection plane, an injector, urea storage and delivery system, air supply for system purging, catalyst, sensors, post oxidation catalyst for ammonia slip, and a controller that typically communicates with the ECU. The controller of these systems often looks at broadcast engine speed, load, or mass air flow to help determine a NOx map. With these parameters the system should be able to inject the proper amount of urea into the exhaust flow. A downfall of this system is the inability to apply it to retrofit applications where mechanical injection occurs and intensive engineering per application would be necessary. Figure 1.2 shows the components of a urea SCR system. The sensors block may contain temperature sensors and pressure sensors for flow and system fail safes.

The exhaust flows from the turbocharger through the first diesel oxidation catalyst (DOC). This catalyst can reduce both $\mathrm{HC}$ and $\mathrm{CO}$ emissions as well as help to optimize the NOx ratio. The exhaust then flows past sensors which are typically temperature sensors used to detect when the exhaust is hot enough for urea injection. Other sensors may be used to monitor pressure in case of plugging of components by particulate matter. Once the system temperature is above the threshold, the urea control unit initializes the injection algorithm. The amount of urea injected corresponds to internal maps that are 
based on communication with the engine control unit. The urea is delivered into the exhaust by a dosing pump or injector. The urea has a separate storage and pumping system. It is also common that an air supply is plumbed to help purge the system. This purging helps remove urea crystals and liquid urea from the system. After urea is injected it becomes ammonia and flows to the main catalyst of the urea-SCR. This is where most of the NOx reduction occurs. However, if the system becomes saturated from over dosing and surpasses the catalyst storage capacity then ammonia may slip through the catalyst. In this case, another clean-up catalyst oxidizes any of the slipped ammonia. Clean-up catalysts may use platinum (Pt) to yield high conversion (99\%) of any slipped $\mathrm{NH}_{3}$ to $\mathrm{N}_{2}$ at low exhaust temperatures (17). Then the "cleaner" exhaust typically flows to the atmosphere.

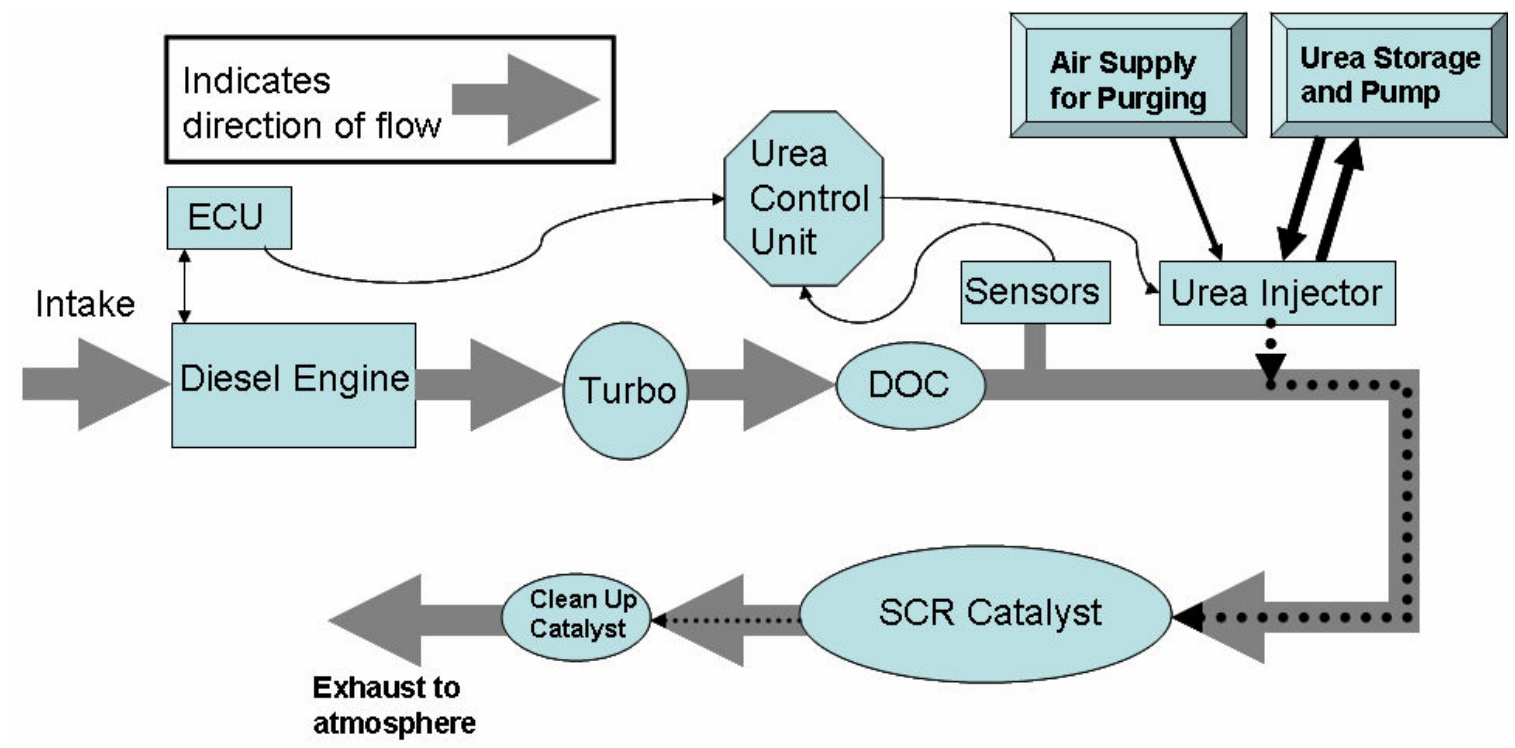

Figure 1.2 Possible Exhaust System Components

The design below is for a novel stand alone system. The design is a broad overview of the system that was developed in this research. The design was chosen for 
simplicity and ease of retrofit applications. This research was done to examine the effectiveness of such a system and make conclusions on its design and function. Many designs for urea SCR systems can be made that fall between this system and the previously discussed system.

The system under consideration will not communicate with an ECU. The exhaust flows from the turbine into the exhaust pipe. The system tested eliminated the DOC before and after the main catalyst. The benefit of their exclusion saved cost and volume. The sensors for this system included a thermocouple and pressure transducers. These were used to calculate the exhaust flow since intake flow will not be used from the ECU. The design also included a NOx sensor placed in the exhaust to measure the NOx levels. Once the urea SCR system temperature threshold has been met, the urea control unit would initialize the injection algorithm. This system utilized corrosive resistant tubes, tanks and pumps. A continuous pump system was used to supply the injector with urea at all times. This system did not utilize an air purging system. In tugboat and ferry class marine vessels air supplies are sparse at best. After the exhaust flowed from the injection plane, it traveled through the main catalyst where NOx reduction occurred. The flow then exited the exhaust system as previously described.

The project hoped to demonstrate $50 \%$ or greater NOx reduction. Fully integrated and highly controlled systems have shown $70-90 \%$ or greater NOx reduction. The goal of $50 \%$ was introduced because to achieve this amount of reduction; the system can be smaller in volume, lowering cost, applied to a wide range of applications and prevent ammonia overflow. Because of the low reduction goal, the likelihood for ammonia slip decreased due to the lower ammonia concentration. The cost could also be decreased 
significantly if pre-oxidation and post-oxidation catalysts were not needed to achieve the target goals.

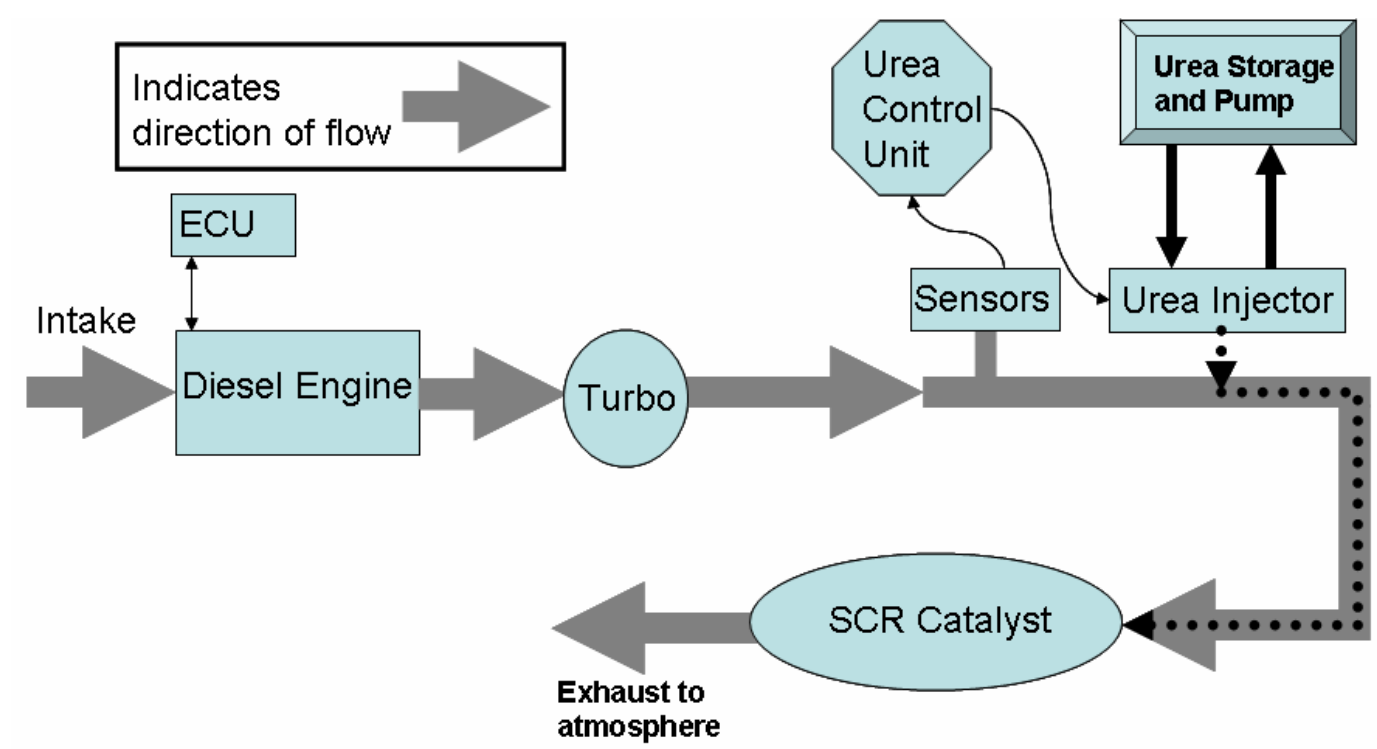

Figure 1.3 Project Design Components

\subsection{Advantages and Disadvantages}

The goal of this research was to verify that the system would work properly and examine the NOx reduction efficiency. The system was to reduce NOx levels by $50 \%$ while minimizing ammonia slip. The system would also need to be easily implemented and calibrated for broad applications. These applications included the ability to endure sustained cycles at temperatures at or greater than $400^{\circ} \mathrm{C}$, measure raw NOx levels of greater than $500 \mathrm{ppm}$, operate over indicative marine cycles without injection failure and measure exhaust mass flow accurately. The system tested had both advantages and disadvantages. The main advantages were ease of installation, fewer parts to fail, low cost and ruggedness. However, the main disadvantage was lower NOx reduction ability, due to lack of ECU communication and conservative dosing strategy. High NOx reduction was not the goal of the research or project. The goal was to design and test a rugged 
system that provided substantial NOx reduction while minimizing ammonia slip. The system was to be novel in design and stand alone. It was to possess the ability to be scaled to a variety of common applications without the various wiring or communications problems. The system above was tested in West Virginia University's (WVU's) Engines and Emissions Research Laboratory. The subsequent sections provide details on the design, set up and testing. It also contains the test results, comments and conclusions. 


\section{Literature Review}

This section contains a review of literature from various sources in the area of mobile urea SCR applications. The work discussed was found in technical papers from independent companies, research universities and national laboratories.

\subsection{Improved SCR Systems for Heavy Duty Diesel Engine Applications}

Engineers at Degussa-Huls AG performed both gas bench and engine bench tests on a urea SCR system (18). Variables such as catalyst type, size, temperature and gas compositions were examined as well as their effects on NOx conversion. The results showed that NOx conversion was increased below $300^{\circ} \mathrm{C}$ when a pre-oxidation catalyst was used. This was due to a higher $\mathrm{NO}_{2} / \mathrm{NO}$ ratio. Gas bench tests also showed that with a controlled increase in hydrocarbons showed no effect on the NOx reduction of the given catalyst. Engine bench tests were run using a 4.0L heavy duty turbo-charged direct injection diesel engine as well as a 2.5L DI TCI passenger vehicle. Results of these tests showed no negative impact on SCR catalyst aging; however, some deactivation was noted on the pre-oxidation catalyst. The diesel used in engine tests contained $230 \mathrm{ppm}$ of sulfur. The best NOx conversions occurred in stages where catalyst temperatures were above $300^{\circ} \mathrm{C}$. Overall, it was found that with a "rude" constant urea injection system NOx conversion of above $70 \%$ could be obtained. It is also important to note that it was found that a decrease in catalyst volume of $50 \%$ resulted in only a $10 \%$ NOx reduction penalty.

\subsection{Development of Urea DeNOx Catalyst Concept for European Ultra-Low Emission Heavy-Duty Diesel Engines}

TNO Road-Vehicles Research Institute from the Netherlands designed and tested a DeNOx catalyst on a 12 liter Euro 2 engine and reported their results in 1995 (19). 
Catalysts were provided by Johnson Matthey. Both the oxidation and SCR catalysts were 400 cells per square inch (cpi). For their testing the oxidation catalyst was placed post SCR to ensure the oxidation of any slipped ammonia. This system utilized engine speed and load to form NOx engine maps. The highest conversion efficiencies occurred between 300 and $400^{\circ} \mathrm{C}$. In this region $85-90 \%$ reductions occurred. Transient tests were performed and the thermal inertia of the catalyst system was examined. It was found that it took significant time for the catalyst to reach the $300^{\circ} \mathrm{C}$ light off temperature after temperature sensors showed $300^{\circ} \mathrm{C}$ exhaust temperature. However, it was shown that this could also be used as an advantage since urea injection could occur longer as the catalyst cools to below $300^{\circ} \mathrm{C}$, allowing for buffer. The most significant conclusion was that the DeNOx system was capable of reducing steady state NOx emissions from $7.5 \mathrm{~g} / \mathrm{kWh}$ to $2.5 \mathrm{~g} / \mathrm{kWh}$ and transient levels from $6.5 \mathrm{~g} / \mathrm{kWh}$ to $2.6 \mathrm{~g} / \mathrm{kWh}$ with average tailpipe ammonia emissions on the order of 3 parts per million (ppm).

\subsection{Urea-SCR Catalyst System Selection for Fuel and PM Optimized Engines and Demonstration of a Novel Urea Injection System}

This paper focused on the testing of various catalysts configurations and sizes in order to meet Euro V levels (20). The tests included configurations with pre- or postoxidation catalysts. The SCR catalyst volume was varied between 15, 30 and 45 liters. The SCR system was applied to the exhaust from a 12 liter $400 \mathrm{hp} \mathrm{HDDE} \mathrm{that} \mathrm{was}$ certified to meet Euro II standards without any after treatment. The system utilized a digital dosing pump and control unit. The control unit collected data from NOx sensors, $\mathrm{O}_{2}$ sensors, temperature sensors and engine intake air flow sensors. This was similar to the current design in that it did not rely on engine speed or load. The tests showed high 
conversion efficiency when using oxidation catalysts and a 45 liter SCR catalyst.

However, the combination of 15 liter pre-oxidation catalyst with 15 liter DeNOx catalyst achieved $83.5 \%$ reduction with an ammonia slip of only $3 \mathrm{ppm}$. It was decided that the best scenario would be to increase the cell density from 130 cpi to 300 cpi so that catalyst volume may be reduced by $2 / 3$. Therefore, the optimal size DeNOx catalyst for a $12 \mathrm{~L}$ 400hp engine would be nearly 20 liters. The SCR system also showed reduction of HC and $\mathrm{CO}$ on the order of 90 percent.

\subsection{RJM Corporation (Production Systems)}

RJM ARIS Technology offered urea injection systems that achieved 75-90\% NOx reduction for diesel and natural gas engines, both stationary and marine (21). The company's Advanced Reagent Injection System (ARIS) utilized eutectic urea in conjunction with a pulse width modulated injection system. They offered both vanadium/titanium and zeolite based catalysts. Systems offered cover engines from 100$3000 \mathrm{hp}$ and a temperature range from $250-650^{\circ} \mathrm{C}$. The system utilizes an ECU to formulate NOx maps for urea injection. The system communicated to the engine and used one or more of the following parameters: engine speed, load or NOx signal. The system did not need an air supply, as the pump for the injection system is constant flow from tank to injector and back to the tank. The company claimed that its system is the most cost effective and highly effective NOx reduction system. 


\subsection{Off-Highway Exhaust Gas After-Treatment: Combining Urea-SCR, Oxidation Catalysis and Traps}

Earlier studies were found to produce promising results in the early 1990's (22). That research focused on testing of the HUG urea SCR catalyst system that was implemented in marine applications in the early 90's. This system utilized a dual phase injection system that injected the aqueous urea solution along with air through the same nozzle. The system also utilized a post-oxidation catalyst to reduce the amount of ammonia slip. The catalysts that were used had a low cell density of 40 cpi. The control algorithm used engine load and stored NOx maps for injection. Application on a ferry between Sweden and Denmark yielded highly promising results. The system showed 96.5 and $95.3 \%$ reductions in NOx for full load and part load conditions, respectively. Ammonia slip was limited to less than 10 ppm for both cases. The paper also discussed the advantages of amorphous chromia converters for low temperature scenarios. Work showed conversion rates on the order of $80 \%$ for temperatures as low as $100^{\circ} \mathrm{C}$.

\subsection{Thick Film ZrO2 NOx Sensor for the Measurement of Low NOx Concentration}

A significant factor in the reliability and precision of urea SCR systems lied in the ability to accurately measure NOx. Improved NOx sensors have an error of $+/-2 \%$ full range. Older NOx sensors were higher with a range of $+/-10 \%(23)$. Researchers at NGK Insulators, Ltd. tested the new sensor on a Toyota D-4 engine and found the sensor could monitor less than 100 ppm of NOx behind after treatment catalysts. It was found that through new control of the first internal cavity the sensor offset could be minimized to counteract the presence of residual oxygen. Benefits of these sensors allowed for better 
control and higher conversion efficiencies of urea SCR systems. These sensors also functioned well for on-board diagnostics to detect catalyst or system failure.

\subsection{Development of Urea-SCR for Heavy-Duty Trucks Demonstration Update}

As part of Mack Trucks' Consent Decrees, (24) they have investigated and implemented urea SCR systems in a portion of their heavy-duty truck fleet (25). Their paper discussed some of the over-the-road test results. The engine used for the study was a 12 liter $350 \mathrm{hp} \mathrm{I-6.} \mathrm{The} \mathrm{catalyst} \mathrm{was} \mathrm{Vanadium-Titanium} \mathrm{with} \mathrm{a} \mathrm{total} \mathrm{volume} \mathrm{of} 45$ liters. The system utilized engine data and a controller to properly dose the correct amount of urea. Thick film $\mathrm{ZrO}_{2}$ sensors were used to monitor NOx. For this study neither a pre- nor post- oxidation catalyst were used. Standard $500 \mathrm{ppm}$ sulfur diesel fuel was used and the oxidation catalysts were not used due to sulfate formation. For the first year the cell density of the catalyst was $100 \mathrm{cpi}$. It was upgraded to $200 \mathrm{cpi}$ for year two. The average NOx reductions from over the road measurements for each year were $63 \%$ and $71 \%$, respectively. The urea consumption rate was on the order of five percent or less of the diesel fuel consumption rate. It was valuable to note, with minimal ammonia slip and no oxidation catalysts, that such high conversion efficiencies were feasible.

\subsection{The Development and Performance of the Compact SCR-Trap System: A 4-Way Diesel Emission Control System}

Their paper examined a four-way pollution control system that included a Continuously Regenerating Diesel Particulate Filter (CR-DPF) and annular SCR system with ammonia slip catalyst (26). This urea SCR system directly communicated with the CAN bus of the Volvo 12L $465 \mathrm{hp}$ engine. The SCR catalyst volume was 1.6 times that of the engine displacement. The cell density of the catalyst was $350 \mathrm{cpi}$. The system did 
utilize the on-board air compressor to assist urea injection and mixing. The lower limit for injection of this system approached minimum temperatures of $160^{\circ} \mathrm{C}$. The NOx conversion during cold starts near this temperature was only $55 \%$. However, the weighted average of the hot and cold starts show and average NOx conversion of $79 \%$. The original engine-out certification was $5 \mathrm{~g} / \mathrm{bhp}-\mathrm{hr}$. After the SCR installation, the NOx fell to $1.2 \mathrm{~g} / \mathrm{bhp}-\mathrm{hr}$, which was under the $2007 \mathrm{EPA}$ limit. The previous results were obtained from the US Heavy Duty Transient test cycle. NOx conversions of up to $92 \%$ were achieved on the European Stationary Cycle (ESC). The average ammonia slip during testing was $9 \mathrm{ppm}$ with maximum values of up to $60 \mathrm{ppm}$.

\subsection{Development of Urea-SCR System for Heavy-Duty Commercial Vehicles}

This reviewed paper looked at various components of a urea SCR system for use with large commercial vehicles in Japan (27). The given engine had a displacement of 13L. The studies were performed using the Japanese transient cycle. This cycle had average lower speeds and lower engine temperatures as with marine diesel applications. This study also used the Bosch urea injector system. The engines were modified with higher injection pressures and EGR to reduce PM emissions so the system would be PM compliant without DPF after treatment. With this measure, the fuel penalty was decreased by $6.5 \%$. The study estimated that the cost of urea would be equivalent to $2.5 \%$ of the fuel. In this case, the overall fuel efficiency increase was $4 \%$ while reducing $\mathrm{NO}_{\mathrm{x}}$ emissions by $70 \%$. Long term results of the study showed only a slight decrease in conversion efficiency. Their research also looked at the basic compatibility of materials used within the system. It was found that the urea solution had little corrosive effects on stainless steel, aluminum, cast iron and galvanized steel. More noticeable effects were 
found on bronze and copper. The system also showed promise with freeze prevention systems utilizing engine coolant heat exchangers within the urea tank.

\subsection{Simulation on the Optimum Shape and Location of Urea Injector for Urea- SCR System of Heavy-duty Diesel Engine to Prevent $\mathrm{NH}_{3}$ Slip}

Simulations and research were conducted at Hanyang University on the shape and location of various urea injectors modeled in conjunction with an SCR catalyst (28). The research looked at varying the number of holes between 1,2, 4, 6 and 8; the distance from injector plane to brick face in the intervals of $1.5,3,5$, and 7 diameters in length; and various injection pressures from 1 to 2 bar. Modeling was completed to optimize the previously mentioned characteristics so as to minimize mal-distribution of the multiphase flow on the brick face. The result of the modeling showed that after placing the injector 5 diameters up stream of the catalyst that little could be gained by moving it to a location of 7 diameters upstream. It was also found that best distribution results were from a 4 hole injector. The second best was 2 holes with 6 and 8 holes being next. A 1 hole injector provided a large injection velocity, which increased the chance for wall impingement. The 6 and 8 hole injectors were found to provide a small injection velocity, the effect of which did not assist in the turbulent mixing. Higher pressures were also found to assist in the mixing process. It was also noted that in the case of perpendicular injection wall impingement occurred in the axial direction, but also that when injection was parallel with flow that some radial wall impingement occurred as well.

\subsection{Diesel Emission Control Technology -2003 in Review}

Control of diesel emissions evolves rapidly as research areas continue to grow. Timothy Johnson of Corning Inc. annually writes "year in review" papers summarizing 
the state diesel emission technologies (29). He reviewed various SCR research results that showed promise for use in heavy duty and light duty NOx reduction. Much research focused on the application of pre-oxidation catalysts in combination with urea SCR systems in order to optimize the $\mathrm{NO}_{2} / \mathrm{NO}$ ratio. As reported in the literature, an increase in $\mathrm{NO}_{2}$ content from $13 \%$ to $30 \%$ yielded a $\mathrm{NOx}$ reduction increase from 35 to $50 \%$.

Reviewed research also showed promise with zeolite catalyst at low temperatures and the use of NOx sensor for the control of mobile urea SCR systems. NOx reductions of near $40 \%$ were also reported at temperatures as low was $200^{\circ} \mathrm{C}$. All of these results showed promise for a stand alone system with a NOx reduction target of 50\%. 


\section{System Configurations and Hardware}

The original design of the system was to be simple and robust. The following specifications drove system design and each subsequent section describes the approach taken to fulfill the necessary specification. The system needed to be self-contained and function properly without communicating with the specified engine. The basic parameters needed for the urea SCR system included exhaust flow rate, pressure, temperature and estimated $\mathrm{NO}_{\mathrm{x}}$ content. To measure these parameters, a flow tube was designed that would house the necessary sensors. The sensors included a differential pressure sensor attached to a pitot tube, an absolute pressure sensor and a temperature sensor. Sensor signals and software were implemented in a system controller. Hardware needed for the system included a urea storage system, urea supply pump, injector and mount, flow tube and catalyst. The flow tube was standard aluminized exhaust pipe. The sensors were installed to this section of pipe and placed upstream of the catalyst. The flow tube sensors performed all necessary measurements and the system controller calculated urea demand and determined the state of urea injection. This was determined to be the necessary set up for a basic stand-alone urea SCR system.

\subsection{System Controller}

Since the system was to be stand-alone, all of the necessary parameters needed for control would have to be read, stored and used by the system itself. Therefore, the system needed an independent controller. The controller would need to take in various analog, digital or CAN signals and use those signals within the software to run the system. The controller would need to calculate the NOx level and the corresponding amount of urea 
needed for NOx reduction. Its self-contained software would then deliver the correct metered amount of urea to the exhaust via an injector.

The controller chosen was the Mototron 80-Pin Motohawk. This controller was previously used by WVU's Challenge X team to control various subsystems of a hybrid vehicle (30). It was powered by Motorola MPC555 microprocessor with $448 \mathrm{~Kb}$ of Flash Memory. The operating voltage was 9-16VDC, which was ideal for such automotive applications. The 80-pin had 15 analog inputs, injector driver outputs, PWM outputs, and the ability to communicate via CAN or RS485. The Motohawk software was based in the Simulink environment, which allowed for model-based programming. Programs were saved and built on a PC and then programmed via a KVASER module and Greenhill Software to the 80-pin unit. Also available with this controller was the MotoTune software. This software allowed for monitoring of the system in real time as well as calibration and data collection capabilities. Figure 3.1 below shows the controller and its wiring harness. It can be connected to the necessary sensor inputs and outputs. 


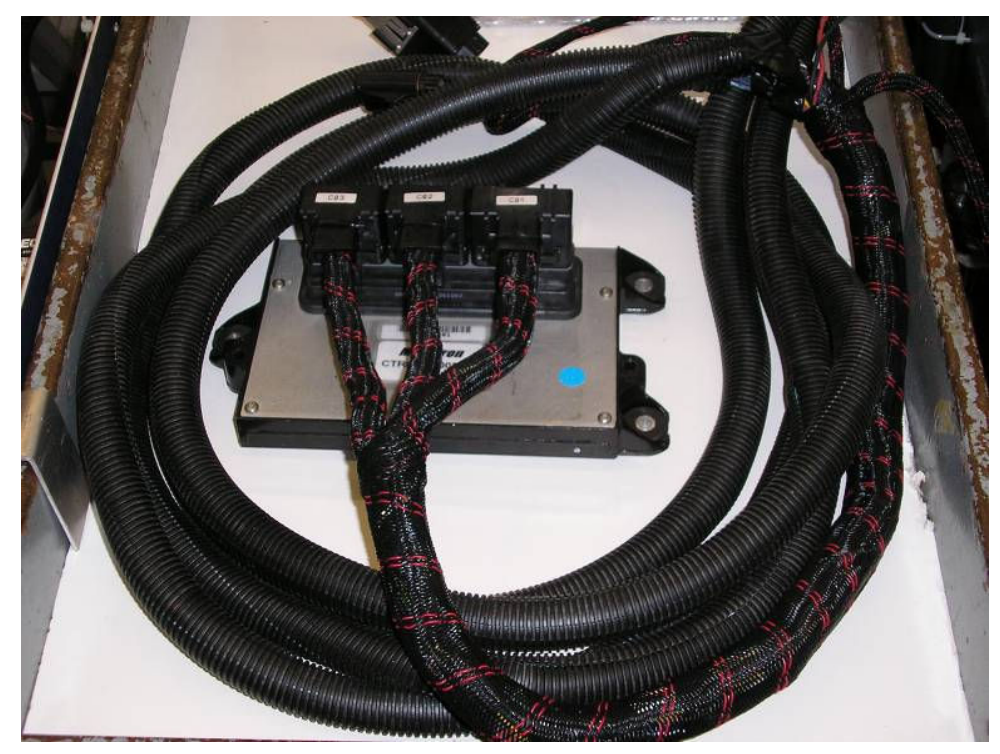

Figure 3.1 MotoHawk 80-Pin Controller and Wiring Harness

\subsection{Urea}

The urea used for this system was TerraCair SCR grade urea. It was a eutectic solution of $32.5 \%$ in water. The liquor was formaldehyde free because of Terra Industries' urea production processes (31). Table 3.1 below shows the basic properties of the provided 5-gallon sample. Figure 3.2 shows a picture of the automotive grade urea. An MSDS was provided in Appendix A.

Table 3.1: Typical Physical Properties of 32.5\% Aqueous Urea Solution: DeNOx Grade Meets Specifications of DIN 70070:2005 and ISO 22242-1:2005 for NOx Abatement Technologies.

\begin{tabular}{|c|c|}
\hline Parameter & Typical \\
\hline Urea Concentration & $32.5+/-0.7 \%$ \\
\hline Specific Gravity at $20^{\circ} \mathrm{C}$ & $1.087-1.093 \mathrm{~kg} / \mathrm{m}^{\wedge} 3$ \\
\hline Refractive Index at $20^{\circ} \mathrm{C}$ & $1.3814-1.3843$ \\
\hline Free Ammonia (alkalinity) & $0.2 \% \max$ \\
\hline Biuret & $0.3 \% \max$ \\
\hline Formaldehyde & Formaldehyde Free \\
\hline Insoluble Matter & $20 \mathrm{ppm} \max$ \\
\hline
\end{tabular}




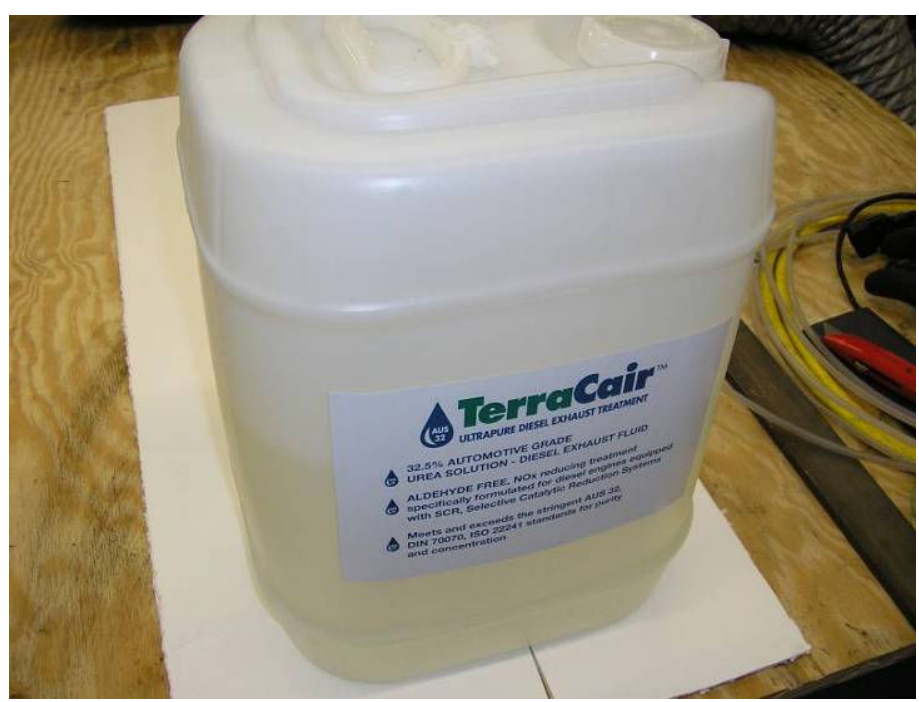

\section{Figure 3.2 Automotive SCR Grade Urea}

\subsection{Urea Storage Tank, Lines and Fittings}

As discussed earlier and described in the literature, most metals showed minor amounts of surface corrosion when used as wetted parts with urea. Brass and bronze materials were incompatible with urea and were not used in system construction. Figure 3.3 below shows the custom fabricated urea storage tank. The tank had a 4-gallon capacity. It was designed to hold the necessary fuel pump unit, discussed the next section. The overall dimensions of the tank were 9x9x13 inches. The tank was fabricated and tig welded from eighth inch aluminum sheet metal. The exact tank, pump and plumbing designs were not essential to system functionality. Lines used on this system were standard 5/16" high-pressure automotive fuel lines. The flexible lines worked well for the short-term duration of these tests. All hard line fittings to connect the flexible lines were standard Swagelok stainless steel fittings. 


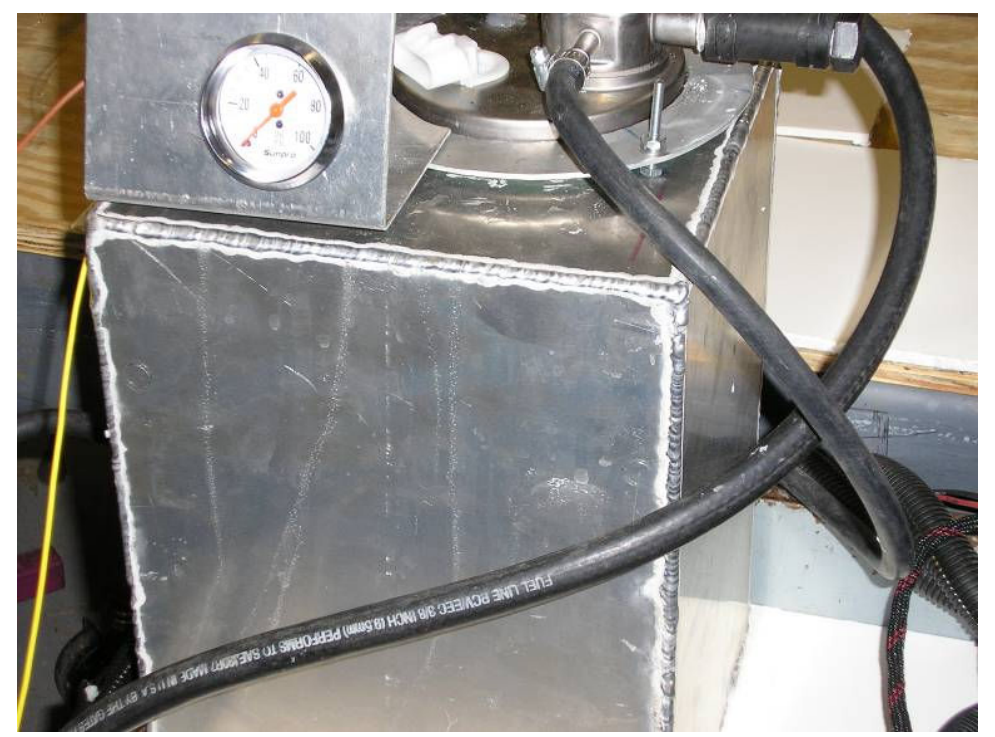

Figure 3.3 Urea Storage Tank with Fuel Line and Pressure Gauge

\subsection{Injector and Fuel Pump}

The fuel injector and pump from a 5.3L GM Flex Fuel engine were used in this research. Both urea and ethanol are slightly corrosive and these parts were thought to be more durable and compatible than standard gasoline injectors and pumps. The fuel pump was installed in the top of the urea tank and sealed with a rubber o-ring. The fuel pump was powered by 12 VDC with a 20 -amp circuit fuse. The pump unit did not contain a return line. The fuel pump was internally regulated to 58 psi when power was applied. A mechanical pressure gauge was installed for visual inspection during testing. Software control applied power to the pump at all times. Problems during testing from urea heating were not observed. For extended use, cooling precautions may prove necessary. The pump would not need to run at all times. Two suggested alternative control methods would be; to power the pump only as the system neared the threshold temperature for injection or to monitor line pressure based on an electronic pressure sensor. 
Custom mounts were fabricated to hold the fuel injector and allow the pressurized o-rings to seal properly. The top mount was machined from aluminum, with an inlet port for urea. An internal channel allowed the urea to flow to the back side of the injector. The injector fit into the bored hole of the piece tightly in order for the upper o-ring to seal properly. The fuel-injector flow capacity was rated at 28 pounds per hour. This characteristic may not have been the same for urea as the working fluid. Injection strategies for needle lift and duration were also different for the control of this system. Typical demand from this injector based on urea system control logic was on the order of $25 \%$ of its maximum injection flow rate.

\subsection{Thermocouple and Transmitter}

Exhaust temperature was one of the main parameters used by the system. A standard Type K Chromel/Alumel thermocouple was used to measure the temperature. The thermocouple was $1 / 8$ " in diameter and 6 inches long. The probe was inserted to the centerline of the flow tube and held in place with a stainless steel compression fitting. The operating temperature range for the thermocouple was -200 to $1250^{\circ} \mathrm{C}$. The thermocouple output was scaled to a 5 volt analog input for the controller. An Omega STCTX-K2 series thermocouple transmitter was used to generate the necessary signal. The measurable temperature range for this transmitter ranged from -18 to $538^{\circ} \mathrm{C}$. The input voltage was from 9-30 volts and was set to 12 volt. The accuracy of the transmitter is $+/-5 \%$ of the full-scale range. The transmitter was to be kept below $85^{\circ} \mathrm{C}$. The sensor output was 4-20 mA. A $250 \mathrm{ohm}$ resistor was placed between signal and ground in order to produce a measurable 1-5 volt input. Each degree increment was represented by 7.3 $\mathrm{mV}$. This $1-5$ volt signal was read by the MotoHawk to determine the temperature for use 
within the program. The input for this block was 16 bit analog to digital converter. With the available 1023 bits, the system measured temperature changes of approximately one half degrees.

\subsection{Pressure Sensors}

Both absolute and differential pressures were needed by the system to calculate the properties of the exhaust gas as well as the volumetric flow rate. The absolute pressure signal was generated by a cost efficient, easily available automotive MAP sensor. The sensor is made by MSD Ignition and used for aftermarket applications. The sensor input was 5 volts, which was supplied by an analog output of the MotoHawk. The sensor output was $1-5 \mathrm{~V}$ volts over a 2 bar range. The accuracy of this sensor was not known. It was chosen because of its automotive applications and cost.

The differential pressure (DP) was more important due to its large varying range. The DP sensor would also need durability against the corrosiveness and heat of the exhaust. Differential pressure sensors that were capable of measuring the induced pressure differences and withstanding exhaust gases were sparse. Common available ranges were 0-1 in. w.g., 0-10 in. w.g., 0-1 psi and larger. The 0-1 psi was equivalent to a range of 0-27.7 inches of water. This easily covered most flows of $\mathrm{C} 1$ class engines. The Omega Model PX2300 was selected; it was rated for high temperature, "wet" flows. The excitation voltage was 9-30 volts and was set by the system at 12 volts. The output of the sensor was $4-20 \mathrm{~mA}$ corresponding to a 1 psi range. The accuracy was $2 \%$ of the full scale range when used for $1.0 \mathrm{psig}$. The operating temperature was from -18 to $80^{\circ} \mathrm{C}$. The inner wetted surfaces were made of stainless steel to protect from corrosion. The signal output wire was connected to ground through a $250 \mathrm{ohm}$ resistor to induce a 1-5 volt 
signal for MotoHawk use. The input block was a 16 bit analog to digital converter block. The smallest measured differential pressure increment was 0.03 inches of water. The output signal was found to be sensitive to input voltage. Large fluctuations due to high current draw of the continuously running pump and corresponding battery charger caused large steady state error. The error was minimized but not completely removed by the use of an inline voltage regulator and use of a separate battery for pump use.

\subsection{Pitot Tubes}

The differential pressure sensor used to calculate flow needed both a high pressure and low pressure port in the exhaust to measure the pressure difference. Many possibilities existed for the flow measurement. WVU previously used Annubars in conjunction with differential pressure sensors for exhaust flow measurements. These acted like averaging pitot tubes with multiple ports along the flow profile. These and other similar devices cost over $\$ 1500$. A custom Pitot tube probe was designed this specific application. The material chosen was stainless steel tubing for its robust mechanical properties. The line size was $1 / 4$ " inner diameter, which would prevent any blocking by particulate matter. Larger tubes would have induced more dead volume which may have caused error in sensor reading while smaller tubes may plug with particulate. Most Pitot tubes measured total pressure at the stagnation point of the probe against the flow. The static pressure was typically measured in a plane perpendicular to the total pressure port. Available Pitot tubes achieved these two measurements in the same probe by using a dual wall collinear tube. This design was not used for the custom Pitot tube because of the bending procedure and probe mounting. Instead, the static pressure probe would mimic the total pressure probe but be place behind and rotated 180 
degrees. Due to the nature of the layout of the pressure probes, the typical coefficients used to evaluate velocity based on velocity pressure were different. A 1/8 inch PFA tube was used to connect the Pitot tubes and the pressure sensor. This reduced the dead volume of the measurement system. These and all other necessary ports were attached to the flow section.

\subsection{Injector Mount and Standoff Tube}

The previously described injector was typically used in lower temperature environments, on the intake system of flexible fuel engines. For this application, it needed to deliver the urea directly into the exhaust flow. The mounting system and standoff tube were specially designed so to protect the seals of the injector from hot exhaust gases and to reduce the injector temperature to avoid problems with urea clogging. The lower mount that accepted the bottom o-ring of the injector was originally made of stainless steel, but it was decided that a more insulating material should have been used. The next choice was a machined ceramic tube. This piece was not used because it cracked during machining due to its brittle nature. The final design utilized a drilled rod of Teflon with a rated temperature limit of $260^{\circ} \mathrm{C}$. As seen in Figure 3.4, the Teflon accepted the bottom of the injector and is sandwiched together with three $1 / 4$ " bolts and lock washers. Under the stainless plate is the standoff tube. 


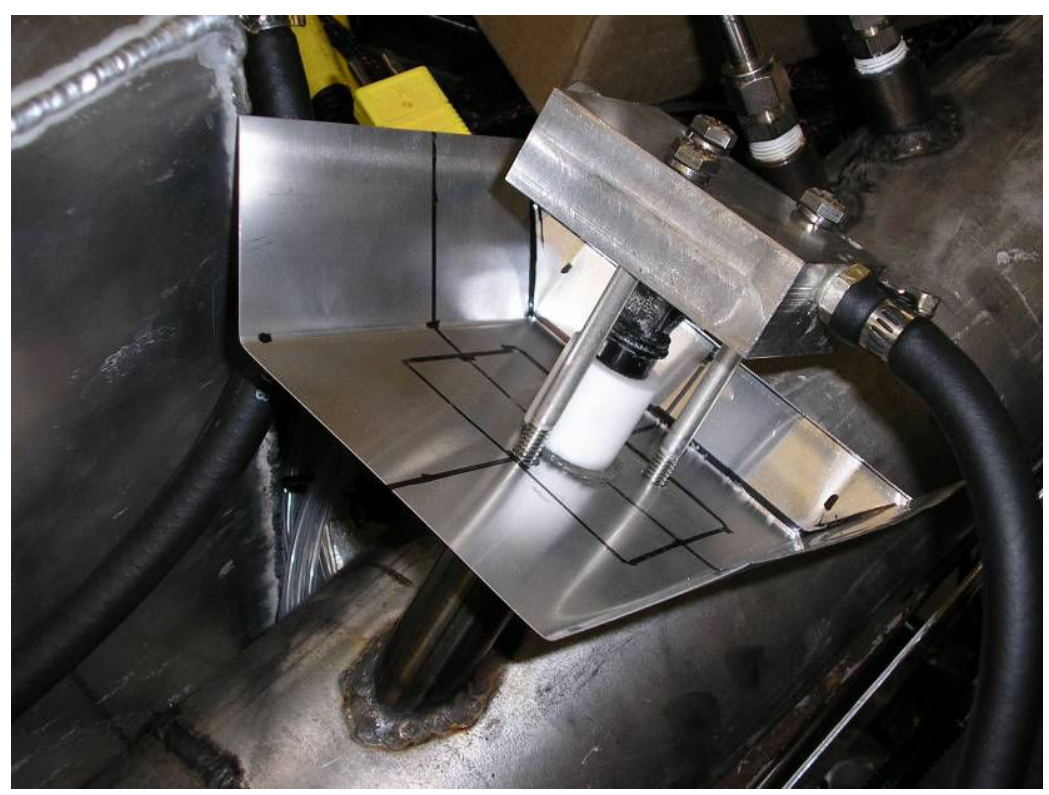

Figure 3.4 Injector with Upper and Lower Mounts Attached to Stainless Steel Standoff Tube

The standoff tube was made of stainless steel because of its low heat transfer coefficient for conduction and its ability to be attached to the flow tube. It was welded to the exhaust pipe at an angle of 45 degrees and injected with the flow. The spray pattern from this injector was highly atomized at low flow but more stream-like at higher demands. The larger demands occurred when the pulse width was over $25 \%$ duty cycle and larger mass amounts were delivered per injection event. This led to the initial decision of the angle. It was most likely that urea impingement occurred on the opposite wall at larger angles and at smaller angles with low urea flow conditions, the urea would be swept against the upper wall.

The shortest length of the standoff tube was 2.5 inches in length. It was assumed that the thin-wall tubing would behave like a fin. The length $\mathrm{L}$ was calculated from the following equation.

$$
\left(\frac{T_{L}-T_{e}}{T_{b}-T_{e}}\right)=\left(\frac{1}{\cosh (\beta L)}\right) \quad \text { Where: } \beta=\left(\frac{h P}{k A}\right)^{0.5} \quad \text { Equation } 6
$$


$\mathrm{T}_{\mathrm{e}}$ was set to ambient conditions of $20^{\circ} \mathrm{C} . \mathrm{T}_{\mathrm{b}}$ was estimated to be the maximum temperature seen in the exhaust flow, $450^{\circ} \mathrm{C}$. $\mathrm{T}_{\mathrm{L}}$ was set to $200^{\circ} \mathrm{C}$; this would provide a safety factor as the Teflon could be exposed to temperatures up to $260^{\circ} \mathrm{C}$. P was found to the outer perimeter of the tube, 0.0798 meters. The area $\mathrm{A}$, was found to be $9.63 \times 10^{-5}$ square meters. The heat transfer coefficient of stainless steel, $\mathrm{K}$, was set to $15 \mathrm{~W} / \mathrm{mK}$. An estimated coefficient for $\mathrm{h}$, was set to $12 \mathrm{~W} / \mathrm{m}^{2} \mathrm{~K}$. The estimated was taken from similar examples from a heat transfer book, along with the fin equation (32). With these values, the length $\mathrm{L}$ was found to be 0.059 meters or 2.32 inches. This was rounded up to 2.5 inches allowing room for error. After testing it was decided to also use a heat shield below the injector mount to decrease heat transfer to the injector via convection currents from the hot exhaust. The heat shield was made from 1/64 inch aluminum. Exhaust gasket material was used below and above the heat shield to seal the system.

\subsection{NOx Sensor}

The system needed a sensor that would measure the raw $\mathrm{NO}_{\mathrm{x}}$ content of the exhaust gas flow. The sensor that was chosen for this project was the Smart NOx Sensor from Siemens VDO Automotive. The sensor was of the zirconia oxide type. The sensor had two cavities; the first contained platinum to oxidize $\mathrm{HC}, \mathrm{CO}, \mathrm{H}_{2}$. The second cavity eliminated all of the oxygen content and chemically reduced all $\mathrm{NO}$ to $\mathrm{N}_{2}$ and $\mathrm{O}_{2}$. The oxygen generated from this secondary reduction process was measured as an electrical current and represented the amount of NO. The sensor was calibrated at the factory and was used in conjunction with its proprietary controller. The controller was powered via a 12 volt source. The only output of the sensor controller was communication via CAN 
protocol. This application worked well with the MotoHawk controller as it had two available CAN buses.

\subsection{Flow Section}

The flow section refers to the section of exhaust that housed the necessary sensors and urea injector. Aluminized steel was selected because of its availability and common use in exhaust systems. The size of the flow tube was important for a number of reasons. Typical pipe sizes ranged from 4-6 inches in diameter for engines indicative of the $\mathrm{C} 1$ marine class. Decreased pipe diameters below 4 inches would result in increased backpressure. The pressure drop across the system was proportional to the square of velocity; therefore it was also proportional to the square of the area. Pressure drops could increase by $50 \%$ or more by a system that was sized to small. A custom diameter would have required custom transitions, fittings, and clamps. The exhaust section out of the turbine for this engine was 5 inches in diameter. This was the most likely candidate; however, the flow rate in this section needed to be in the correct range to retrieve good resolution from the differential pressure sensor. Engine intake flows for this system were on the order of a maximum of 800-1000 standard cubic feet per minute. The following equations were used to solve for the necessary parameters.

$$
\begin{array}{cc}
Q=\text { Velocity } \times \text { Area } & \text { Equation 7 } \\
\text { Area }=\pi\left(\frac{D}{2}\right)^{2} & \text { Equation 8 } \\
\Delta P=k \rho V^{2} \quad \mathrm{k} \text { calibrated near }=1.5 \times 1 / 2 \text { for this setup } & \text { Equation 9 }
\end{array}
$$


If the standard flow was converted to actual flow at low density and high temperature of the exhaust, the maximum flow rate was above 2000 cubic feet per minute. Table 3.2 below shows the induced velocity pressures for the 4", 5" and 6" pipe sizes.

Table 3.2: Pressure Ranges for Maximum Flow of 2000 CFM and Minimum Flow of 150 CFM.

\begin{tabular}{|c|c|c|c|}
\hline Pipe Diameter (Inches) & 4 & 5 & 6 \\
\hline Area (Square Feet) & 0.087 & 0.136 & 0.196 \\
\hline $\begin{array}{c}\text { Maximum Differential Pressure } \\
\text { (Inches of Water) }\end{array}$ & 26.29 & 10.77 & 5.19 \\
\hline $\begin{array}{c}\text { Minimum Pressure (Inches of } \\
\text { Water) }\end{array}$ & 0.15 & 0.06 & 0.03 \\
\hline
\end{tabular}

Figure 3.5 represents the estimated pressures in the exhaust system for a test cycle during original testing of the flow device. The first iteration was tested on a 1992 Detroit Diesel Corporation engine. This engine produced similar intake flow rates as compared with the John Deere engine used for final testing. The results from actual test data were similar to those calculated. 


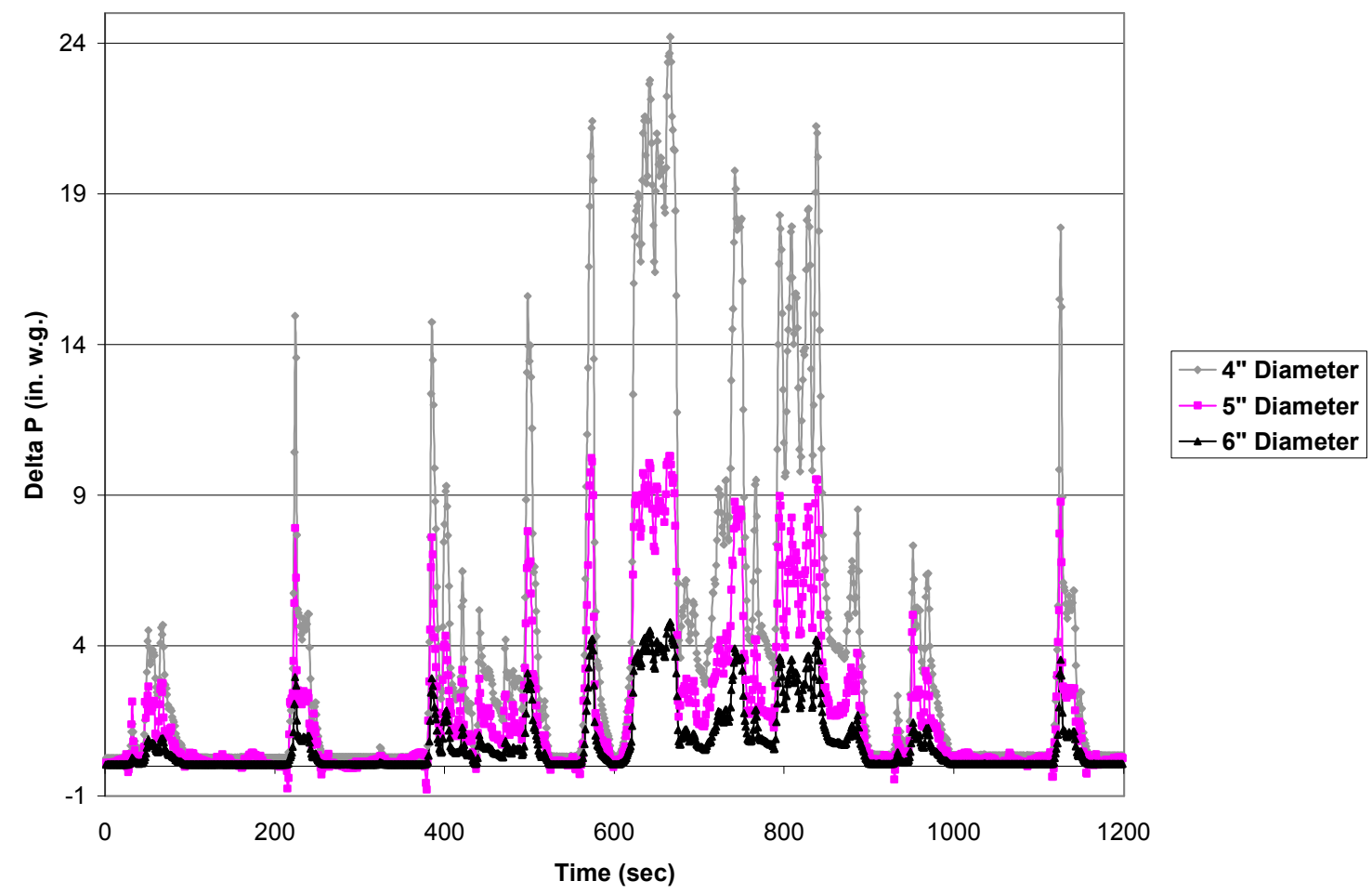

Figure 3.5 Differential Pressure for Various Diameter Flow Tubes

From the results above, the measurable range of differential pressures was directly related to pipe diameter. A 5-inch flow tube was chosen for this design. Higher resolution could be achieved with a 4-inch pipe but this may have led to over ranging the sensor and undesirable backpressure. It would have also limited the variation of testable engine sizes and flows. It was clear that for a 6 -inch pipe, the flow would need to be much larger in order to retrieve better low flow events, however; larger turbine outlet ports would be indicative of larger engines with possible larger flows.

\subsection{Catalyst}

The last major component of the system was the urea SCR system catalyst. Eight catalyst bricks were received by WVU. The catalysts were extruded ceramic titaniumvanadium bricks. Their outer dimensions were 150x150x450 mm. The wall thickness was 
on the order $0.25 \mathrm{~mm}$. The cell density was approximately $130 \mathrm{cpi}$. Engineers from the supplier suggested that 4 bricks be utilized for our catalyst based on gas content, temperature and flow rate of exhaust. The 4 bricks were arranged in a $2 \times 2$ configuration as suggested. The catalyst bricks were wrapped with fibrous matting that held the components in place within the catalyst can. The mat was supplied as a sample from Unifrax Corporation. The canning was made from stainless steel with $45^{\circ}$ tapered takeoffs on both the inlet and outlet. Turbo-flanges were welded on both sides for attachment to the exhaust system via 5 inch turbo-clamps. The distance between the injector and brick face was maintained at no less than 5 diameters or approximately 25 inches. The system was calibrated with an LFE calibration system at WVU's EERL. During calibration, data was collected on the pressure drop across the catalyst as a function of flow. Figure 3.6 shows an example of the data collected. The maximum pressure drop from testing was less than 9 inches of water with flows less than 900 SCFM. 


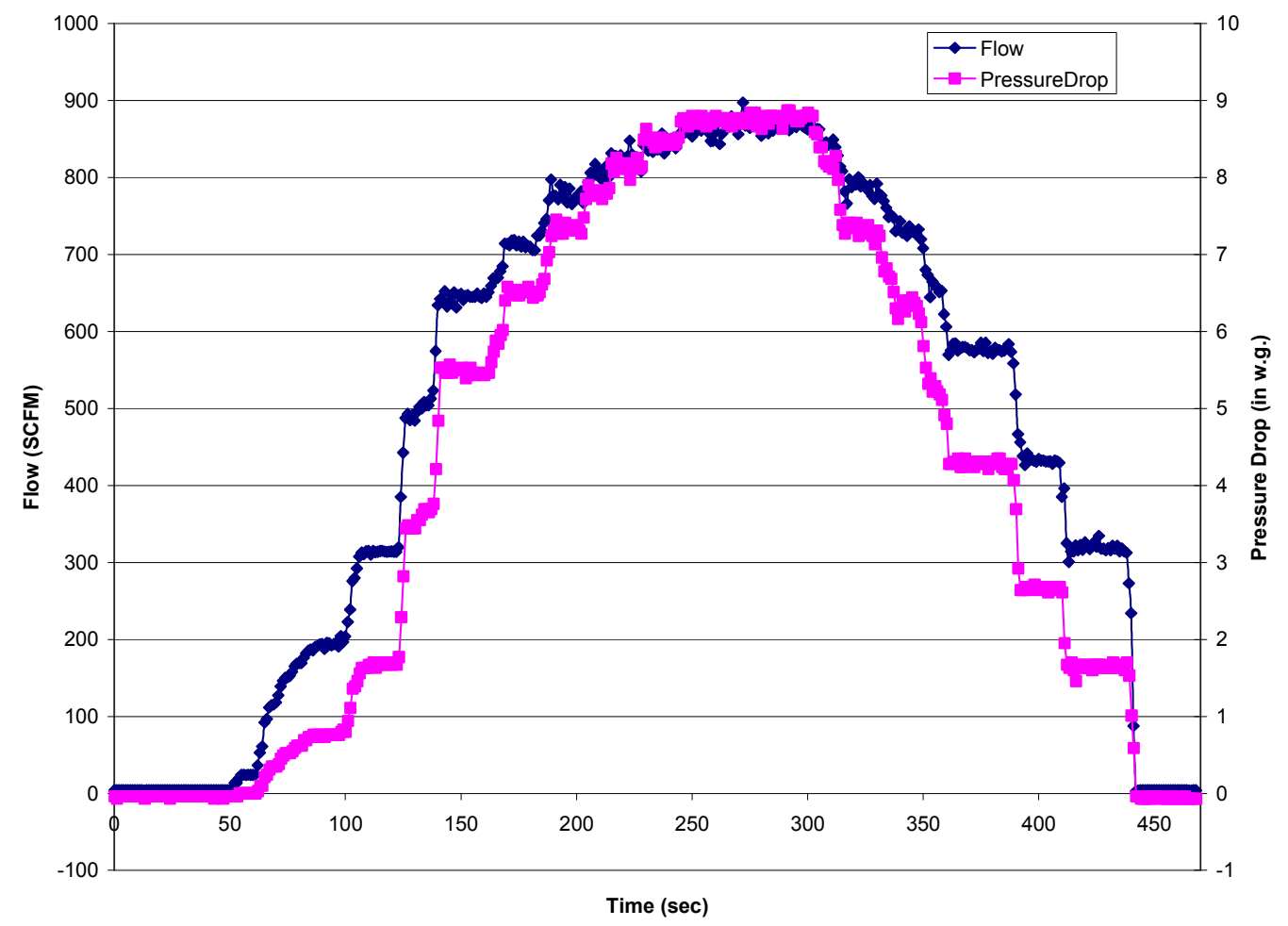

Figure 3.6 Flow and Pressure Drop Across the Catalyst

\subsection{Complete Bench System}

Figure 3.7 below shows the complete system during bench testing. All of the sensors were mounted to an aluminum plate and attached to a cart. The cart contained 12 volt batteries, controller, and urea and tank system. The flow section was attached to the catalyst. This setup allowed for the system to be easily transported into place and the flow section installed into the exhaust. Flexible lines were utilized during testing for convenience. 


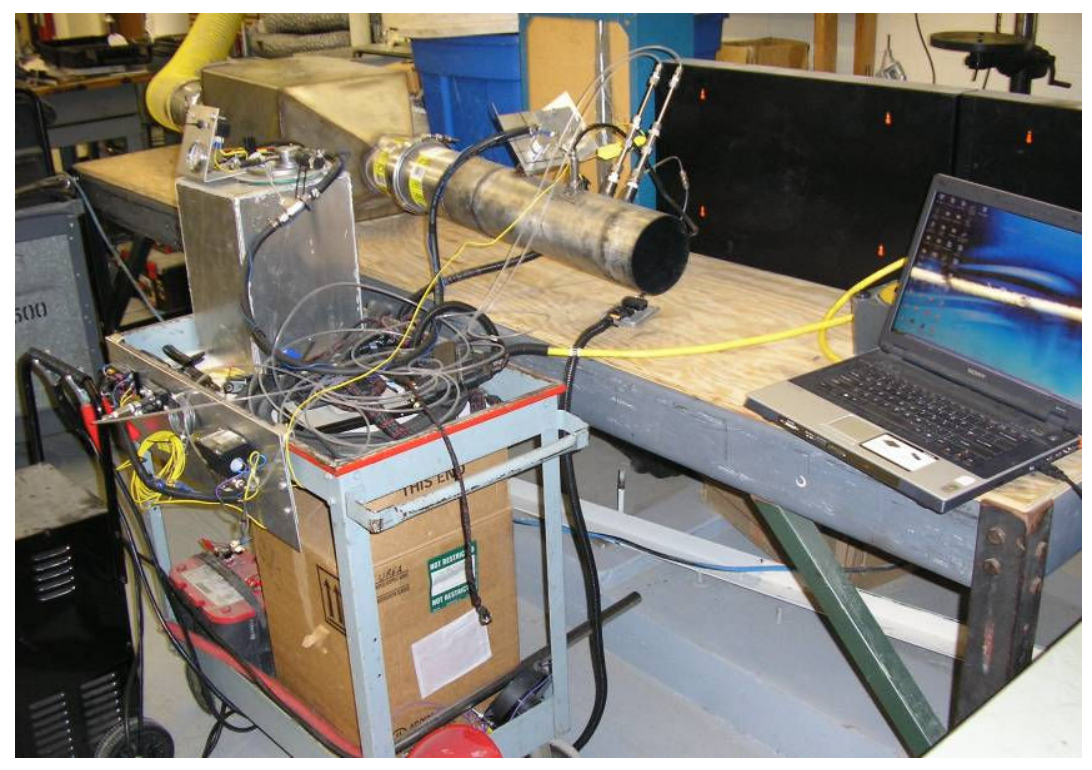

Figure 3.7 System for Bench Test 


\section{System Model and Control Logic}

The following section describes the model-based control of the urea injection system. The MotoHawk programs were designed in the Simulink environment of Matlab. The MotoHawk software added libraries of various MotoHawk blocks to the standard Simulink libraries. The MotoHawk blocks used in the program included input blocks for analog inputs, pulse width modulation blocks for control of relays and injector, display blocks for use in MotoTune data collection, calibration blocks for sensor calibration, CAN 'Send and Receive' blocks for communication, and override blocks for default values. All other blocks and logic were available in the normal Simulink libraries. The following sections describe the logic of the system and all subsystems.

Figure 4.1 below shows the complete system model. The inputs and outputs occurred in the triggered subsystem named 100ms Foreground. This designation allowed the system functions and calculations to occur at $10 \mathrm{~Hz}$. The CAN blocks were necessary to establish CAN communications on the controller as well as set parameters such as the baud rate. The main power relay set both power on and off conditions. 


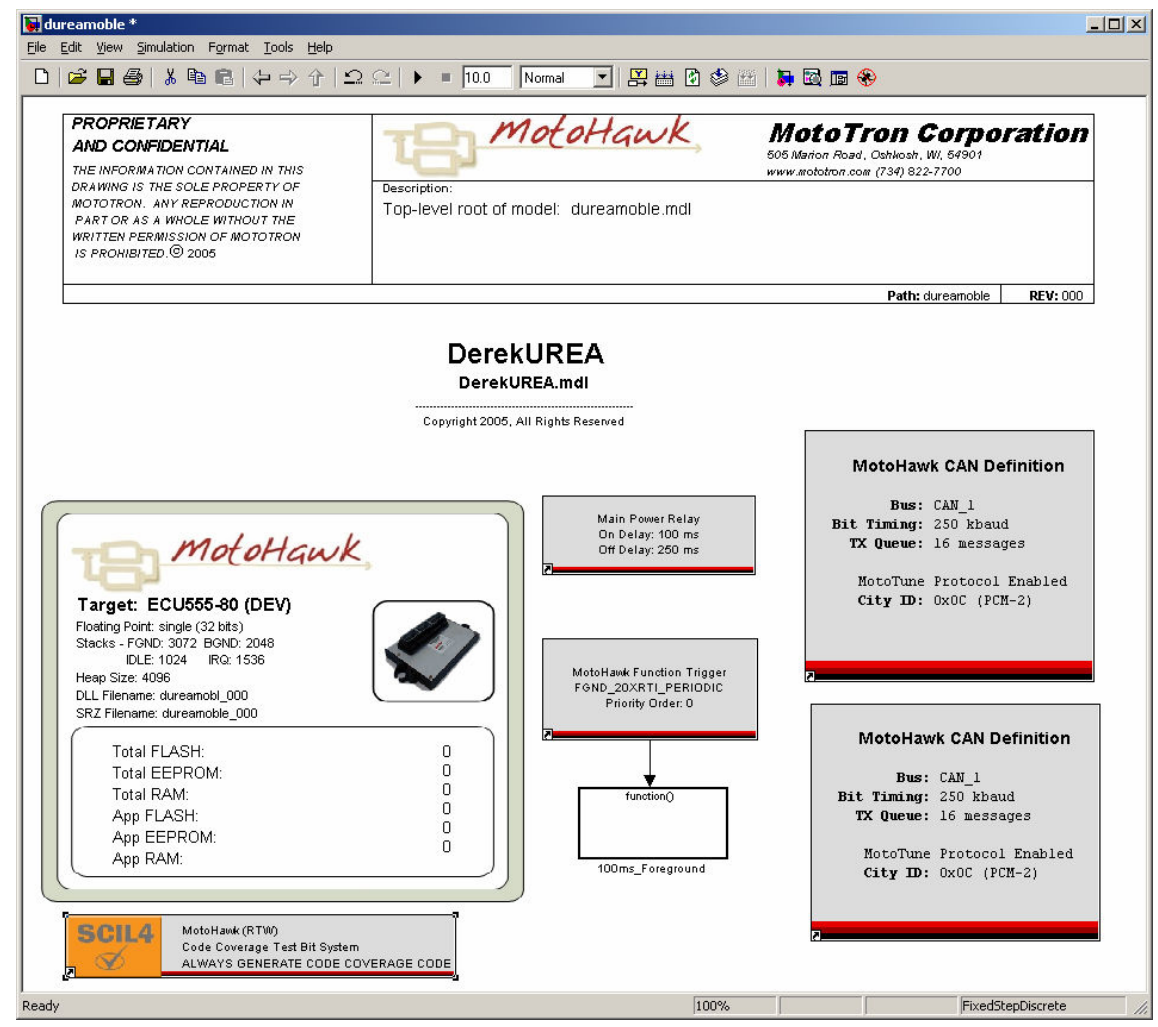

\section{Figure 4.1 Complete System Model as Viewed in Simulink}

Figure 4.2 shows the $100 \mathrm{~ms}$ Foreground subsystem. This was the main subsystem that contained all of the input subsystems, calculations and the injector output. The inputs are shown on the left side of the figure and the information flowed from left to right through various calculations and logic conditions until it flowed to the output of the system at the right side. 


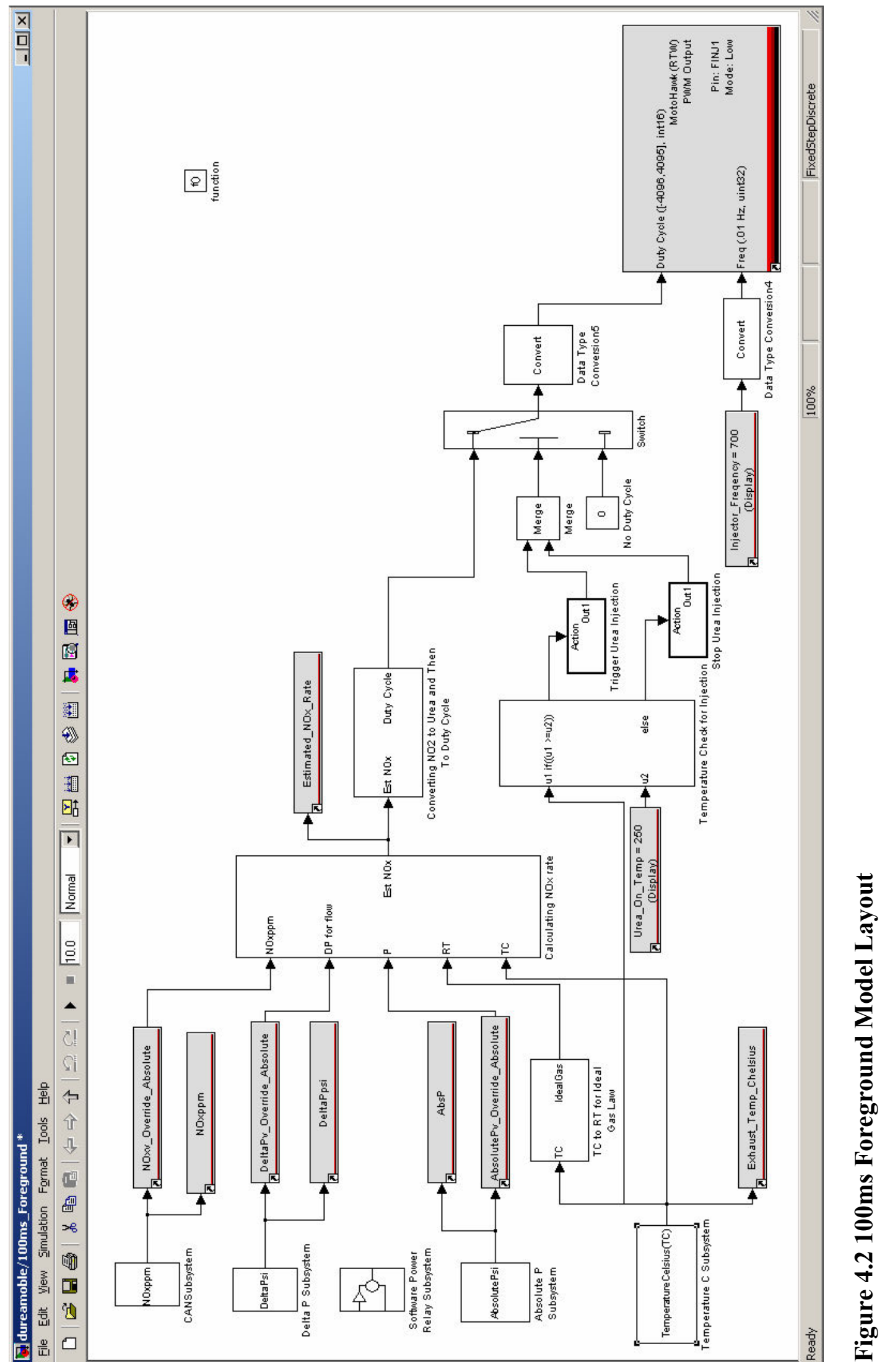




\subsection{Inputs}

\subsubsection{CAN/NOx Sensor}

The first input was the CAN block. Inside of this subsystem were the CAN read and send message blocks. The send block transmitted the proprietary start message every $50 \mathrm{~ms}$ to the NOx sensor. The read block received the NOx sensor's proprietary transmitted messages at the same interval. This message contained both the NOx level in ppm, Oxygen level in percent and other status messages. The only output of this subsystem was the NOx level that will be used to calculate NOx mass flow rates. All other messages were sent to display blocks, which were monitored. Figure 4.3 shows a MotoHawk CAN subsystem with read and write blocks.

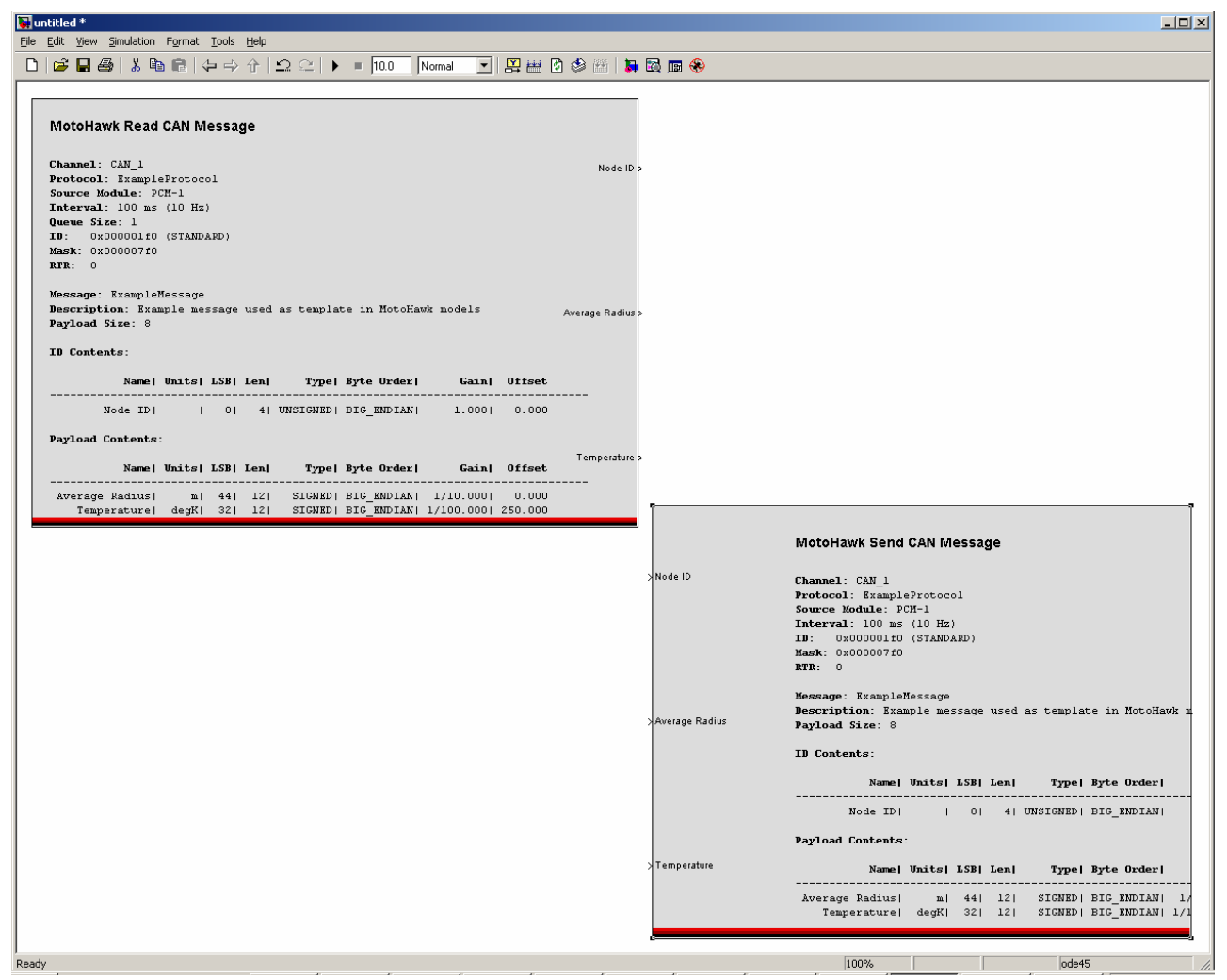

Figure 4.3 Standard MotoHawk CAN Read and Send Message Blocks 


\subsubsection{Differential Pressure Sensor}

The second input was for the differential pressure subsystem. This subsystem was described in detail as all other subsystems were similar and will not be covered in detail. This subsystem contained an input block. The input block parameters were set to match the previously determined input pin into the MotoHawk. The input signal voltage was read by the Motohawk and converted to a digital signal. From this block, the signal went through a data type conversion block. The digital signal was then converted back to the sensor voltage range via the first triangular gain block. For this input, the signal was divided by 1023 bits and multiplied by the maximum voltage of 5 volts.

The signal was then calibrated using a MotoHawk calibration block. The calibration blocks connected to two separate summing blocks. The output of the sensor was 1-5 volts, with 1 volt representing sensor zero. The 5 volts corresponded to the sensor at maximum output. This calibration value was subtracted from both the input and constant 5 volts to set the correct range of approximately $0-4$ volts. This allowed for calibration, as the zero output did not always correspond to a direct value of 1 . This value of 1.1 was changed real time in MotoTune to calibrate and zero the sensor.

The constant value of 27.77 referred to the $0-27.77$ in. w.g. (0-1 psi) range of the system. Two display blocks showed both the differential pressure in in.w.g. as well as its corresponding digital value. The value then passed through the saturation block. This saturation block was used due to the accuracy of the system from analog to digital conversion. The output of the sensor was sensitive to small disturbances and when the system was zeroed, the value fluctuated around zero but included negative numbers. The saturation block was used to keep the value between the sensor limits of 0 and $27.77 \mathrm{in}$. w.g. The value was then fed into another gain block to convert the value to psi for use in 
later calculations. This final output of this subsystem was the differential pressure in psi.

Figure 4.4 shows the differential pressure subsystem.

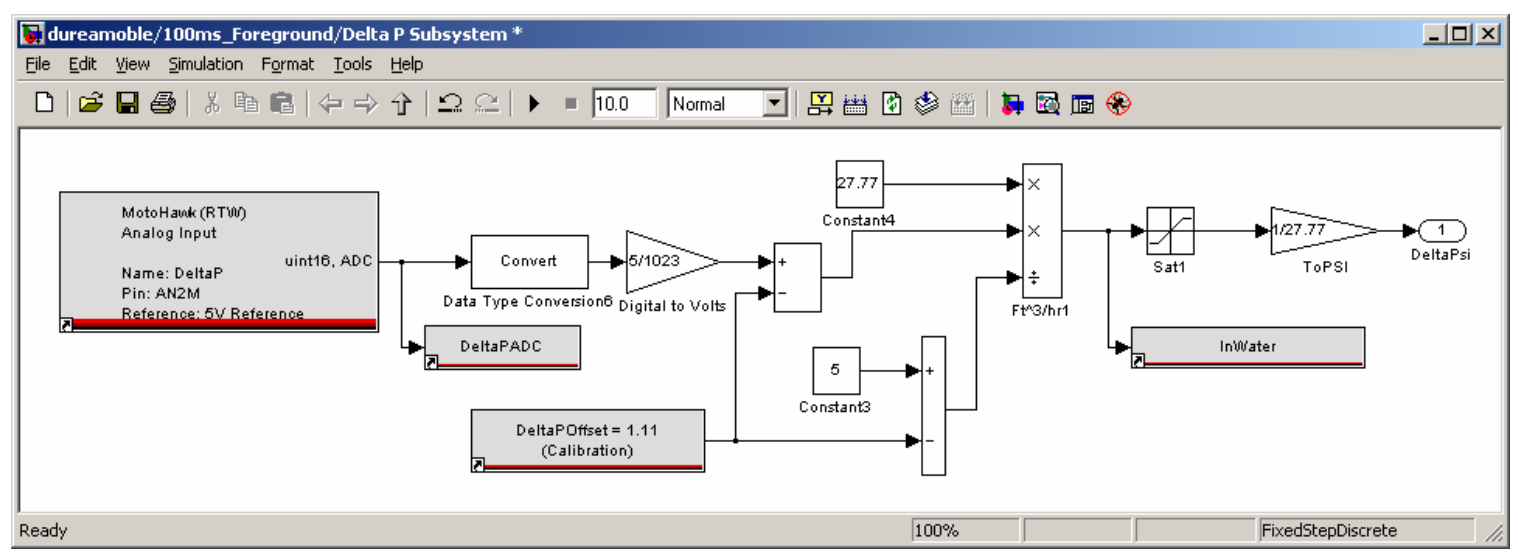

Figure 4.4 Differential Pressure Subsystem with Analog Input and PSI Output

\subsubsection{Absolute Pressure Sensor}

The next input occurred within the absolute pressure subsystem. The corresponding signal was received from the sensor and converted to the digital value.

This value was converted to engineering units and calibrated via a calibration block. The sensor had a complete range of 0-2 bar or 0-29 psi. A saturation block was included but not needed and served only as a default pass band. The output was in units of psi and was used in later calculations. Figure 4.5 shows the absolute pressure subsystem.

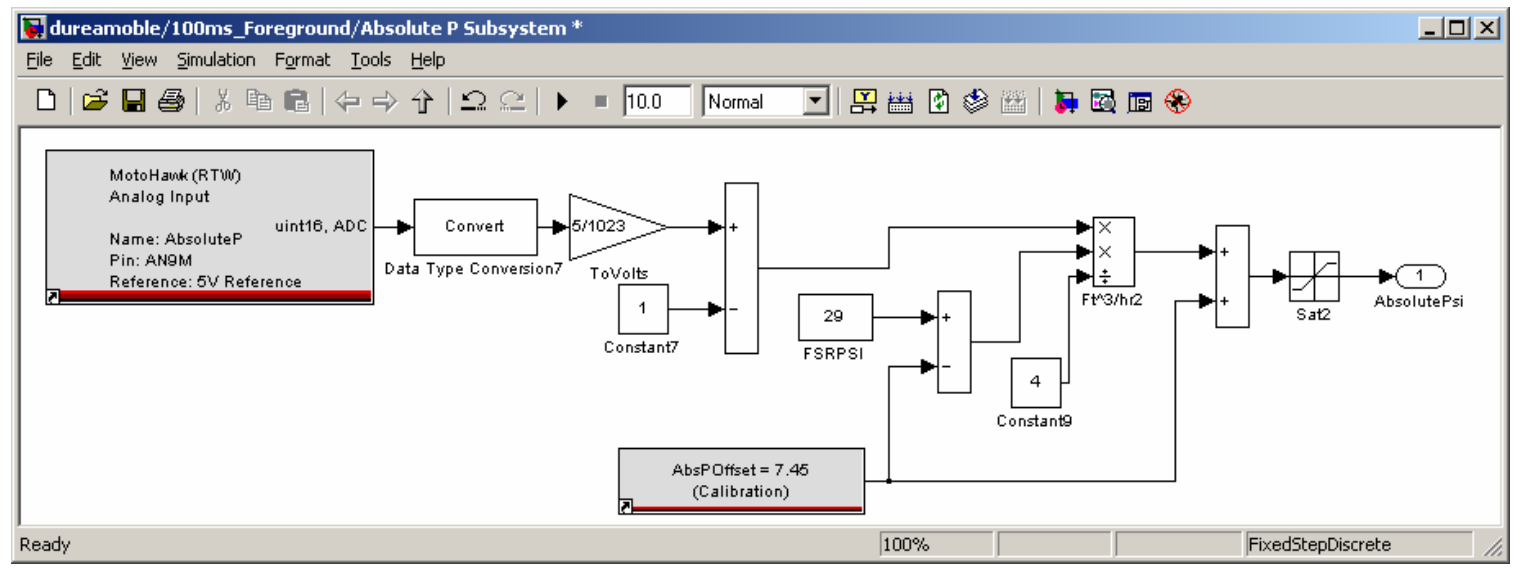


Figure 4.5 Absolute Pressure Subsystem in the Simulink Environment

\subsubsection{Temperature Sensor}

The last sensor input occurred in the temperature subsystem. The analog signal was converted to digital data and then back to engineering units. The range input on the Motohawk again accepted 0-5 volts but the sensor output was between 1 and 5 volts. This difference was corrected by scaling the data to the full range from $0-4$ corresponding to -18 to $538^{\circ} \mathrm{C}$. The output of this system was in degrees Celsius and was later used by multiple parts of the program. Figure 4.6 shows the temperature subsystem.

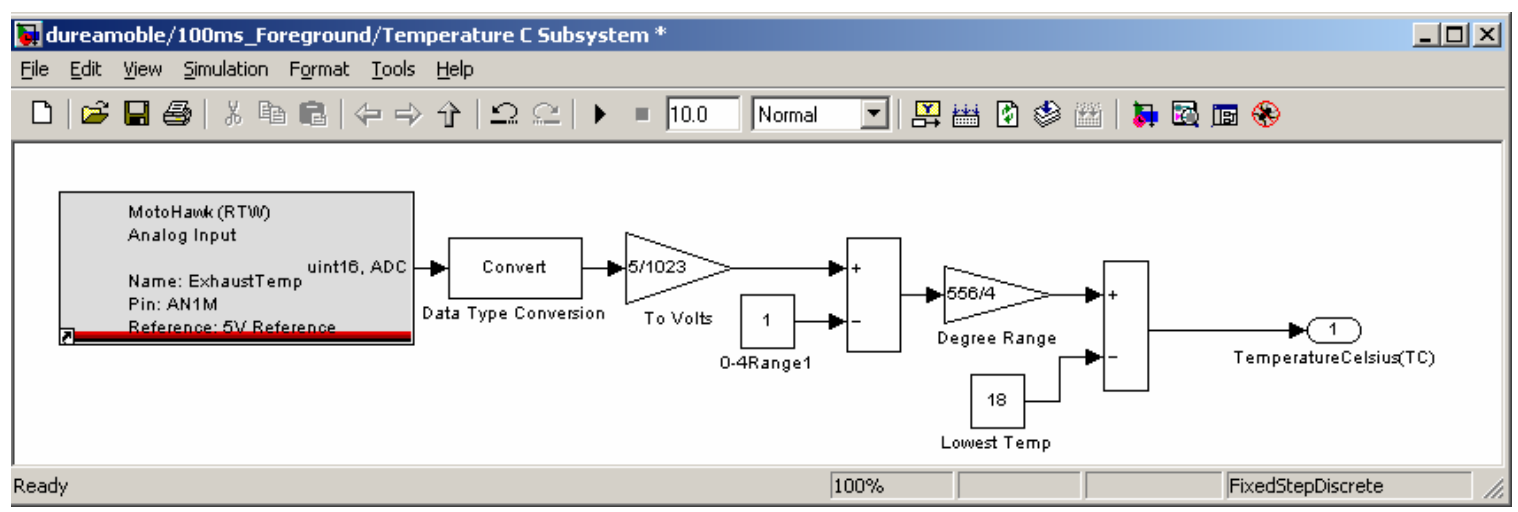

Figure 4.6 Temperature Subsystem in Simulink

\subsection{Other Subsystems}

\subsubsection{Main Power Relay}

The main power relay subsystem was located at the left of Figure 4.2, next to the input subsystems. This subsystem was utilized to control a relay that powered everything in the system except for the controller. The subsystem utilized an if/else block to control an output pin of the MotoHawk. If the 'Display' value was 1, then the 'System On' route was followed and the action subsystem sent a value of 4095 through to the analog output block. This corresponded to grounding that pin. If the display value was 0 then the else 
route was followed to the 'System Off' action subsystem which sent a value of zero through to the analog output block. This corresponded to 5 volts. The output was the injector duty cycle or pulse width modulation (PWM); with an input of duty cycle 0 for positive voltage 4095 for ground. The PWM also required an input frequency; the minimum value of $1.19 \mathrm{~Hz}$ was used. The system allowed the sensors and pump to shut down separately from the controller during testing. The software switch also allowed for control of the system from a different location via USB and Mototune. Figure 4.7 shows the main power relay subsystem.

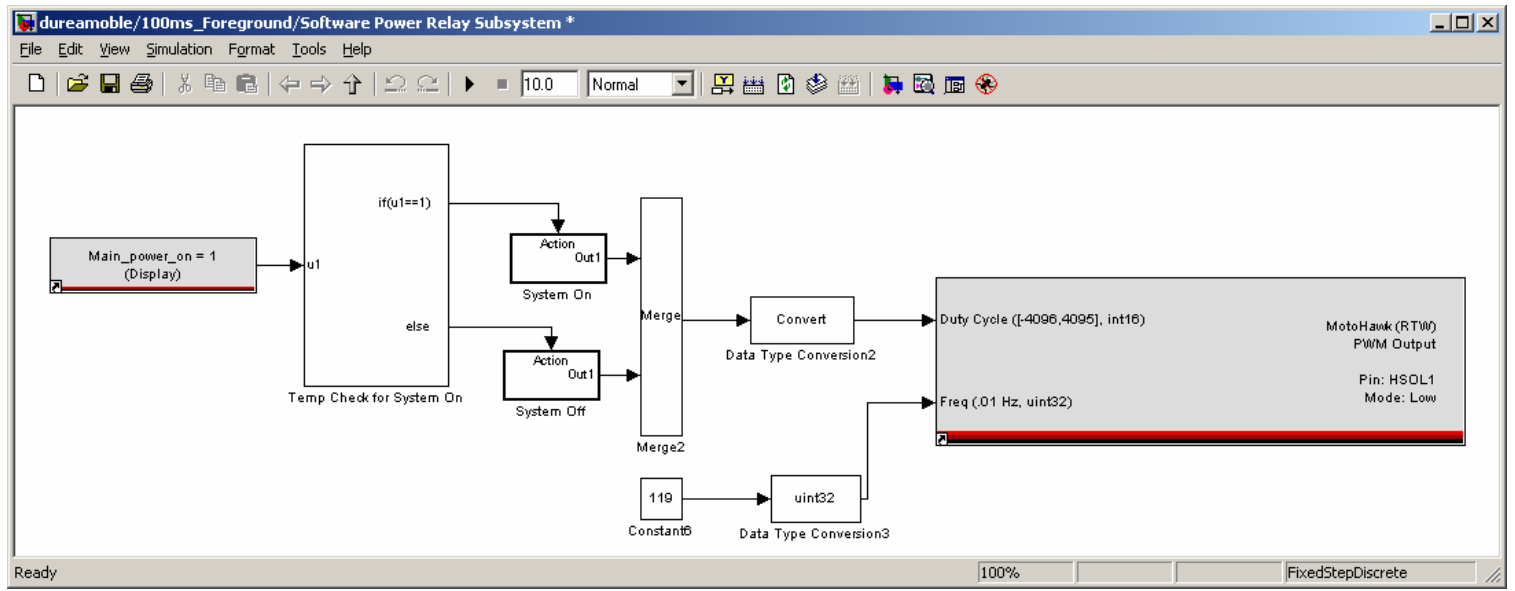

Figure 4.7 Main Power Relay Subsystem for Software Control of System

\subsubsection{Temperature Conversion for Ideal Gas Law}

The temperature conversion subsystem changed the temperature in degrees Celsius to absolute Rankine. Calculations used the inch pound system. Equation 10 shows the conversion from Celsius to Rankine.

$$
T_{\text {Rankine }}=\left(\frac{9}{5} T_{\text {Celsius }}+32\right)+460
$$

Equation 10

The absolute temperature was multiplied by the gas constant for air, $53.29 \mathrm{ft} \cdot \mathrm{lb}_{\mathrm{f}} / \mathrm{lb}_{\mathrm{m}} \cdot \mathrm{R}$. This final value was the denominator of the right hand side of the ideal gas law shown in 
the form of Equation 11. The output was the denominator and was used in the next subsystem. Figure 4.8 shows the temperature conversion subsystem.

$$
\rho=\left(\frac{P}{R T}\right)
$$

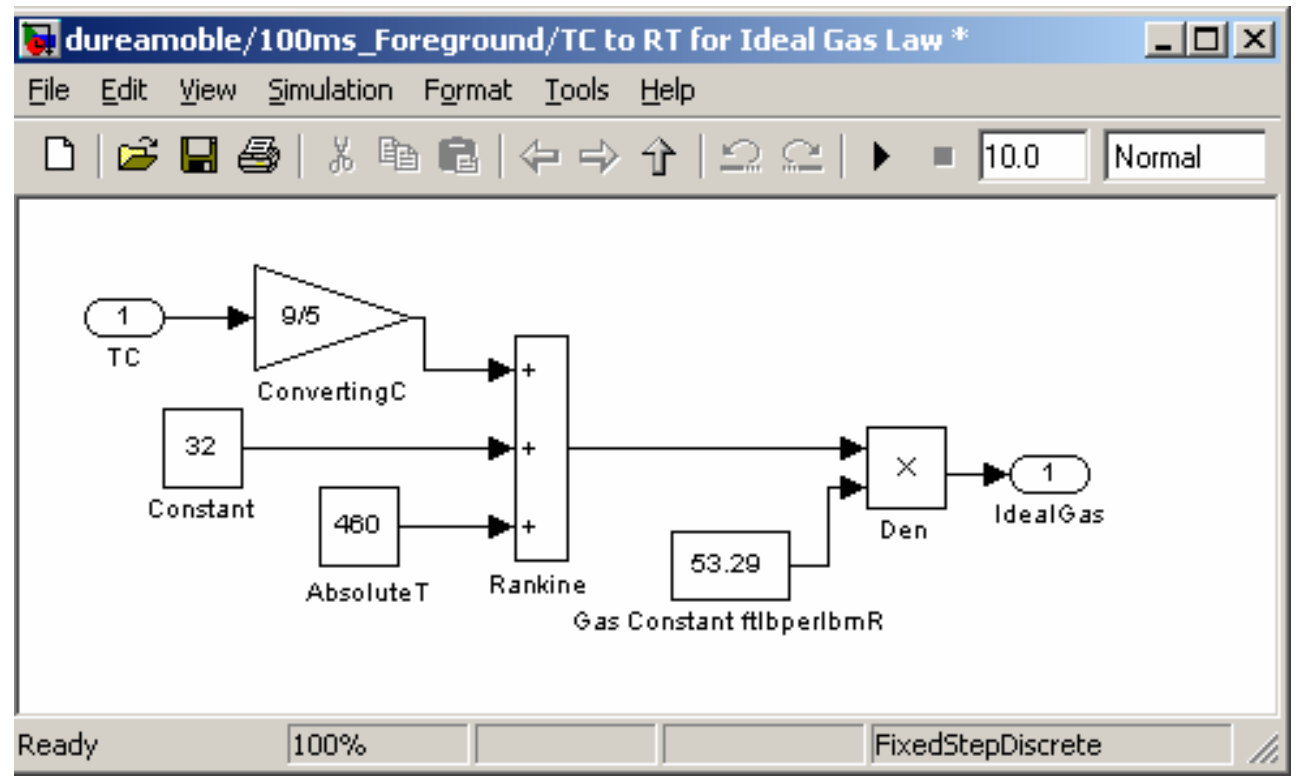

Figure 4.8 Conversion From Celsius to Rankine and Gas Constant for Air

\subsubsection{Calculation of NOx}

The next subsystem calculated the mass flow rate of NOx. The inputs included absolute pressure in psi, differential pressure in psi, NOx concentration in ppm and temperature/gas constant of the flow. The final output value was estimated in grams per unit time of NOx. The mass of NOx was representative of equivalent grams of NO, as found to be the convention in emissions literature.

Constants were contained within the subsystem and labeled in Figure 4.8. There were five fundamental calculations that occurred within this subsystem and correspond to the equations discussed below. 
- Absolute Pressure and Temperature/Gas Constant inputs were used with the aforementioned Equation 11 and are shown below for completeness. These inputs allowed for the calculation of the exhaust gas density.

$$
\rho=\left(\frac{P}{R T}\right)
$$

- The Differential Pressure input was used along with necessary constants and previously determined density to find the velocity of the exhaust gas flow. This calculation was previously discussed in Section 3.10, but Equation 4 is again shown for completeness. The equation was from the simplified form of the Bernoulli equation for incompressible flow. The equation yielded valid results for flows with a Mach number less than 0.3. The maximum Mach number within the exhaust system was $0.124(33)$.

$$
\Delta P=k \rho V^{2} \quad \mathrm{k} \text { calibrated near }=1.5 \times 1 / 2 \text { for this setup } \quad \text { Equation } 9
$$

- Once the velocity had been found from above, the volumetric flow Q, of the exhaust gas was calculated from the previously discussed Equation 7.

$$
Q=\text { Velocity } \times \text { Area }
$$

Equation 7

- The volumetric flow was then used to find NOx concentration. However, for calibration and trouble shooting purposes the volumetric flow rate was converted to a standard flow rate for comparison with separate intake data. Equation 12 was used to convert the flow from CFM to SCFM.

$$
Q_{s t d}=Q_{a c t}\left(\frac{T_{s t d}}{T_{a c t}}\right)\left(\frac{P_{a c t}}{P_{s t d}}\right)
$$


- The last step utilized all of the previously calculated data to solve for the mass flow rate of NOx in the exhaust. The following equation was similar to the NOx calculation equation found in the Code of Federal Regulations 40 Part 86 . The second part of the equation was omitted because it did not apply to the total NOx that was measured within the exhaust. $\mathrm{V}_{\text {mix }}$ refers to the volumetric flow rate previously calculated as $\mathrm{Q} . \mathrm{K}_{\mathrm{H}}$ and Density ${ }_{\mathrm{NOx}}$ were constants. The time step was divided on both sides so the output was NOx in $\mathrm{g} / \mathrm{hr}$. The density used in the equation was for $\mathrm{NO}_{2}$, as stated in the CFR.

$$
N O x=K_{H} \times\left[\left(\frac{N O x_{p p m}}{10^{6}}\right) \times\left(V_{\text {mix }}\right) \times\left(\text { Density }_{N O x}\right) \times(\Delta T)\right] \quad \text { Equation } 13
$$

The subsystem containing these calculations is shown below in Figure 4.9. The default values for constants and flow factors that were not previously discussed in detail can be found in the figure. The output was the $\mathrm{NO}_{\mathrm{x}}$ flow rate in grams per hour. 


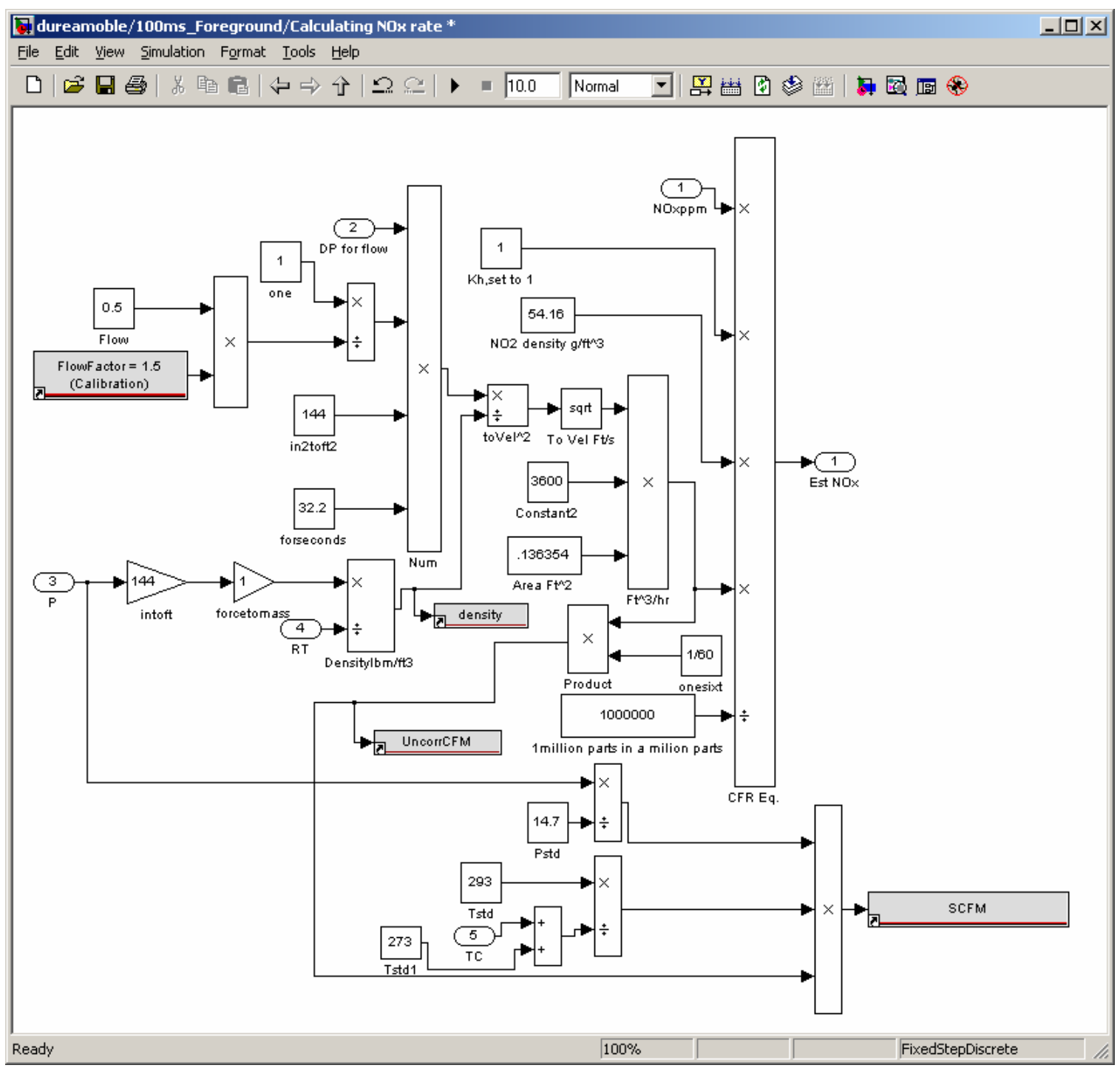

Figure 4.9 NOx Mass Flow Rate Estimation Subsystem

\subsubsection{Urea Rate Calculation}

The next subsystem determined the duty cycle of the injector based on the previously discussed input. This system used multiple gain blocks for unit conversions. The system is described by Equation 14. NOx in $\mathrm{g} / \mathrm{hr}$ was a measure of $\mathrm{NO}_{2}$ in $\mathrm{g} / \mathrm{hr}$. 


$$
\begin{aligned}
& \mathrm{NOx}(g / h r) \times 28 / 44\left(\text { gramsNO }_{\text {grams }_{2}}\right) \times 34 / 90\left({\text { grams } \mathrm{NH}_{3}}_{\text {grams } N O}\right) \times 60 / 34\left(\text { gramsUrea }_{\text {grams } \mathrm{NH}_{3}}\right) \times \\
& 3.077(\text { gramsSolution } / \text { gramsUrea }) \times 1 / 454(\text { lbs } / \text { grams }) \times 1 / 25\left({ }^{100 \% \text { Duty }} / / \text { lbs } / \mathrm{hr}\right) \times \\
& 4095(\text { Bits/DutyCycle })=\text { DutyCycleForPWM }
\end{aligned}
$$

There were also display blocks that were used to validate and perform system diagnostics. The injector duty cycle from Equation 9 fed into a multiplication block. Another display value for 'UreaCorrection' was the second input. This allowed for the overall requested amount to be scaled up or down, regardless of calculation. The output of this system traveled to the PWM output block. Figure 4.10 shows the Urea Rate Calculation subsystem.

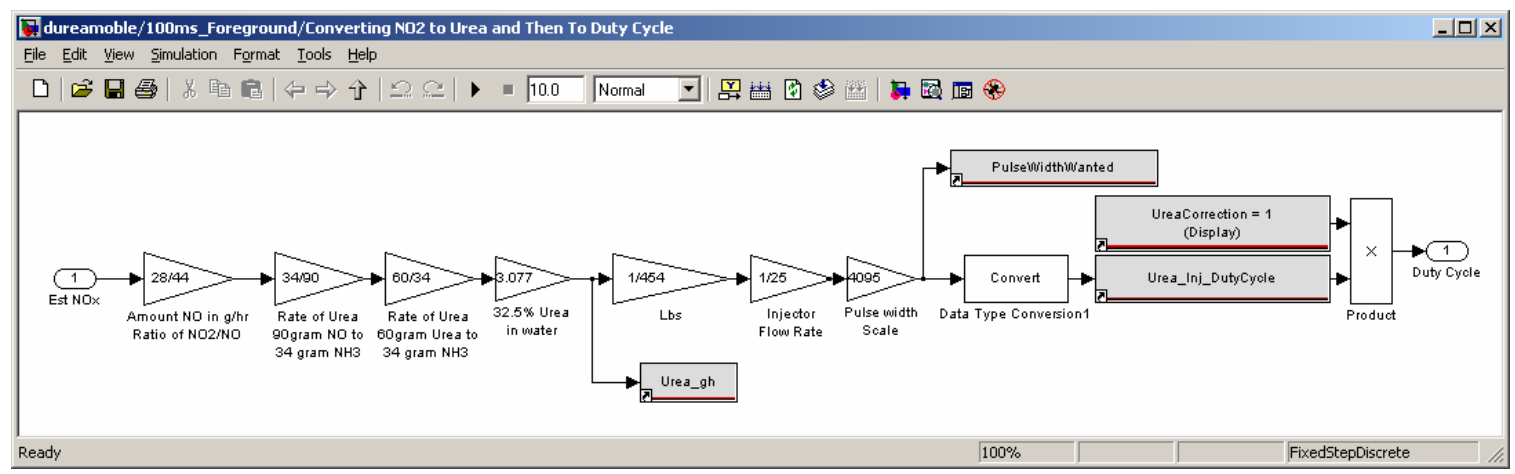

Figure 4.10 Subsystem to Convert NOx Rate into Injector Duty Cycle

\subsubsection{Boolean Switch Logic}

Figure 4.11 shows the software switch that turned the injector on and off. The urea injection was limited by low exhaust temperatures. If the temperature of the system was not adequate, the urea solution would not evaporate and decompose into ammonia by the time it traveled to the catalyst. In that case the system would have urea/ammonia slip. The if/else switch below controlled the injection process based on the thermocouple input and a set point temperature. The set point was a constant display value which meant it 
was changeable in real time in Mototune. This allowed for various testing of different limits, the default value was $250^{\circ} \mathrm{C}$. If the input temperature was greater than the set point, the logic flowed to the 'Trigger Urea Injection' action subsystem. This signal represented a one or a digital 'On'. If the temperature was lower than the set point, the logic flowed through the else branch to the 'Stop Urea Injection' action subsystem. This subsystem represented a digital zero or 'Off'. These merged into the Simulink switch block. If the switch was on, the duty cycle was fed through the switch. If the switch was off then a duty cycle of zero was sent, which correlated to the injector off.

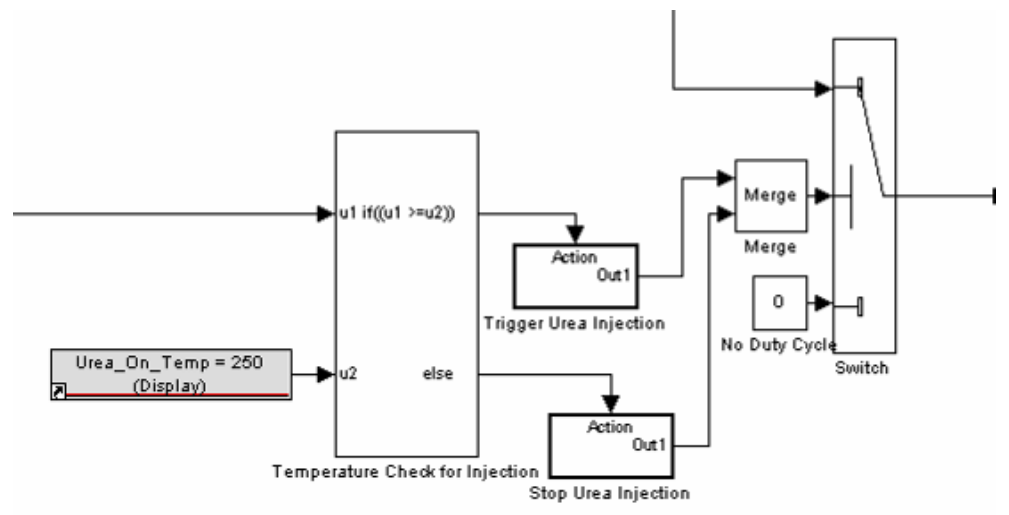

Figure 4.11 Software Switch for Lower Temperature Limit for Urea Injection

\subsubsection{Secondary Subsystem for Temperature Estimation}

Two programs were created for this system. The first program has been previously discussed. The second program contained one extra subsystem that was developed by a WVU graduate student, Francisco Posada. This subsystem was incorporated to estimate effects of the thermal inertia of the catalyst bricks. The subsystem worked on the basis of a lumped mass model for heat transfer. Chemical equations were neglected for this model. The subsystem's input was the temperature from the thermocouple. The initial temperature would have been utilized for the assumed initial brick temperature. The system utilized constant values for catalyst brick properties 
and necessary calculations to account for heating and cooling of the catalyst brick mass. The output of the subsystem was the new temperature to be checked against the set point value for the injector switch. Figure 4.12 shows the catalyst temperature subsystem. Due to lack of testing time, this alternative control has not been tested at this time.

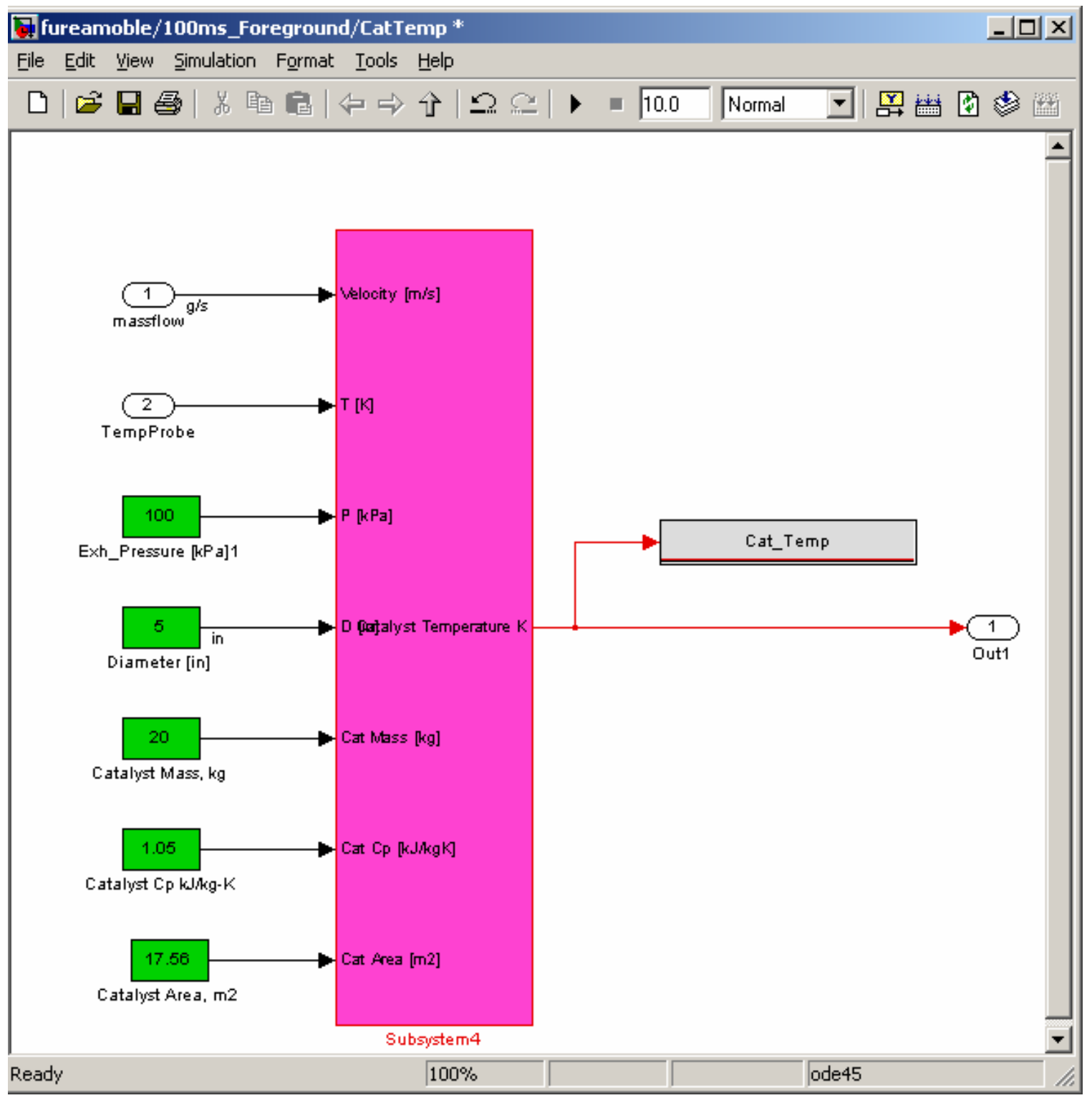

Figure 4.12 Temperature Estimation Subsystem to Account for Thermal Inertia 


\subsection{Output}

\subsubsection{Duty Cycle for Urea Injector}

Previously discussed outputs were in the form of display values that could be viewed and recorded using the Mototune software. The only physical output of the system was the injector duty cycle. Figure 4.13 below shows the PWM output block for the injector. The two inputs to the block were the injector frequency and duty cycle. For this system, the frequency was set to be a constant value. The frequency input had a value of 700 but the units are $0.01 \mathrm{~Hz}$. The actual injector frequency was therefore $7 \mathrm{~Hz}$. The duty cycle input was the top input and was received from the 'Urea Rate Calculation' subsystem. As the amount of urea needed increased, the duty cycle increased allowing the injector to remain open longer, for a greater amount time for urea delivery, increasing the mass flow of urea.

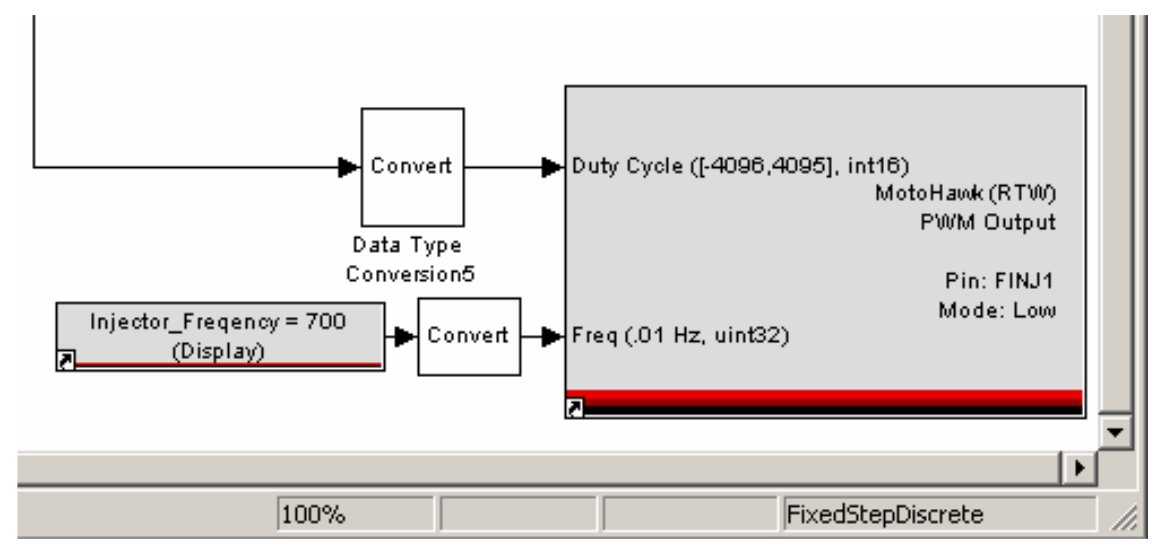

Figure 4.13 Motohawk PWM Output for Urea Injector 


\section{System Testing}

\subsection{Test Engine Information}

The stand-alone urea injection system was tested at WVU's EERL in April of 2008. A narrow test window of three days was available for system setup and testing. The system was installed into the exhaust of an 8.1 liter, 6-cylinder John Deere engine. The engine idle speed was $1192 \mathrm{rpm}$ with a rated speed of $2200 \mathrm{rpm}$ and a high idle speed of $2363 \mathrm{rpm}$. The engine had been previously involved in other testing and was used because of the available background data. The engine-out NOx level was certified at 4 $\mathrm{g} / \mathrm{bhp}-\mathrm{hr}$. The engine map is shown in Figure 5.1 below. The maximum torque was 976 $\mathrm{ft}-\mathrm{lb}$ and the maximum power was $346 \mathrm{hp}$.

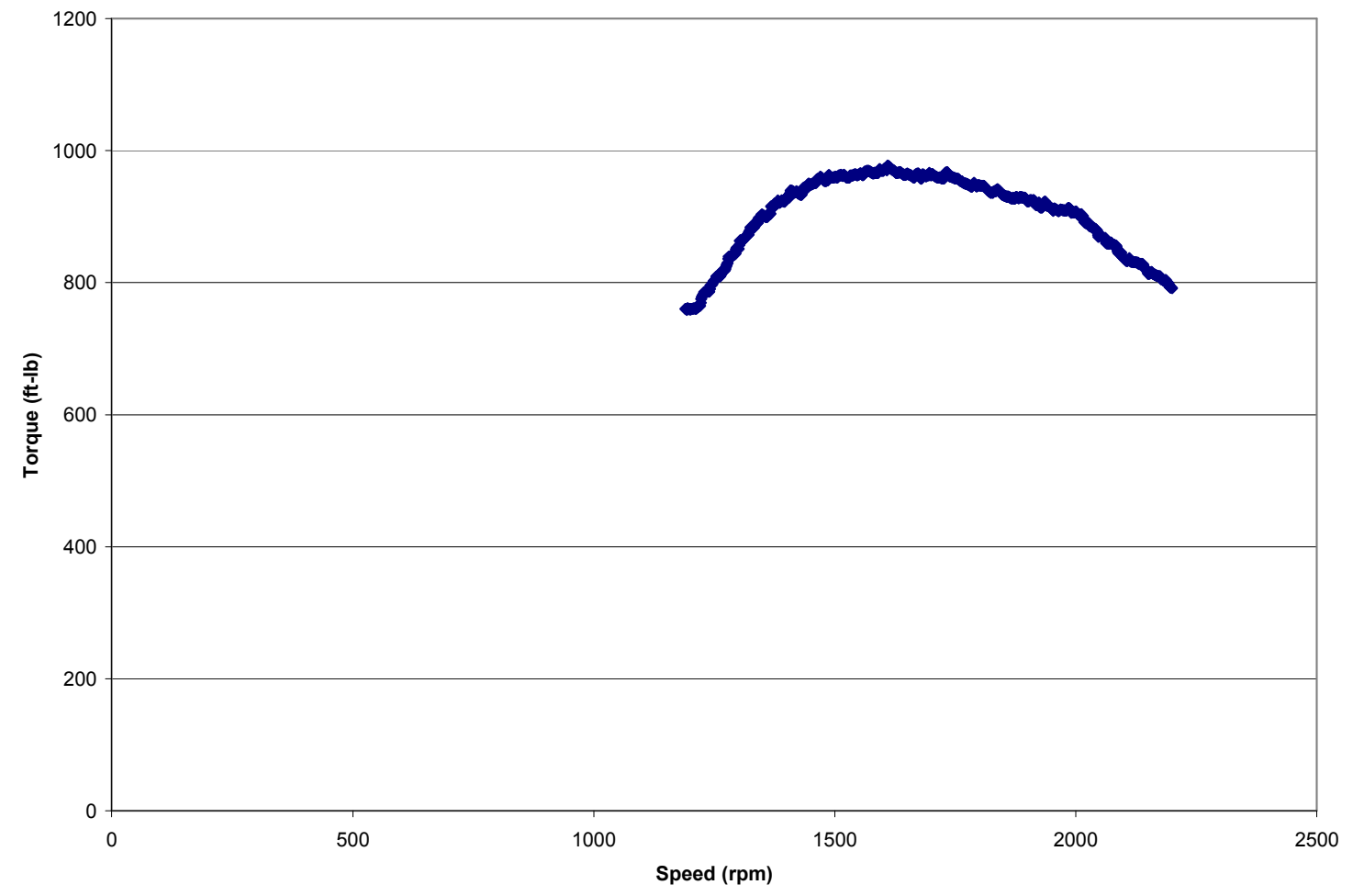

Figure 5.1 Engine Map for John Deere engine 


\subsection{Test Cell Information}

The engine was connected to EERL's GE 800 hp AC Dynamometer for transient

and steady state testing. Figure 5.2 shows the engine and system setup within the test cell. The exhaust was piped from the engine through the urea injection system and catalyst. After leaving the catalyst the exhaust pipe was connected to the full scale dilution tunnel. The dilution tunnel utilized a subsonic venturi system in compliance with CFR 40 Part 86 for 2007 emissions measurement systems. The tunnel flow rate was set at 2300 CFM. Gaseous samples were taken with laboratory grade analyzers and recorded at a rate of 1Hz. PM data was not collected during these tests.

The dilute exhaust gas was continuously sampled for the measurement of $\mathrm{HC}$, $\mathrm{CO}, \mathrm{CO}_{2}$, NOx, and ammonia. $\mathrm{HC}$ was measured with a Horiba FIA 236 heated flame ionization detector. $\mathrm{CO}$ and $\mathrm{CO}_{2}$ were measured with a Horiba AIA 220 infrared analyzer. NOx and ammonia data were collected with an EcoPhysics CLD 822 CM-h chemiluminescent analyzer. The NOx analyzer used typical zero and span gases of zero grade air and $\mathrm{NO} / \mathrm{N}_{2}$ for calibration, respectively. The analyzer was able to measure $\mathrm{NOx}$ on one channel with a value of NOxAM on the second channel. NOxAM was the value representative of both the NOx and ammonia reading. Ammonia was found from the difference between the two readings. Error was introduced when the differencing method was applied to similar numbers. A secondary ammonia analyzer was also used; the Advanced Optima AO2020 was capable of measuring $\mathrm{NO}, \mathrm{NO}_{2}$ and $\mathrm{NH}_{3}$. However, an ammonia span gas was unavailable for analyzer calibration at the time of testing. 


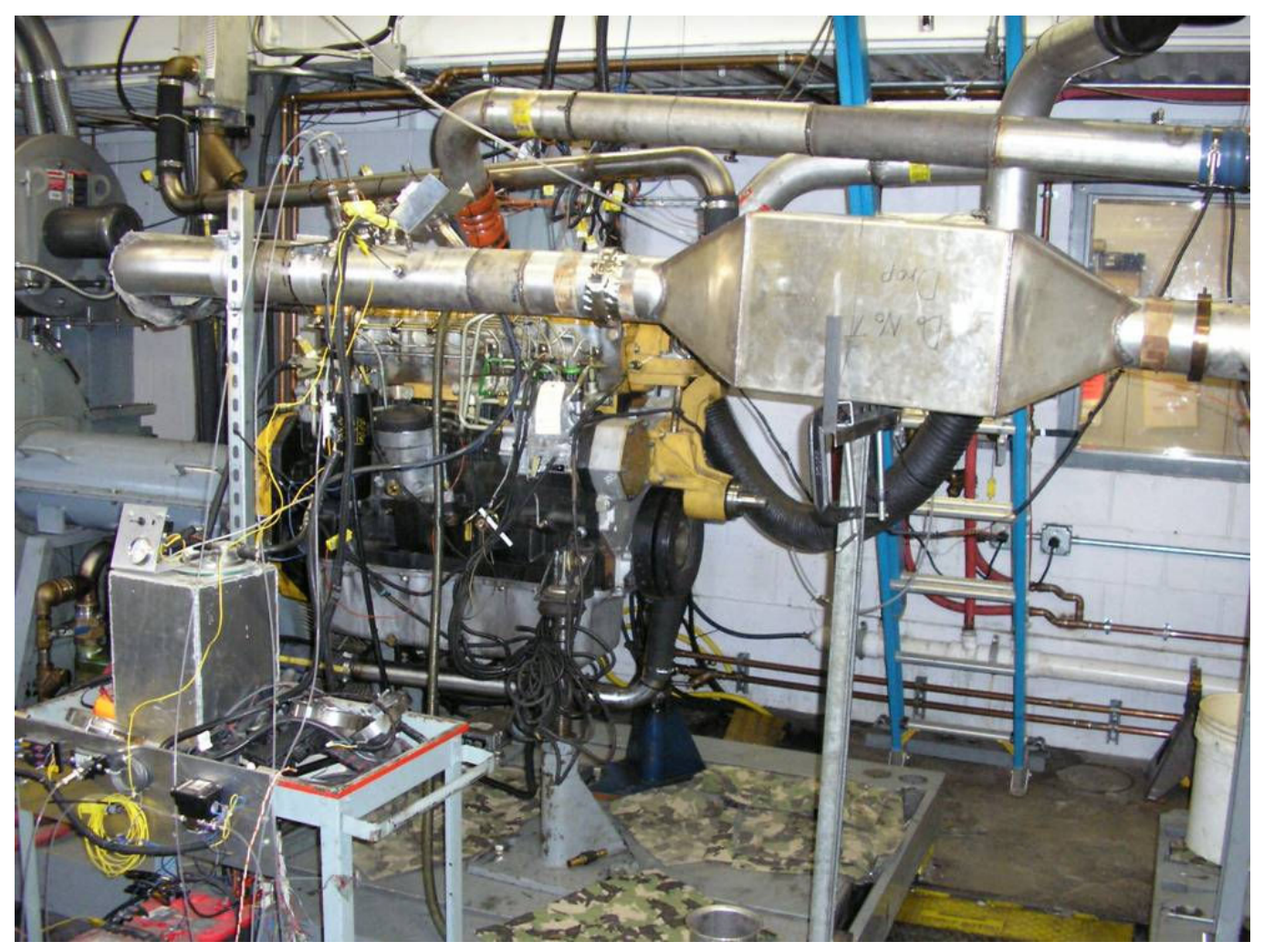

Figure 5.2 Test Cell Setup Showing Urea Injection System, SCR Catalyst, John Deere Engine and Test Cell Dynamometer

\subsection{Test Cycles}

Two test cycles were used for initial system testing. The first test cycle was the Non Road Transient Cycle (NRTC). This cycle is a certification cycle for mobile nonroad diesel engines. John Deere engine used for testing was typical of off road farm equipment, so it was well suited for NRTC testing. Previous testing on the NRTC also allowed for the comparison of emissions values to ensure the installation of the system did not yield different baseline emissions, increase fuel consumption or affect engine performance. Figure 5.3 shows the NRTC cycle based on engine speed. 


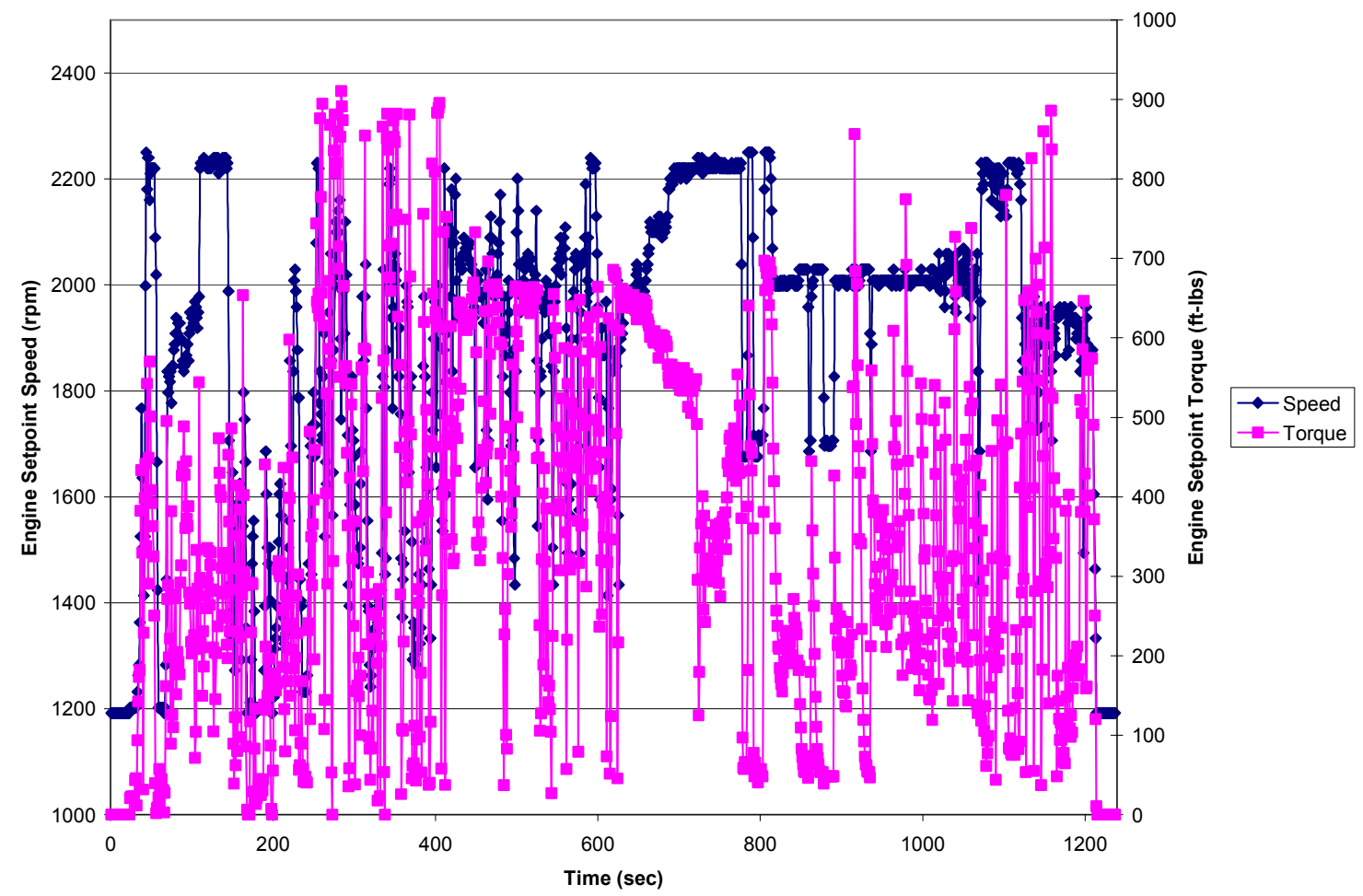

Figure 5.3 NRTC Engine Speed and Torque Set Points

The second cycle utilized was the ICOMIA E5 steady state test cycle typical for marine vessels. Figure 5.4 shows the ICOMIA cycle based on engine speed. The engine and system were allowed to stabilize at the beginning of each mode for 60 seconds.

Figure 5.4 represents only the period when gaseous samples were taken (after the settling time of 60 seconds). Table 5.1 includes data for each mode of the steady state test cycle. 


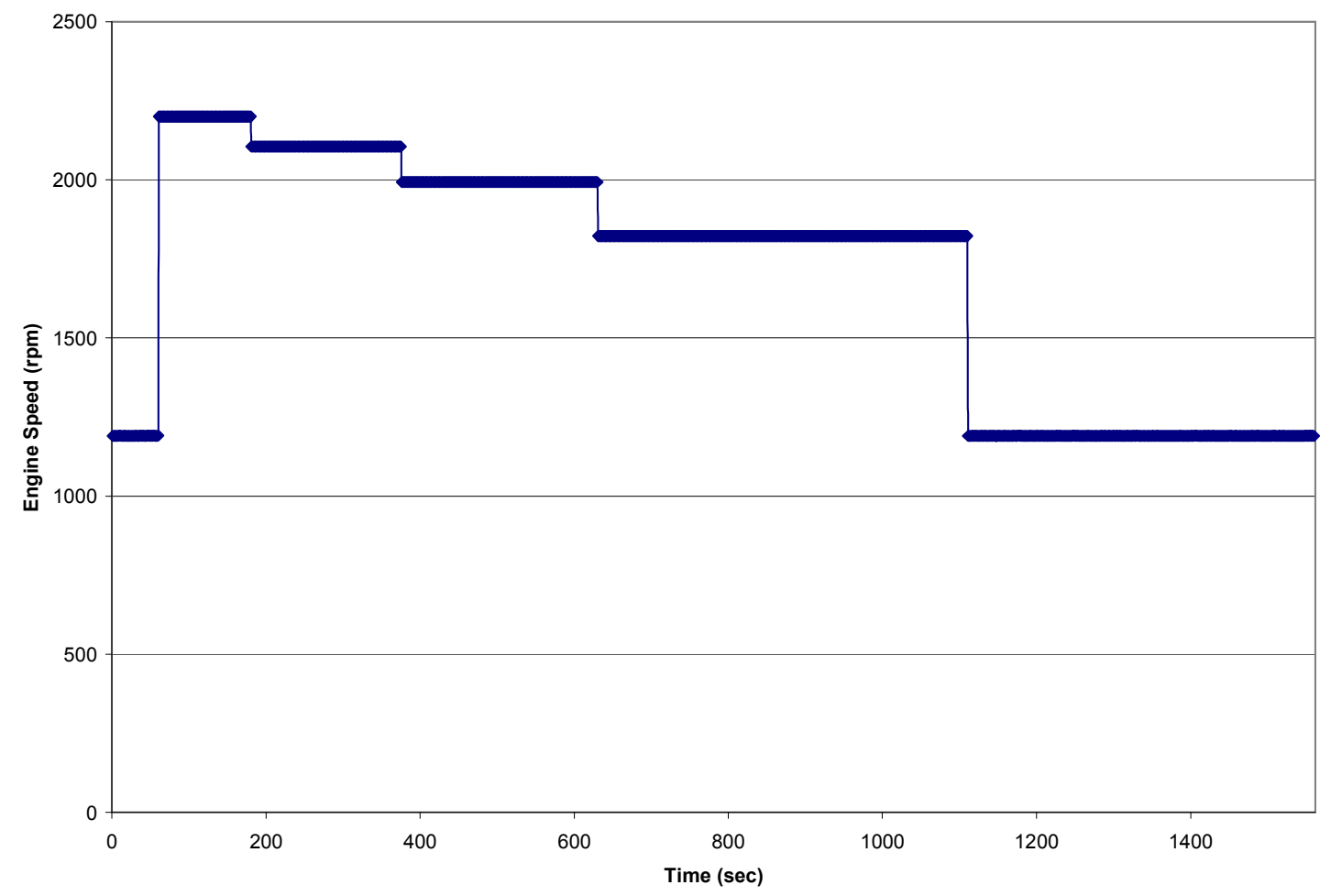

Figure 5.4 Engine Speed for ICOMIA E5 Cycle

Table 5.1 ICOMIA E5 Cycle Mode Data and Set Points

\begin{tabular}{|c|c|c||c|c|c|c|}
\hline Mode & 1 & 2 & 3 & 4 & 5 & 6 \\
\hline Speed \% & Low idle & 100 & 90.58 & 79.46 & 62.54 & Low idle \\
\hline Torque \% & 0 & 100 & 78.91 & 57.20 & 29.55 & 0 \\
\hline $\begin{array}{c}\text { Time of } \\
\text { collection (sec) }\end{array}$ & 60 & 120 & 195 & 255 & 480 & 450 \\
\hline
\end{tabular}

Background runs were performed for each test cycle with the catalyst in place but without injection, for baseline emissions comparisons. All urea injection system changes were made during the multiple NRTC runs. A hot soak period of 20 minutes was used between each cycle for zero/spanning of analyzers, charging of urea system batteries, file renaming and other data reduction tasks. Once the system changes yielded lower ammonia slip and approached the NOx reduction threshold of $50 \%$ on the NRTC, the 
system settings were applied to a final ICOMIA E5 cycle. Complete results are discussed in the following section. 


\section{Test Results}

\subsection{System Correlation Results}

The two main input variables into the urea control system were exhaust flow and NOx concentration. Both inputs were measured by the stand alone urea injection system (UIS) independently of engine parameters or EERL equipment. These two variables were time aligned and compared to EERL data from a laminar flow element (LFE) placed within the engine intake and the EcoPhysics NOx analyzer output. All time alignments were based on the highest coefficients of variation between data sets. These and all other data were collected at a sampling frequency of $1 \mathrm{~Hz}$.

The LFE data was output from the data reduction system in standard cubic feet per minute (SCFM). Therefore, the output data from the urea injection system was compared on a standard level. These two measurements were time aligned for comparison. The NOx level measured by the EcoPhysics was the dilute concentration from the sampling plane of the dilution tunnel. The NOx concentration measured by the Siemens NOx sensor within the urea injection system was a raw measurement. To compare and correlate these two measurements, both were converted into g/sec values. Both the EERL data and UIS data were calculated based on standard volume flow rates. Similar results could be shown for the volume flows that were uncorrected for temperature and pressure.

Figures 6.1 and 6.2 show the comparison and correlation of the EcoPhysics NOx and Siemens NOx on a g/sec basis. The Siemens time delay was originally stated to be up to 1 second. When correlations were compared between Siemens NOx and EERL engine power, a delay of 1 second was found between the two data sets. However, these data 
were previously aligned with flow and data collection at only $1 \mathrm{~Hz}$. The NOx in $\mathrm{g} / \mathrm{sec}$ data sets were time aligned based on correlation to eliminate time delay between the measurement near the engine and measurement at the dilution tunnel sampling plane. As shown in Figure 6.2, the correlation coefficient was found to be 0.943 for a direct comparison of this un-averaged data.

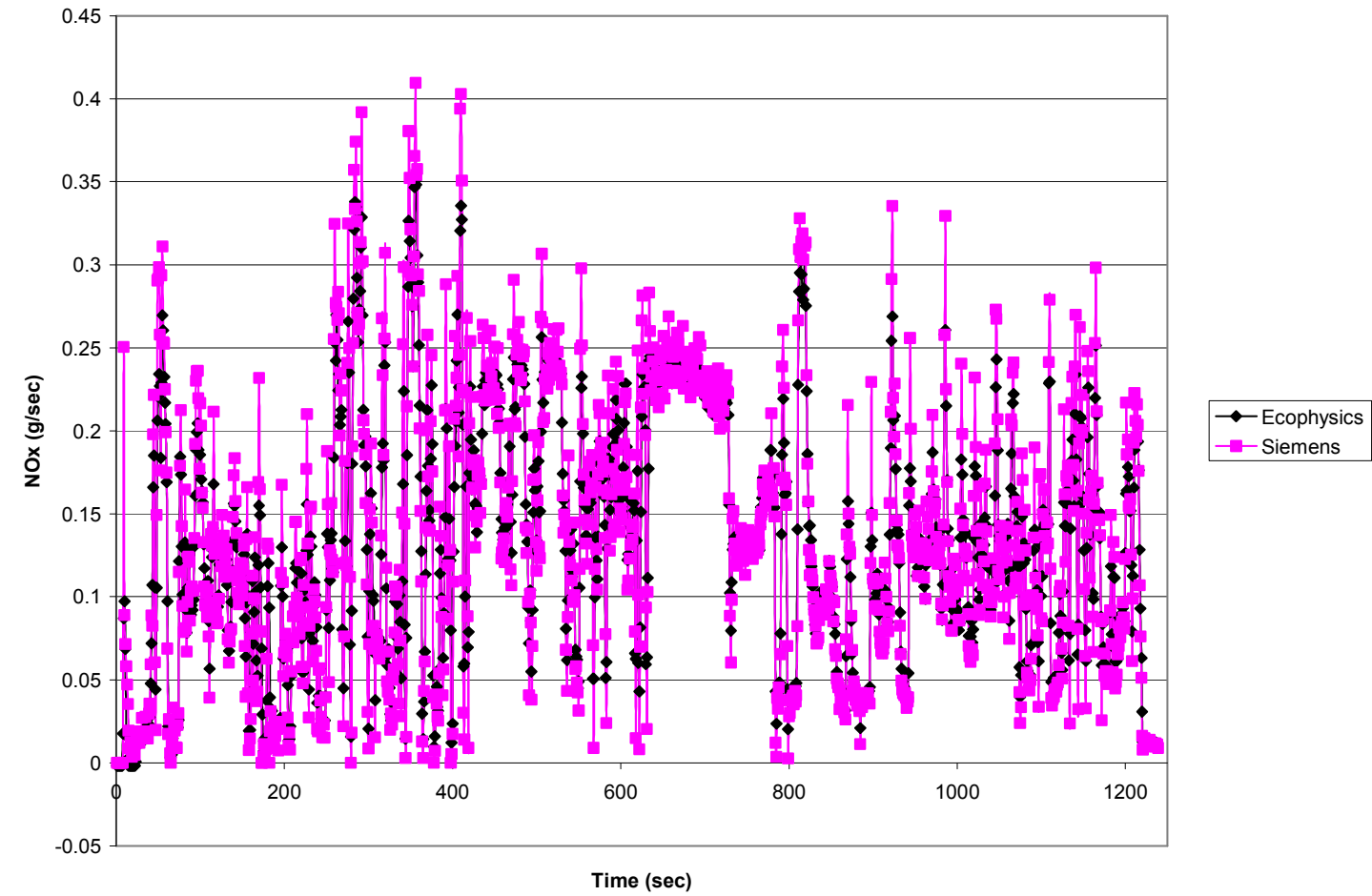

Figure 6.1 EcoPhysics and Siemens NOx Sensor Comparison for NRTC Cycle 


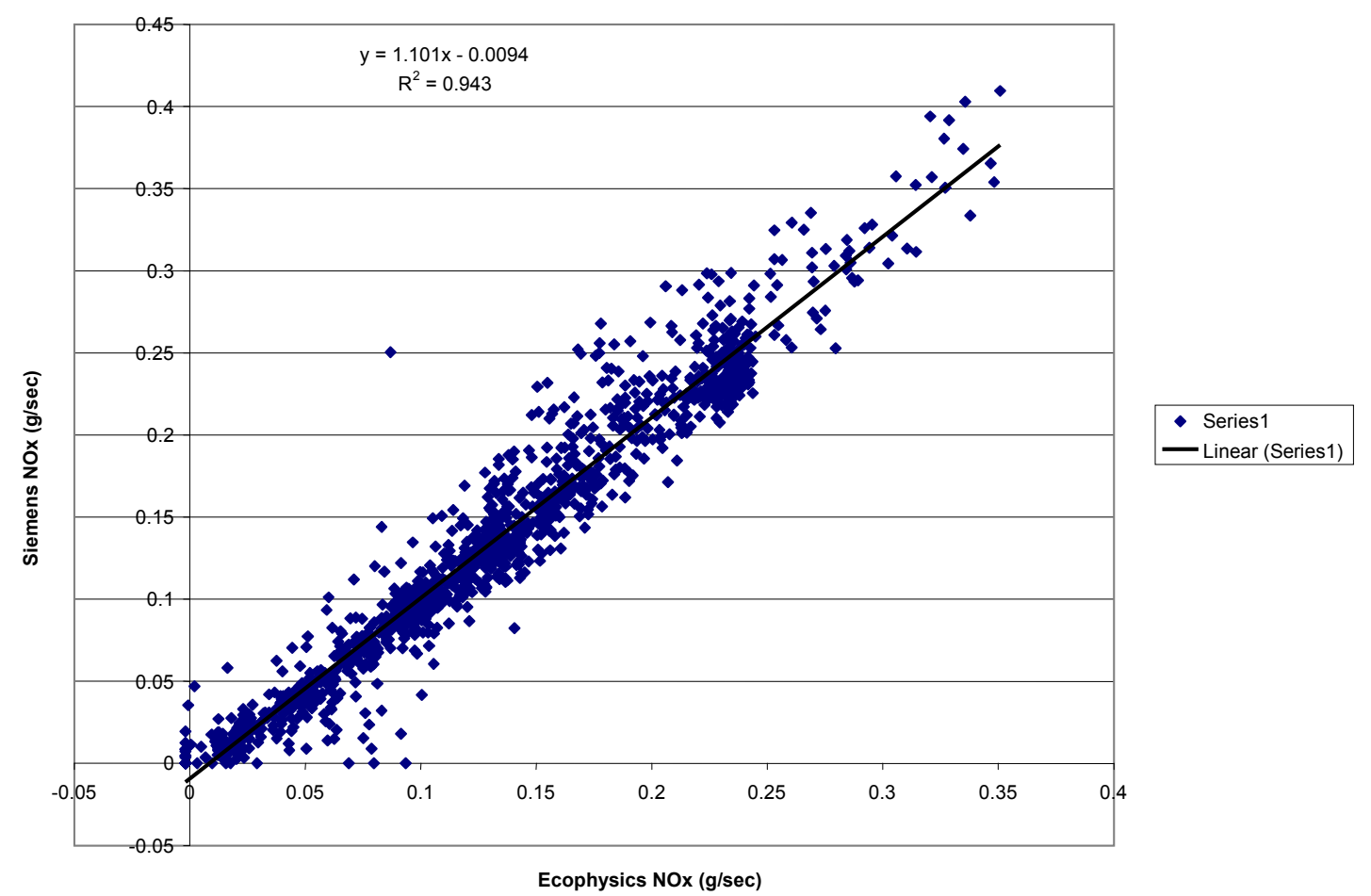

Figure 6.2 Correlation of Siemens NOx Data with Respect to EcoPhysics NOx Data 
A nine point average was applied to the previous data set to smooth variations due to the highly transient nature of the cycle and sensor measurement. Figures 6.3 and 6.4 show the comparison and correlation of the data based on the nine point average. The correlation coefficient increased to 0.9849 . Averaging the data eliminated error at low measurement values where UIS sensors experienced dropout. The UIS control model did not contain any real time averaging methods at the time of testing.

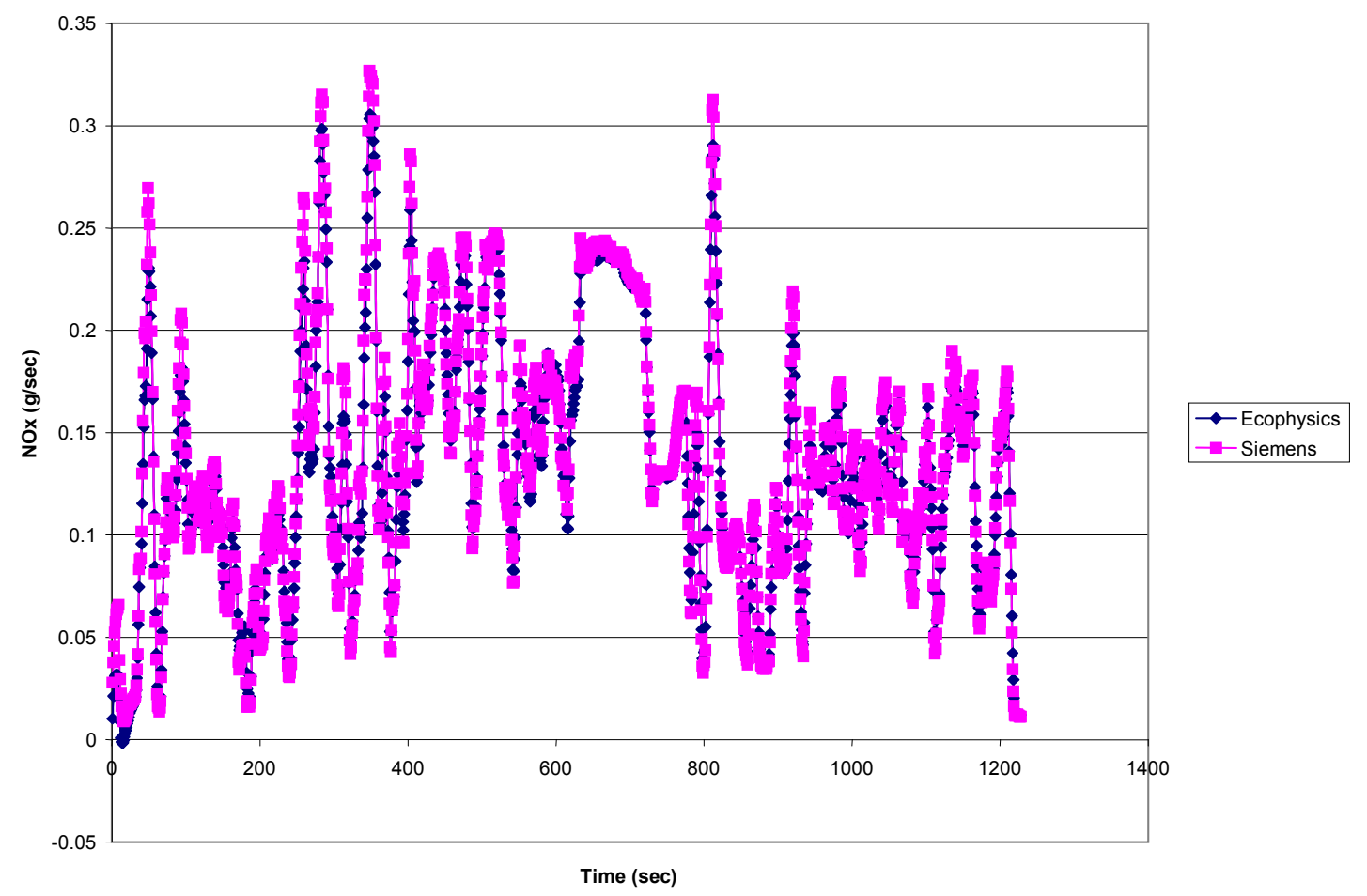

Figure 6.3 9-Pt Average of NOx Readings From EcoPhysics and Siemens NOx Sensor 


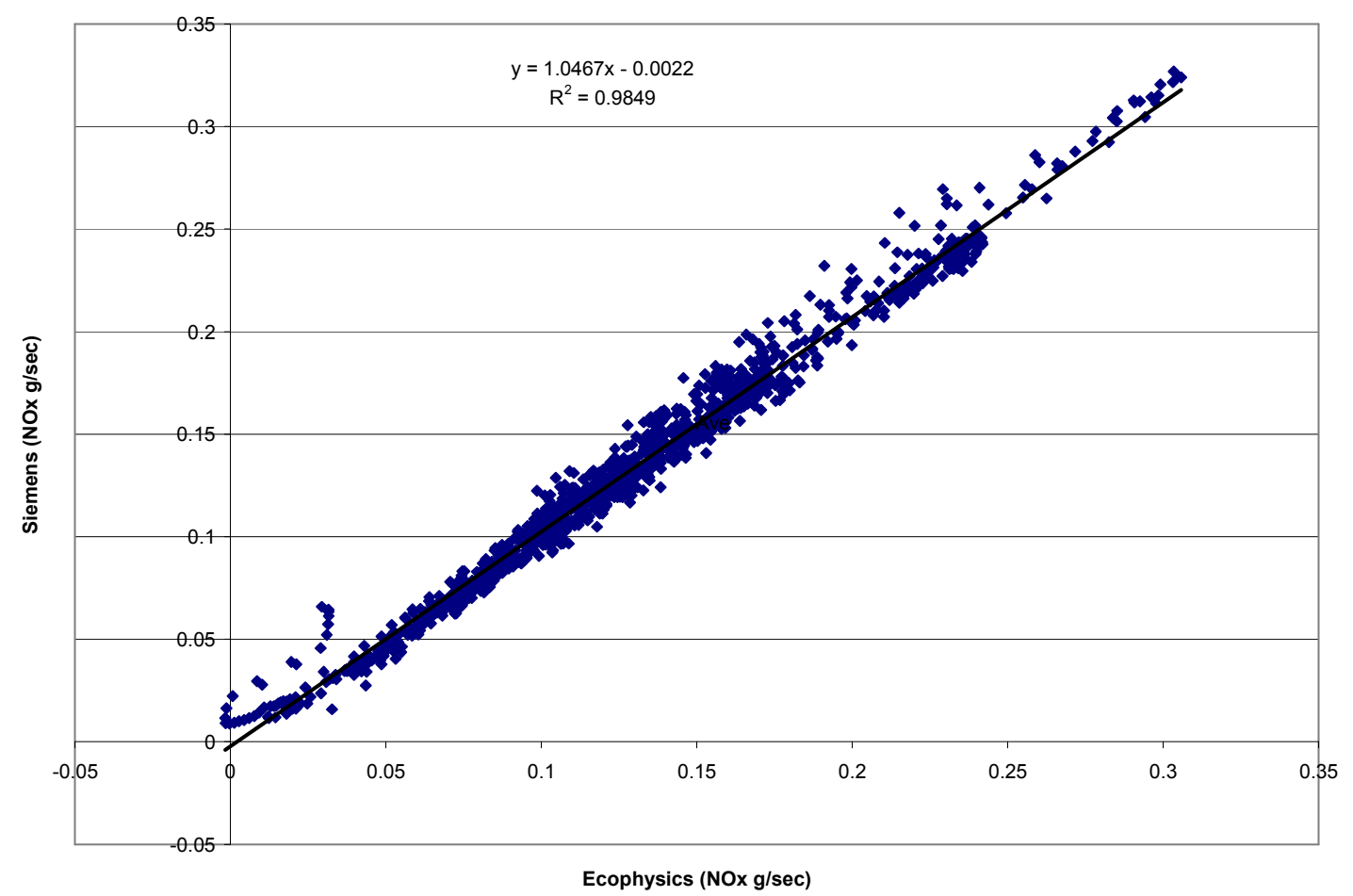

Figure 6.4 Correlation of the Two Data Sets with a 9-Pt Average

The NOx levels for the UIS were determined based on the exhaust flow measurement within the flow tube. Figures 6.5 and 6.6 show the comparison to the LFE and correlation with the LFE. These data sets were not averaged. It was seen that at low flow conditions the Pitot tube/differential pressure measurement dropped out, causing UIS flow to be zero. This error carried through the system calculation and was seen in the low level NOx measurement error of the previous figures. As shown in Figure 6.6 the correlation coefficient of the UIS flow tube with the LFE was found to be 0.9588 . 


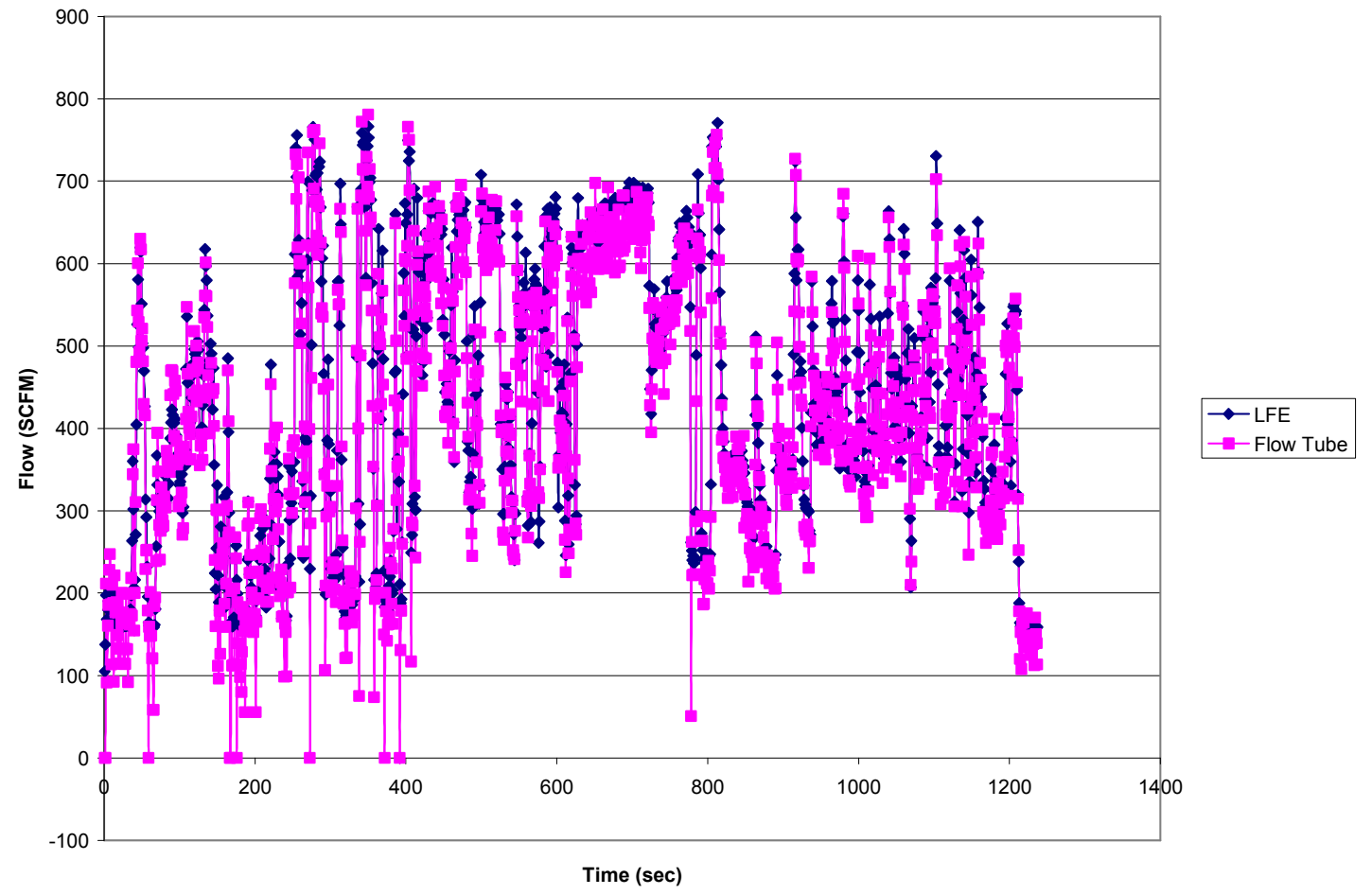

Figure 6.5 Comparison of Flow Tube and LFE for NRTC

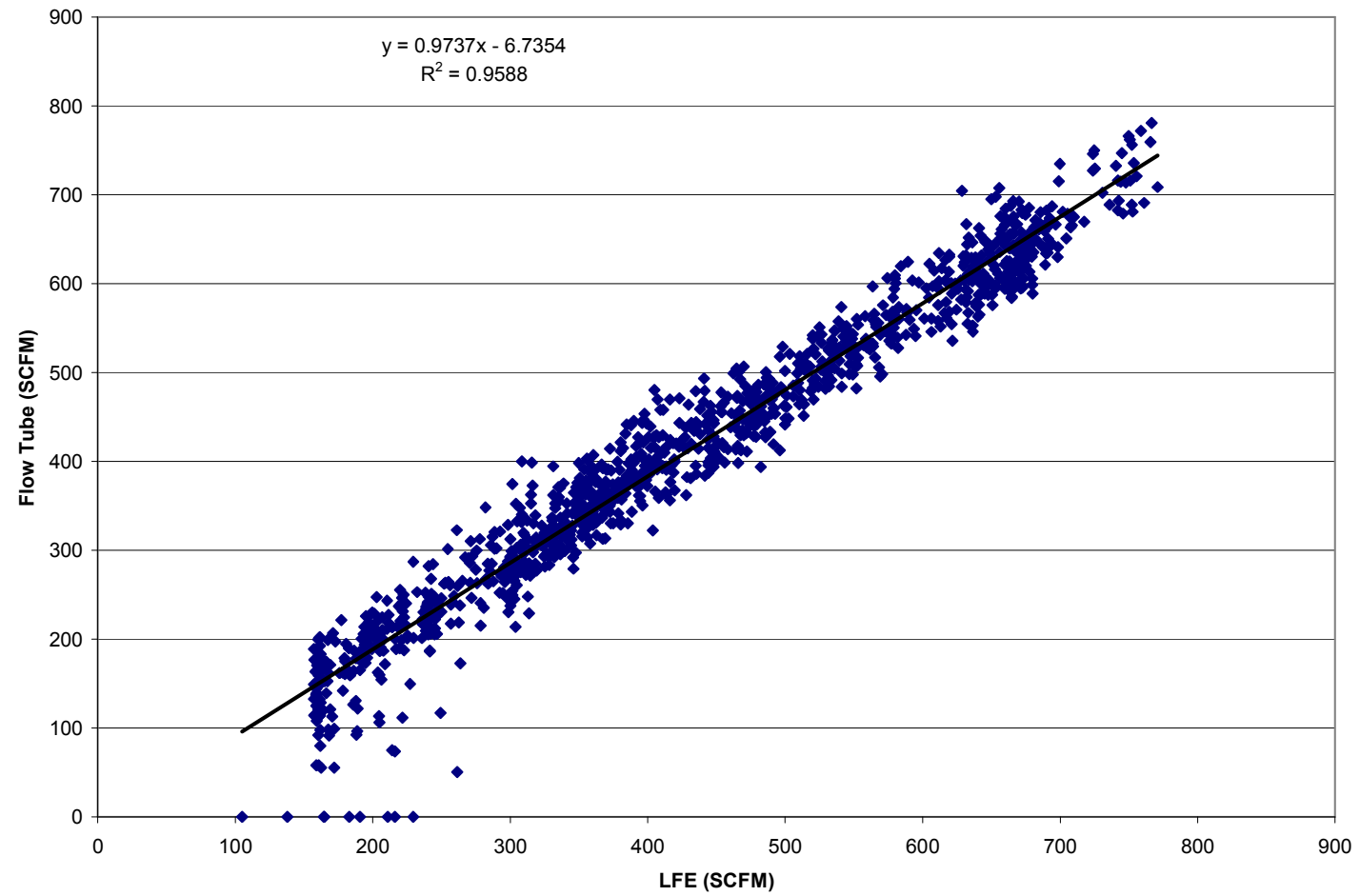

Figure 6.6 Correlation of Flow Tube Against Intake LFE 
Exhaust temperature was a major input variable utilized by the UIS. The UIS flow tube temperature was used within the program and recorded during testing. Two thermocouples were placed in the exhaust system and recorded by the EERL system. The first was placed directly after the exhaust turbine outlet; the second was placed after the SCR catalyst. Figure 6.7 shows all three sensor values for the NRTC. The outputs show a similar trend. The effect of the thermal inertia of the catalyst was seen by the lag in the post SCR temperature. The thermal inertia model discussed in section 4.2.6 was not utilized during the first round of testing. Figure 6.7 shows that it would not have proved advantageous to incorporate this model for the NRTC because of the lack of extended idle conditions, but may prove useful for other transient cycles such as an FTP cycle.

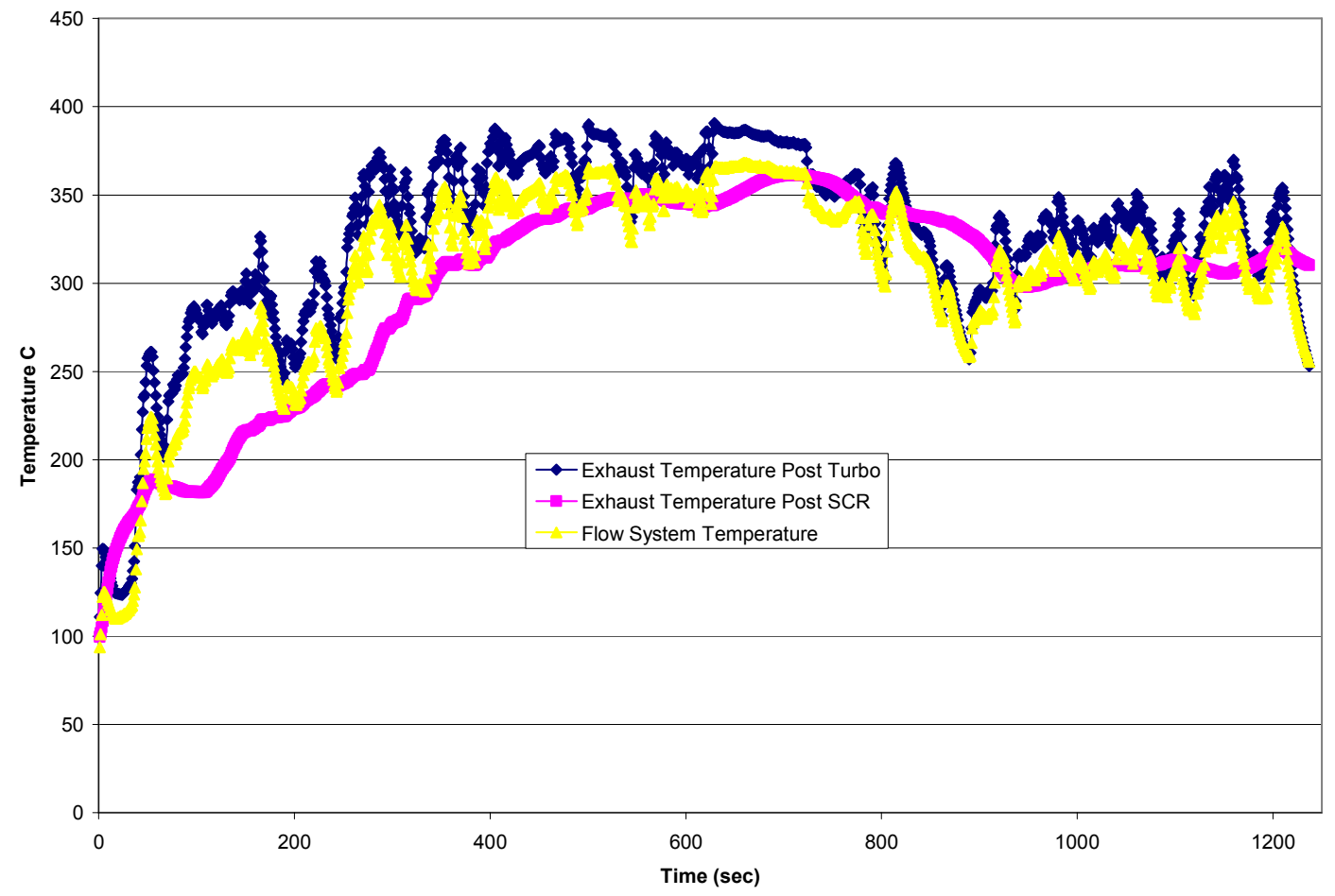

Figure 6.7 Temperature Plot for EERL and UIS Thermocouple Outputs

Data was also recorded for comparisons over the ICOMIA E5 cycle. It was seen from Figure 6.8 that NOx levels were comparable in modes 2, 3 and 4. Over estimation 
occurred during mode 1, the high speed mode. The sensor dropout was again seen by NOx levels during the last mode in Figure 6.8 and with flow levels in the last mode of Figure 6.9. Figure 6.10 shows the EERL and UIS thermocouple outputs. The effect of thermal inertia of the catalyst was seen during the last mode.

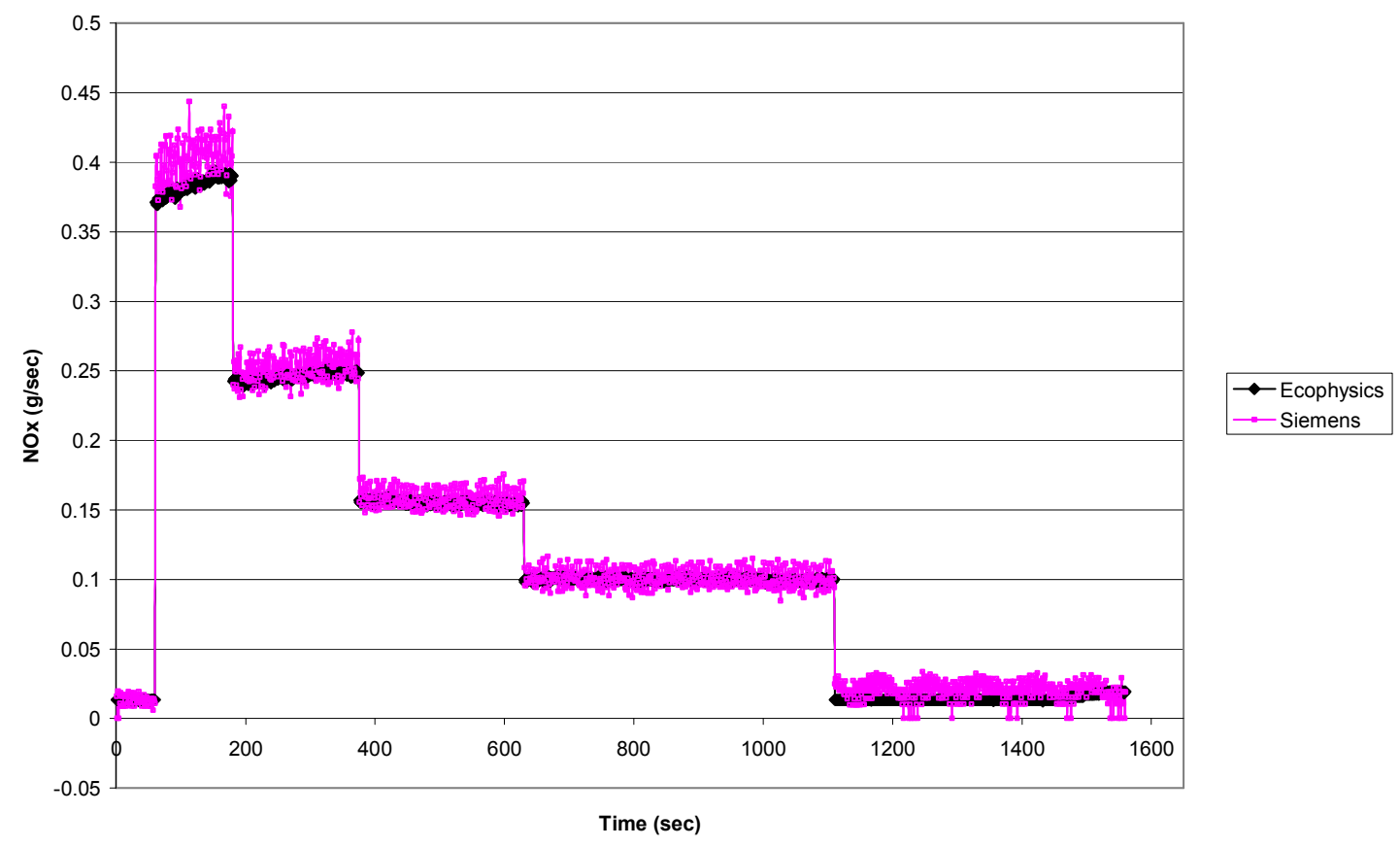

Figure 6.8 NOx Comparisons for the EcoPhysics and Siemens Sensor During the ICOMIA E5 Cycle 


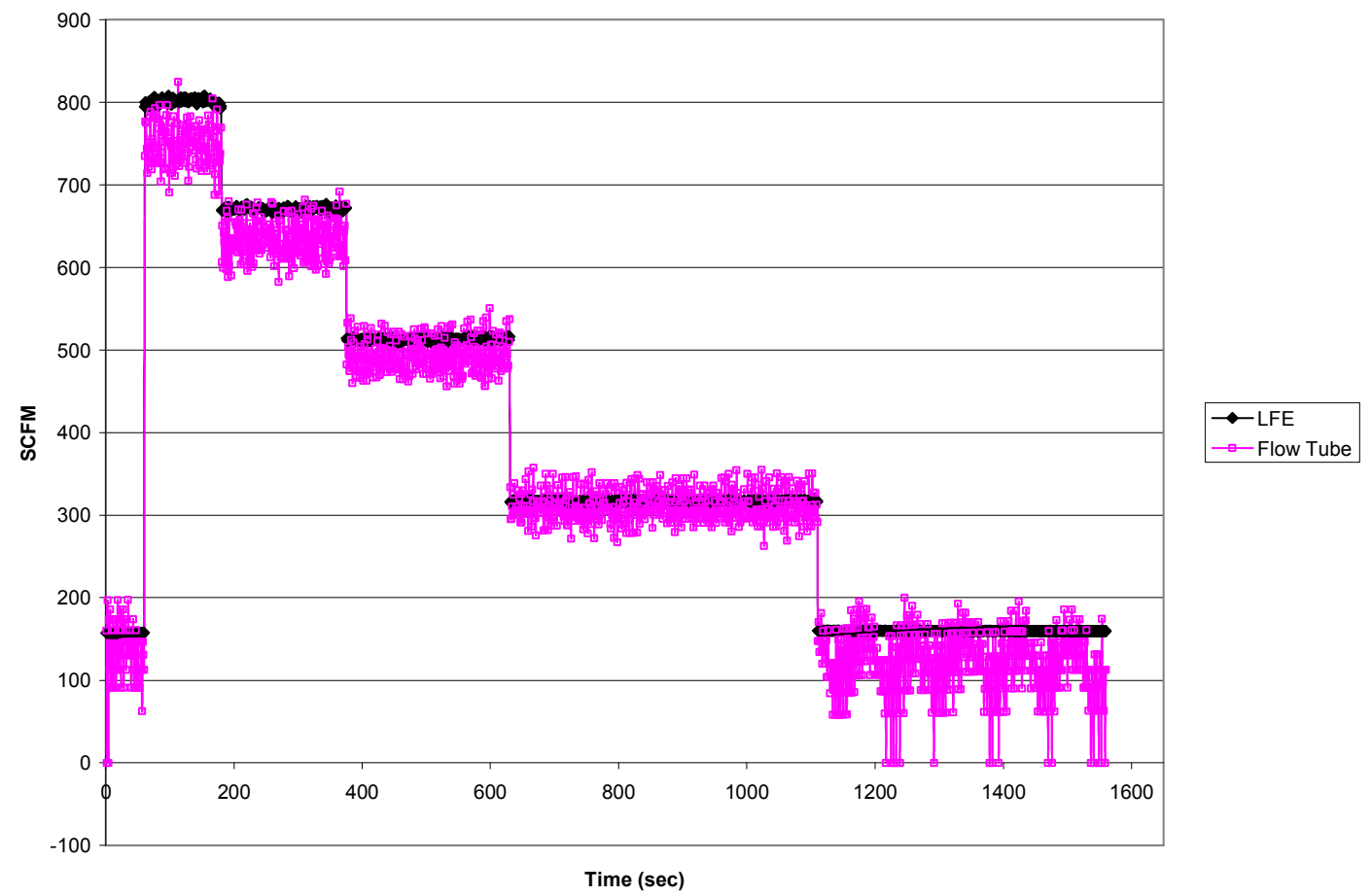

Figure 6.9 Flow Comparison of LFE and UIS Flow Tube for ICOMIA E5 Cycle

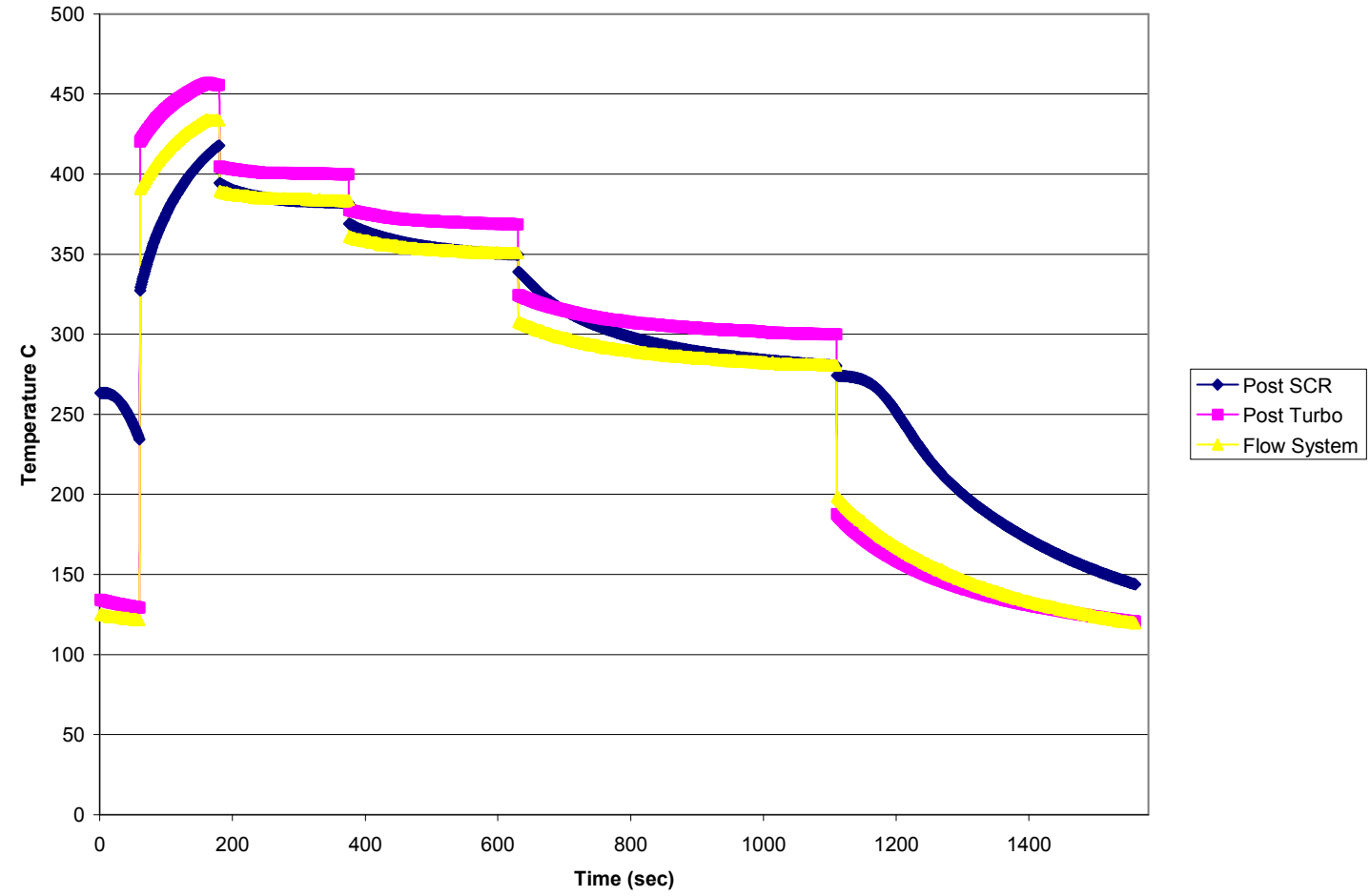

Figure 6.10 Temperature Plot for EERL and UIS Thermocouple Outputs for ICOMIA E5 Cycle 


\subsection{NRTC with varied Duty Cycle}

After the background runs were completed for the baseline emissions levels, multiple NRTCs were run. The initial system settings had a urea dope amount of one. This meant that the urea requested was based on stoichometric reaction of $\mathrm{NO}$ with $\mathrm{NH}_{3}$. Theoretically, if there were no inefficiencies within the system, the reduction in NOx would have been $100 \%$ at this level. Various tests were run with multiple urea dope amounts. The 'Urea Dope' variable was a simple scalar applied to the duty cycle (DC) input of the injector driver. NRTC were run at $100 \%, 70 \%$ and $50 \%$ duty cycle.

Figure 6.11 shows the NOx level as measured by the EcoPhysics analyzer for the background and urea injection runs. As the dope amount was decreased, the NOx level increased towards the baseline run. The various duty cycles were applied in order to minimize the ammonia slip. NOx reduction for the $100 \% \mathrm{DC}, 70 \% \mathrm{DC}$ and $50 \% \mathrm{DC}$ based on cycle average ppm was $63 \%, 54 \%$ and $51 \%$, respectively. NOx reductions based on $\mathrm{g} / \mathrm{bhp}$-hr were $67.4 \%, 56.0 \%$ and $50.0 \%$, respectively. 


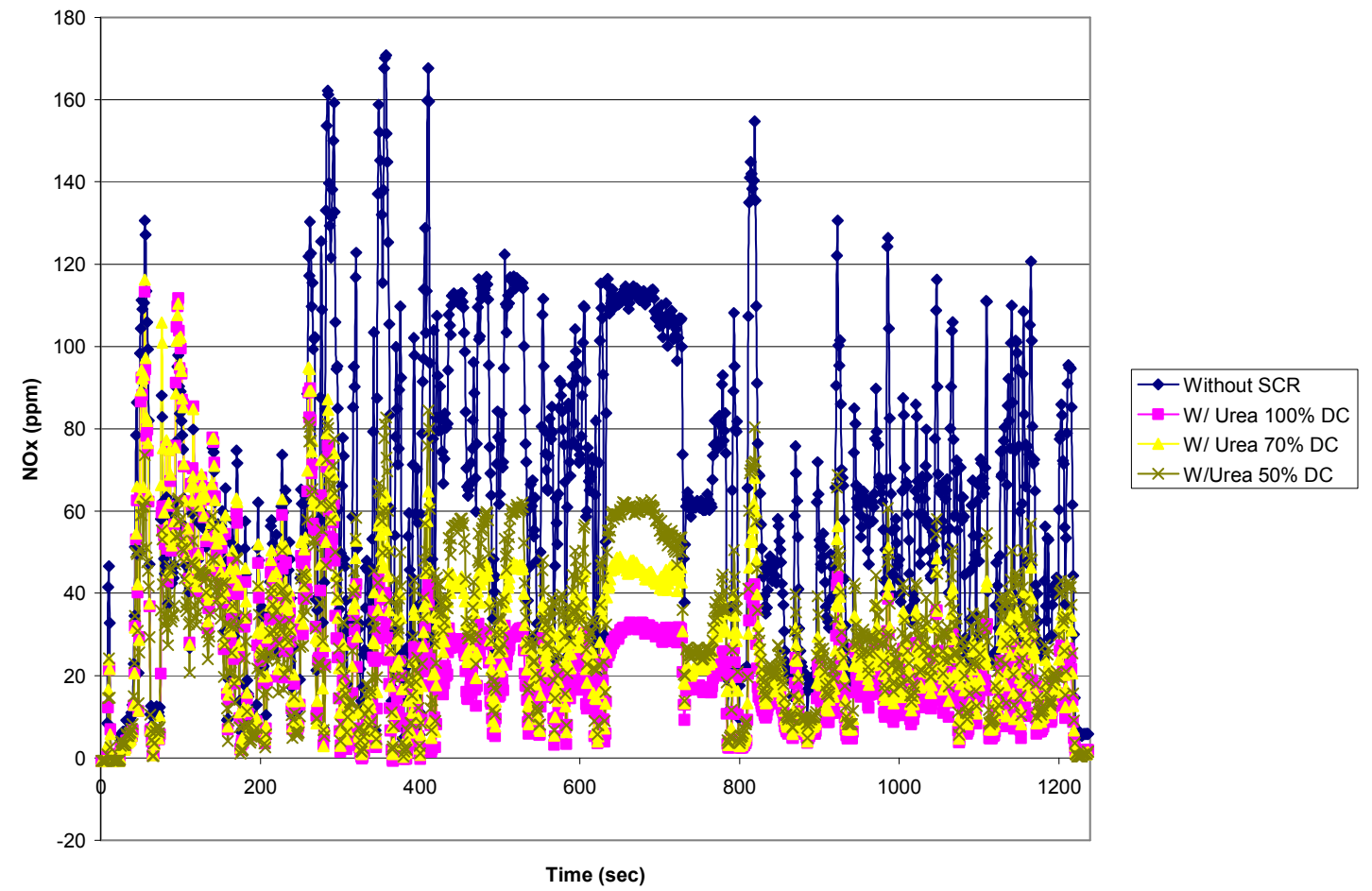

Figure 6.11 Run to Run Reduction in NOx (ppm) Based on Varied Duty Cycle

Figure 6.12 shows the corresponding injection rates for the $100 \% \mathrm{DC}, 70 \% \mathrm{DC}$ and $50 \%$ DC tests. The figure shows that urea injection did not occur when the flow system temperature was under the threshold of $250^{\circ} \mathrm{C}$. The estimated amount of urea delivered for each of tests was 445, 319 and 241 grams, respectively. The average fuel used per NRTC was 7,428 grams based on carbon balance. The amount of urea injected per cycle as a percentage of fuel consumed was 5.99\%, 4.29\% and 3.24\%, respectively. Literature suggested that the maximum values should be no more than $5 \%$ and less dependent upon cycle. 


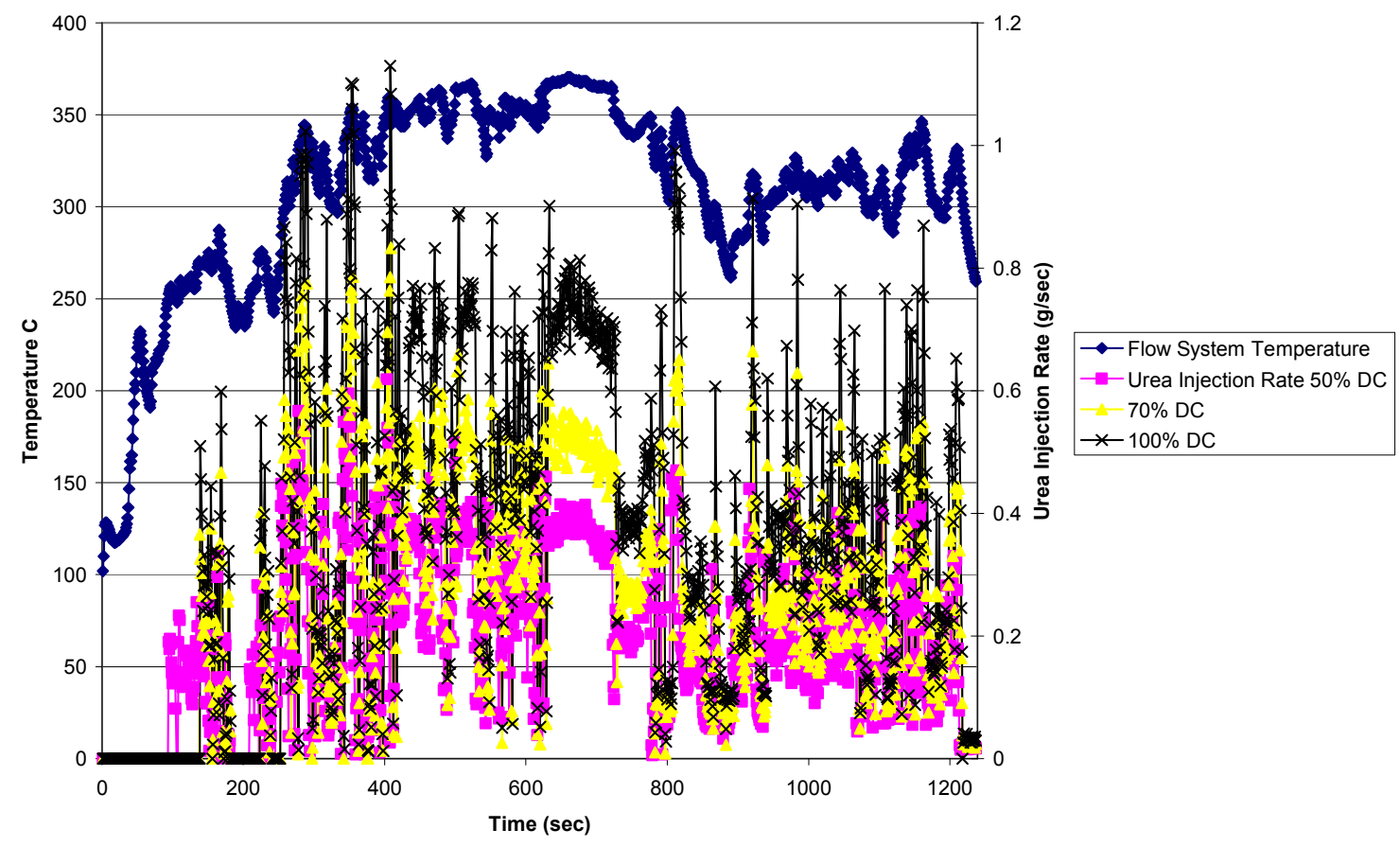

Figure 6.12 Urea Injection Rate Based on DC Requested and Flow Tube Temperature

Each of the various NRTC had significant ammonia slip. If the entire system was overdosed with urea, then $\mathrm{CO}$ spikes should have occurred with the ammonia slip. Figure 6.13 shows the CO for the background NRTC and the urea injection cycles. CO spikes or significant cycle to cycle variation was not found. CO levels for the NRTC background, $100 \%$ DC, 70\% DC and 50\% DC cycles were 1.57, 1.61, 1.67, and $1.55 \mathrm{~g} / \mathrm{bhp}-\mathrm{hr}$, respectively. 


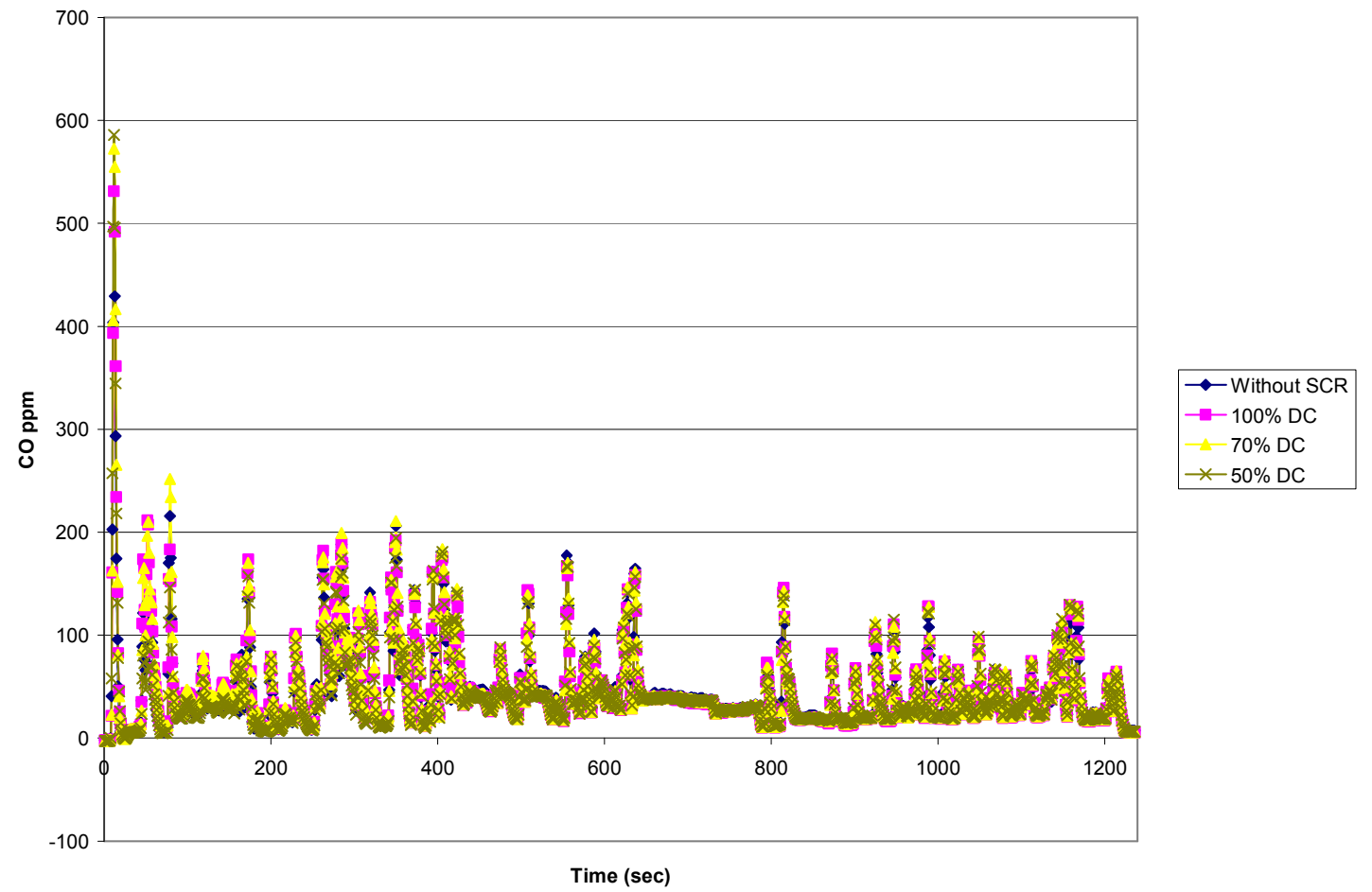

Figure 6.13 NRTC CO Emissions for Various Cycles with and Without Urea Injection

With respect to the goal of minimizing ammonia slip, the NRTC with $100 \%$ DC produced the worst results. Figure 6.14 shows the dilute ammonia levels in ppm that were recorded for the $100 \%$ DC test. Due to the transient nature of the test and the differencing method of the EcoPhysics analyzer background ammonia levels were between -15 and $+15 \mathrm{ppm}$. The un-calibrated AO2020 was over ranged during the test to above its $50 \mathrm{ppm}$ limit. Peak dilute ammonia slip from the EcoPhysics was $50 \mathrm{ppm}$. 


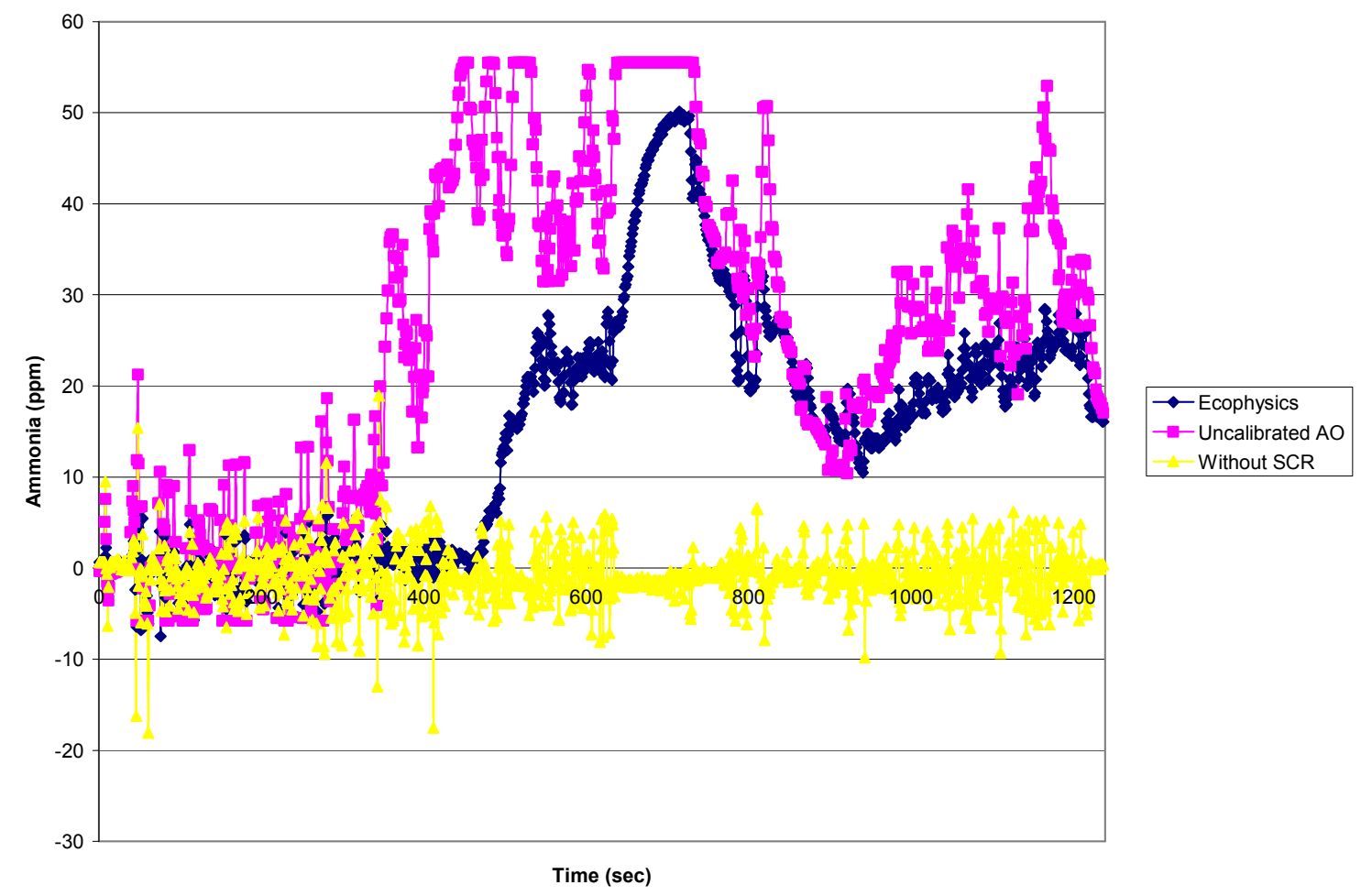

Figure 6.14 Dilute Ammonia Levels for NRTC 100\% DC

When the goal of 50\% NOx reduction with minimized ammonia slip was examined, the NRTC with 50\% DC was the best test. Figures 6.15 and 6.16 illustrate the pertinent results for this test. Figure 6.15 again shows the NOx levels with and without the $50 \%$ DC urea injection. The figure also contained a continuous NOx reduction percentage line. Negative reduction percentages and those above $100 \%$ were set to 0 and $100 \%$ values. Figure 6.16 shows the ammonia slip for this cycle. The maximum EcoPhysics dilute ammonia slip value was $13 \mathrm{ppm}$, with a minimum of $-4 \mathrm{ppm}$ and a cycle average of $5 \mathrm{ppm}$. 


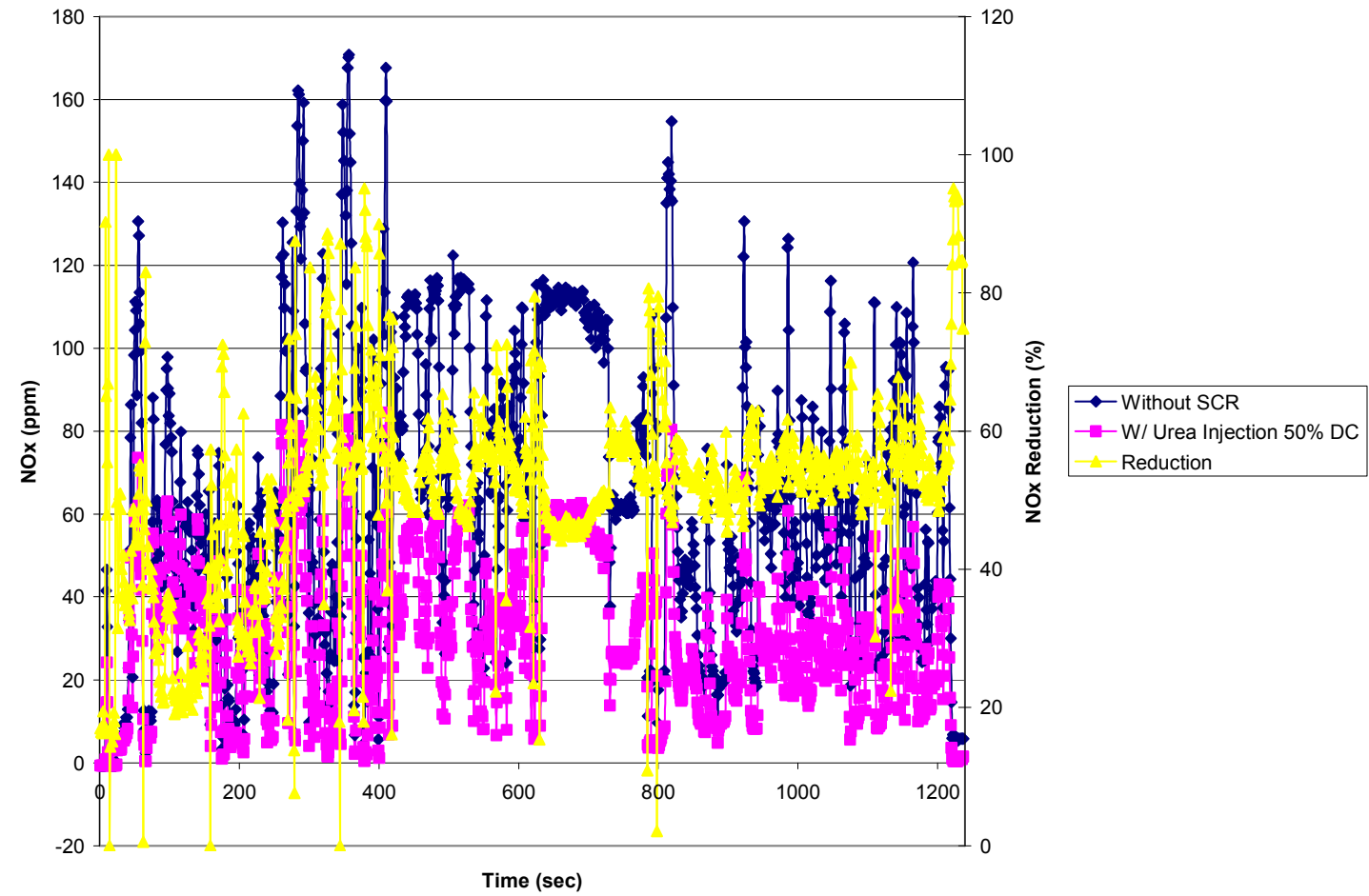

Figure 6.15 NRTC with 50\% DC NOx Results and Continuous Reduction Percentage

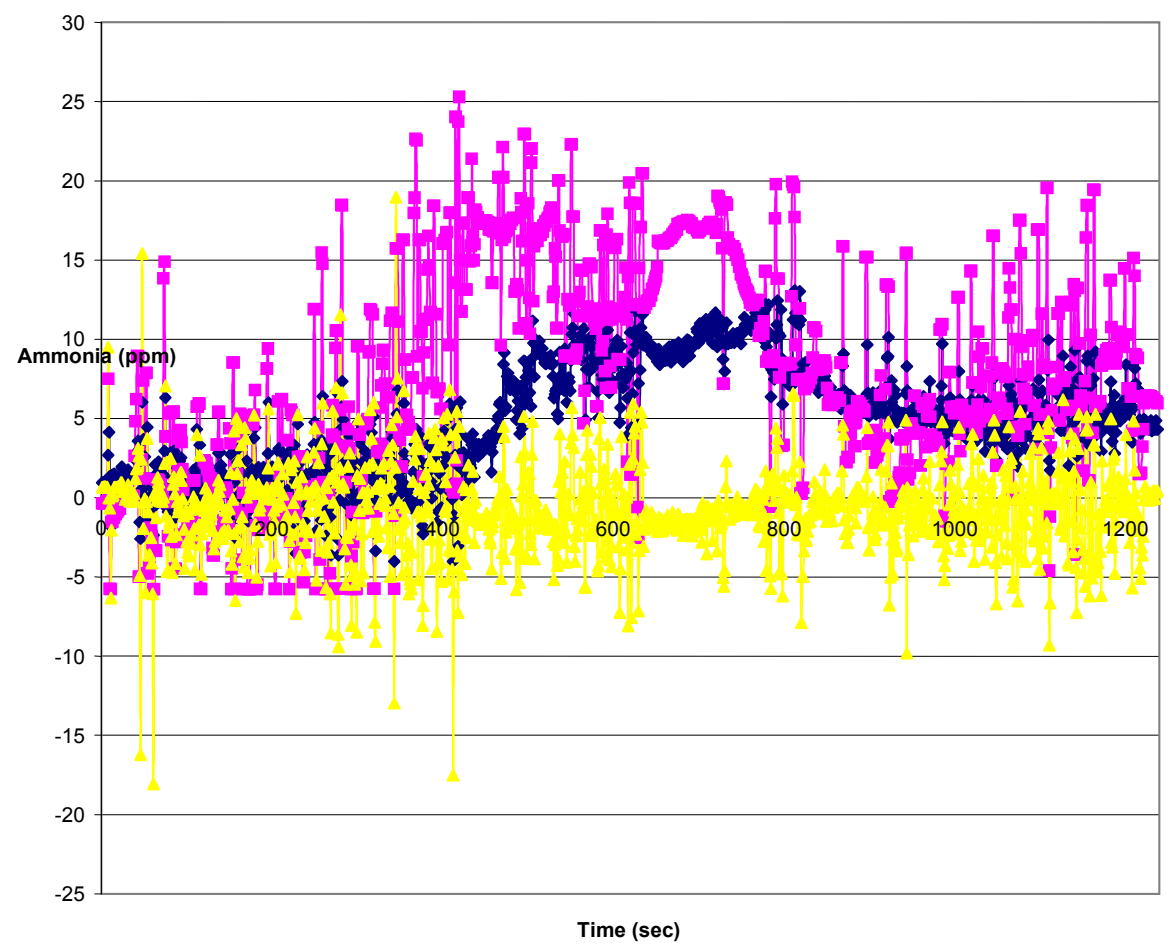

Figure 6.16 Dilute Ammonia Results for NRTC with 50\% DC 


\subsection{ICOMIA E5 with 50\% Duty Cycle}

The multiple NRTC runs were used to make the necessary changes to the system in order to meet the target NOx reduction of 50\% while minimizing ammonia slip through software control. The best NRTC results based on minimization of ammonia slip were obtained by setting the urea dope amount or DC to $50 \%$. This setting was then applied to the ICOMIA E5 cycle. Figure 6.17 shows the results obtained from three E5 cycles. The first data was the NOx levels from the background run without urea injection; the second was a clean up run after the $100 \%$ DC NRTC. The $50 \%$ DC test results are also shown along with continuous NOx reduction. The clean up run was included to visually illustrate the available ammonia storage capacity of the catalyst. The maximum reduction level based on ppm was $52.90 \%$. The average cycle NOx reduction based on ppm was 33.93\%. The reduction results based ppm did not fairly represent the NOx reduction capabilities of the system since the cycle average included all idle modes. When the idle periods were included, the system was above the $250^{\circ} \mathrm{C}$ limit only $67 \%$ of the time. Mode by mode values are represented later. 


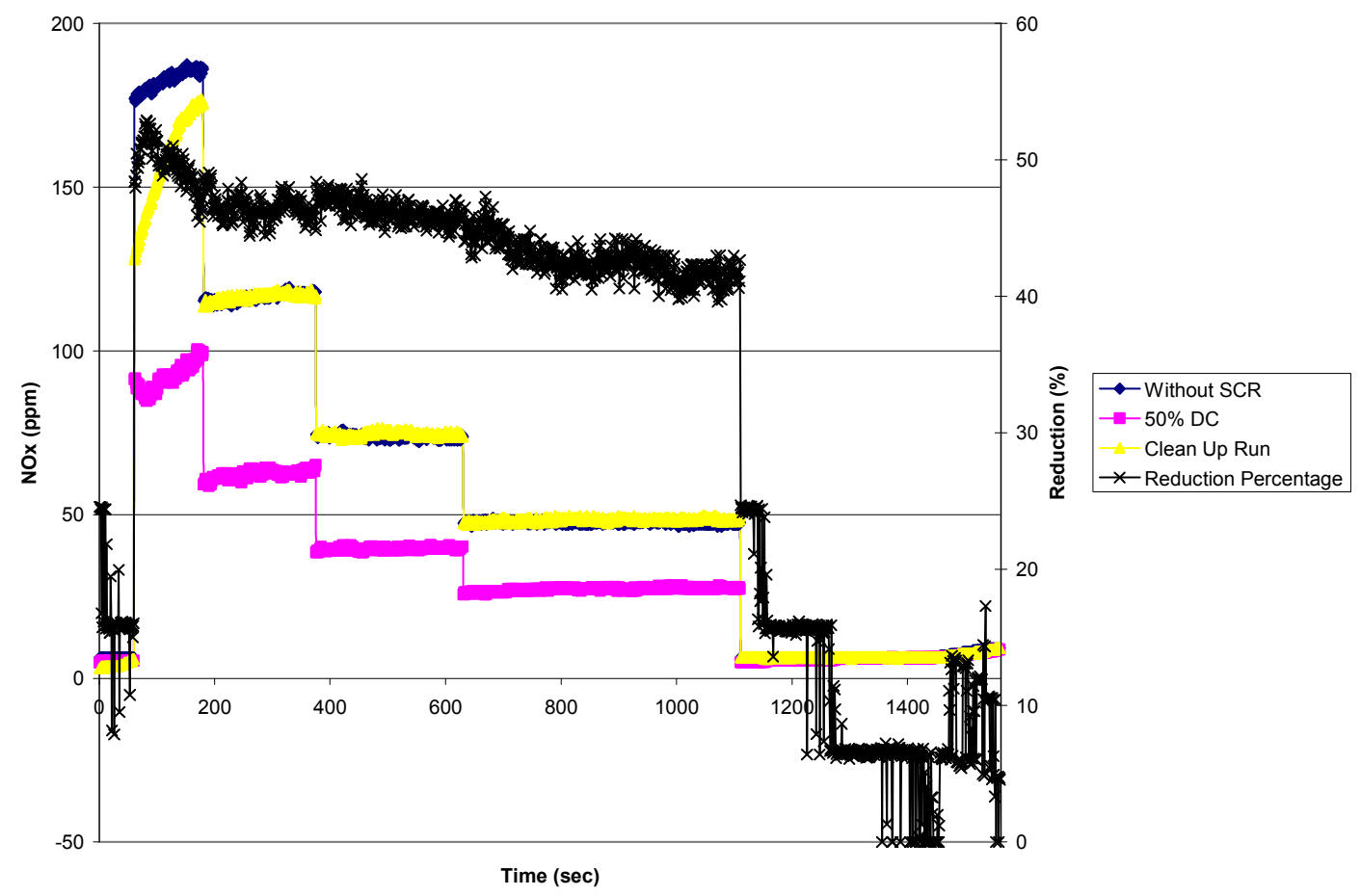

Figure 6.17 ICOMIA E5 Test Results with NOx Reduction Percentage for 50\% DC 
Dilute ammonia samples were also collected for the E5 50\% DC run. Figure 6.18 represents the background ammonia levels without urea injection and the values for the urea injection run. The maximum value from the EcoPhysics was $23.27 \mathrm{ppm}$ of dilute ammonia, with a minimum value of $0.96 \mathrm{ppm}$ and a cycle average value of $7.40 \mathrm{ppm}$.

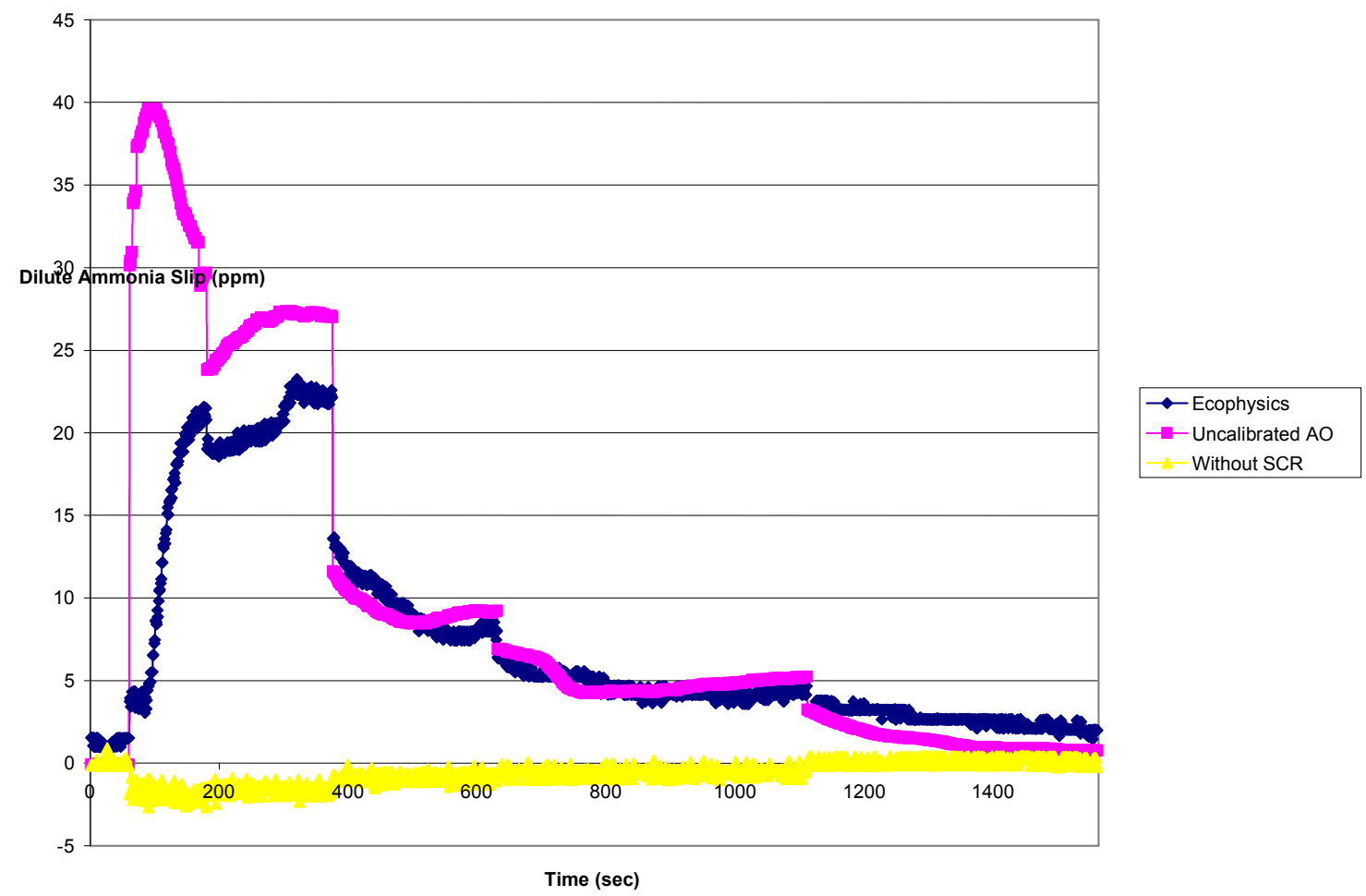

Figure 6.18 Dilute Ammonia Slip Results for E5 50\% DC 
Figure 6.19 shows the carbon monoxide levels for the background and 50\% DC tests. The results again fluctuated between $+/-15 \mathrm{ppm}$ between the cycles. No significant spikes or variations were found.

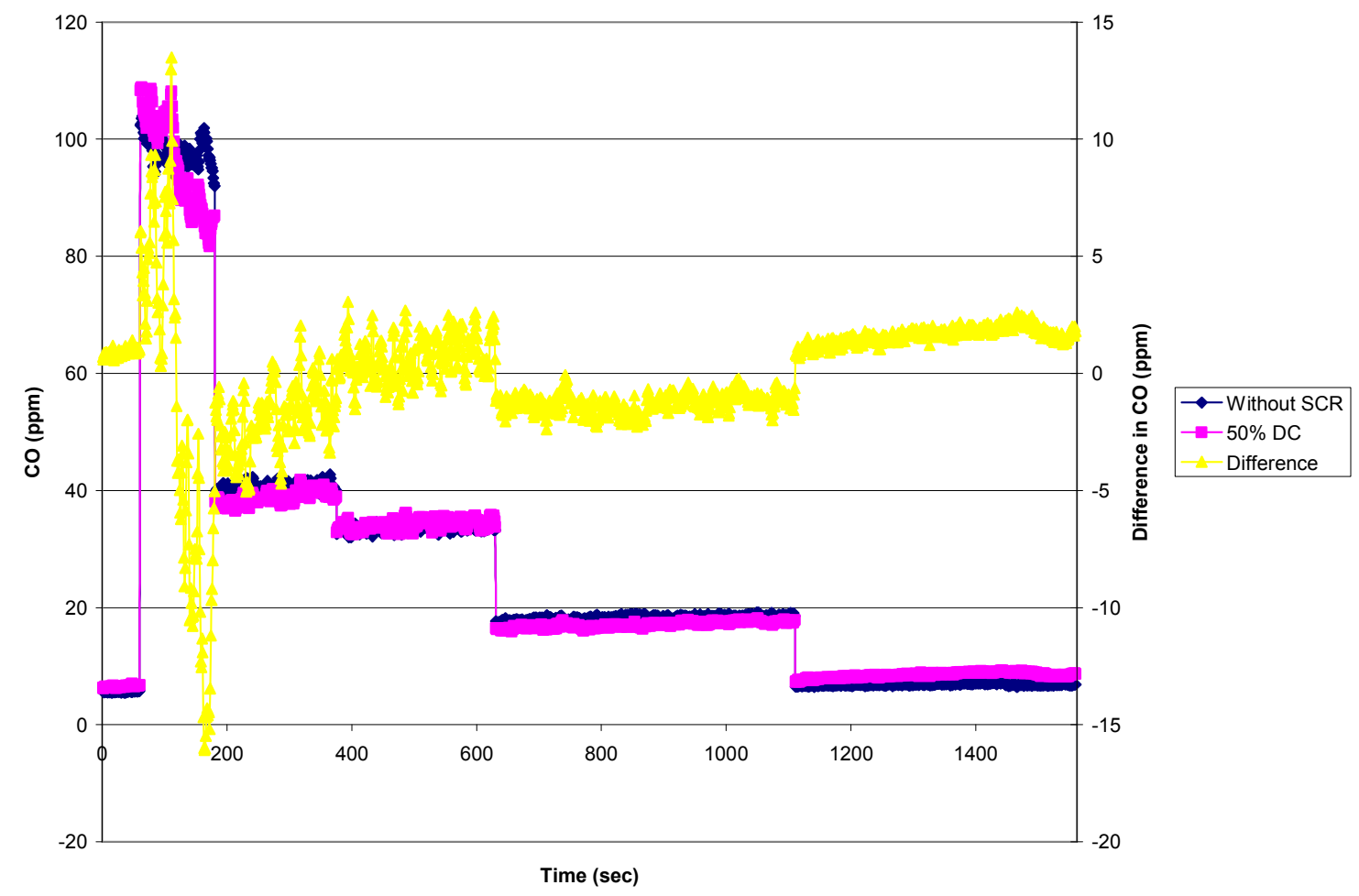

Figure 6.19 E5 Carbon Monoxide Results 
In order to better represent the NOx reduction capabilities of the system Table 6.1 was provided. The table contains mode by mode data for the E5 50\% DC test. Higher reduction capabilities were found per mode on a g/bhp-hr level.

Table 6.1 ICOMIA E5 Mode by Mode Data

\begin{tabular}{|c|c|c|c|c|c|c|}
\hline Mode & 1 & 2 & 3 & 4 & 5 & 6 \\
\hline Speed \% & Low idle & 100 & 90.58 & 79.46 & 62.54 & Low idle \\
\hline Torque \% & 0 & 100 & 78.91 & 57.20 & 29.55 & 0 \\
\hline Time Weighting & $\begin{array}{c}\text { Added for } \\
\text { idle start up }\end{array}$ & 0.08 & 0.13 & 0.17 & 0.32 & 0.30 \\
\hline Time of collection (sec) & 60 & 120 & 195 & 255 & 480 & 450 \\
\hline Baseline Nox g/bhp-hr & -- & 3.48 & 3.65 & 3.44 & 4.69 & -- \\
\hline With Urea SCR 50\%DC & -- & 2.03 & 1.9 & 1.79 & 2.64 & -- \\
\hline Reduction \% & -- & 41.67 & 47.95 & 47.97 & 43.71 & -- \\
\hline Fuel used (grams) & 31.36 & 1846 & 2150 & 1932 & 1796 & 238.6 \\
\hline Urea delivered (grams) & 0 & 160.45 & 168.46 & 132.86 & 147.80 & 0.06 \\
\hline Urea as \% of Fuel & 0 & 8.69 & 7.84 & 6.88 & 8.23 & Negligible \\
\hline
\end{tabular}




\section{Conclusion and Recommendations}

From the discussed results, it has been shown that an independently controlled, stand-alone urea SCR system was feasible for retrofit applications to reduce diesel engine NOx levels. A system was designed, constructed and tested to demonstrate its functionality. The system had four basic input signals: differential pressure, absolute pressure, temperature and NOx concentration. The system was controlled independently of engine parameters. An injection system was able to deliver metered amounts of urea to the exhaust stream based on a system algorithm. Testing at WVU's EERL showed no system failure throughout multiple tests over a two day period.

It was found that the target reduction of $50 \%$ was possible, but dependent upon test cycle. Higher reduction was possible during transient cycles because of the lack of idle time and buffer ability of the catalyst. Reduction fell to below the target of $50 \%$ only due to software control to minimize ammonia slip. The system showed NOx reduction capabilities of $41-67 \%(\mathrm{~g} / \mathrm{bhp}-\mathrm{hr})$ based on cycle or mode values with and without urea injection. The system showed significant dilute ammonia slip with higher NOx reduction values. The lower average values of 5-7 ppm may be deemed acceptable, but are not raw numbers. Dilution ratios would raise the average raw concentration to 25-35 ppm. Even though ammonia slip was detected, no noticeable CO spikes of greater than $+/-15 \mathrm{ppm}$ occurred in either the NRTC or ICOMIA E5 cycles. Implementation of the UIS into the exhaust system had no negative impacts on engine performance. NOx values and work values for the NRTC were consistent throughout the two day testing and were the same as results obtained from previous testing work of this engine. 
From the preceding conclusions, recommendations were made to possibly increase the urea injection system performance on NOx reduction while minimizing ammonia slip. Since no noticeable spikes in $\mathrm{CO}$ occurred, the ammonia slip may have been a result of mal-distribution of the urea on SCR bricks. The proposed maldistribution would most likely have been the result of poor atomization from the urea injection system. Pooling due to wall impingement did occur causing a small leak of liquid post injection plane and pre SCR. The injection rate was fixed at $7 \mathrm{~Hz}$ allowing for a maximum duration of injection of nearly 142 milliseconds. Due to the high flow of this injector a maximum duty cycle request of no greater than $32 \%$ for the NRTC was ever demanded. This equated to maximum injection events of no greater than 45 milliseconds. For further research, the injection rate could be double or tripled for better atomization on a per injection event basis. Since the mass per injection event would decrease, the fluid moment would decrease leading to enhanced mixing with the exhaust stream. The distance from the plane of injection to SCR face could also be increased from the previous value of 5 diameters to 7-10 diameters for enhanced turbulent mixing. If these changes yielded significant improvements in ammonia slip, then the DC could again be increased to improve the overall NOx reduction percentage.

Other recommendations would include a standard length between piping bends and Pitot tubes to ensure a fully developed velocity profile, averaging methods to decrease the noise of low pressure measurements, lowered temperature threshold to $200^{\circ} \mathrm{C}$, and the use of a temperature estimation model. 
If all of these changes still yielded unacceptable ammonia slip then a passive postSCR oxidation catalyst could be utilized to eliminate ammonia slip. Further research on this system and other variations should be done as the results of this research are promising for a stand alone urea SCR system to be applicable in retrofit applications for diesel engines. 
References:

1.) R. Mital, J. Li, S.C. Huang, B.J. Strola, R.C. Yu, J.A. Anderson and K. Howden, "Diesel Exhaust Emissions Control for Light Duty Vehicles," SAE 2003-01-0041, 2003.

2.) W.W. Pulkrabek. Engineering Fundamentals of the Internal Combustion Engine. New Jersey: Prentice Hall, 2004.

3.) "Air Toxics in New England." U.S. Environmental Protection Agency. 2007. EPA. 16 Aug. 2007 < http://www.epa.gov/ne/eco/airtox/diesel.html>.

4.) J. Gleshoff, M. Pfeifer, A. Shafer-Sindlinger, P.C. Spurk, G. Garr, T. Leprince and M. Crocker, "Advanced Urea SCR Catalysts for Automotive Applications," SAE 2001-01-0514, 2001.

5.) W. Fraser, P. Marchman, D. Martinez and D. Thomas. "Reducing Air Emissions from Marine Diesel Engines: Regional Recommendations.", June 3, 2004.

6.) D. Kodjack, F. Kamakate, and J. Dixon. "New Study: Air Pollution from Ships Overtakes Road Traffic." The International Council On Clean Transportation. March 22, 2007.

7.) “Overview of EPA's Emission Standards for Marine Engines." U.S. Environmental Protection Agency. EPA420-F-04-031. August 2004.

8.) "Median Life, Annual Activity, and Load Factor Values fro Nonraod Engine Emissions Modeling." U.S. Environmental Protection Agency. EPA420-P-04-004. April 2004.

9.) "Staten Island Ferry Alice Austen Vessel SCR Demonstration Project: Final Report." M.J. Bradley \& Associates, Inc. August 2006.

$<$ www.mjbradley.com/documents/Austen_Alice_Report_Final_31aug06.pdf $>$.

10.) C. Witherspoon, Executive Officer, California Air Resource Board.

11.) "What Is the Texas Emission Reduction Plan (TERP)?" Texas Commission on Environmental Quality. 20 April 2008.

< http://www.tceq.state.tx.us/implementation/air/terp/program_info.html>.

12.) "A Comparative Analysis of the Feasibility and Cost of Compliance with Potential Future Emission Standards for Heavy- Duty Vehicles Using Diesel or Natural Gas." Sierra Reseach, Inc. SR00-0202. February 2000.

< http://www.cleanairnet.org/infopool/1411/articles-59978_resource_1.pdf $>$.

13.) M.D. Kass, J.F. Thomas, S.A. Lewis, J.M. Storey, N. Domingo, R.L. Graves, A.Panov and P. Park, "Selective Catalytic Reduction of NOx Emissions from a 5.9 Liter Diesel Engine Using Ethanol as a Reductant," SAE 2003-01-3244, 2003. 
14.) S. Choi, Y. Yoon, S. Kim, G. Yeo and H. Han, "Development of Urea-SCR System for Light-Duty Diesel Passenger Car," SAE 2001-01-0519, 2001.

15.) C. Lambert, R. Hammerle, R. McGill, M. Khair and C. Sharp, "Technical Advantages of Urea SCR for Light-Duty and Heavy-Duty Diesel Vehicle Applications," SAE 2004-01-1292, 2004.

16.) C.M. Schar, C.H. Onder, H.P Geering and M. Elsener, "Control-Oriented Model of an SCR Catalytic Converter System," SAE 2004-01-0153, 2004.

17.) T. Kentaro. "High Performance Catalysts to Prevent Ammonia Slip." Kagaku to Kogyo. Vol. 56, No. 6, Pg. 682. 2003. ISSN: 0022-7684.

18.) J. Gieshoff, A. Schafer-Sindlinger, P.C. Spurk, J.A.A. van den Tillaart, and G. Garr, "Improved SCR Systems for Heavy Duty Applications," SAE 2000-01-0189, 2000.

19.) C. Havenith, R. P. Verbeek, D. M. Heaton and P. van Sloten, "Development of a Urea DeNOx Catalyst Concept for European Ultra-Low Emissions Heavy-Duty Diesel Engines," SAE 95652, 1995.

20.) I. Gekas, P. Gabrielsson, K. Johansen, L. Nyengaard and T. Lund, "Urea-SCR Catalyst System Selection for Fuel and PM Optimized Engines and a Demonstration of a Novel Urea Injection System," SAE 2002-01-0289, 2002.

21.) “75-90\% NOx Reduction for Diesel \& Natural Gas Engines.” RJM ARIS Technology. 14 June $2007<$ http://rjm.com/html/a_nox_control.htm>.

22.) H.T. Hug, A. Mayer and A. Hartenstein, "Off-Highway Exhaust Gas AfterTreatment: Combining Urea-SCR, Oxidation Catalysis and Traps," SAE 930363, 1993.

23.) N. Kato, H. Kurachi and Y. Hamada, "Thick Film ZrO2 NOx Sensor for the Measurment of Low NOx Concentrations," SAE 980170, 1998.

24.) “Order and Consent Decree: Mack Truck Corporation and Renault V.I." $\underline{\text { U.S. }}$ Environmental Protection Agency. 10 May 2008.

< http://www.epa.gov/compliance/resources/decrees/civil/caa/mackall.pdf>.

25.) W. Miller. "Development of Urea-SCR For Heavy-Duty Trucks Demonstration Update." Mack Trucks, Inc. 2000.

26.) A. P. Walker, R. Allison. "The Development and Performance of the Compact SCR-Trap System: A 4-Way Diesel Emission Control System,"

SAE 2003-01-0778, 2003. 
27.) K. Hirata, N. Masaki, H. Ueno and H. Akagawa, "Development of Urea-SCR system for Heavy-Duty Commercial Vehicles," SAE 2005-01-1860. 2005.

28.) S. J. Jeong and W. S. Kim. "Simulation on the Optimum Shape and Location of Urea Injector for Urea-SCR System of Heavy-duty Diesel Engine to Prevent $\mathrm{NH}_{3}$ Slip." SAE 2005-01-3886. 2005.

29.) T.V. Johnson, "Diesel Emission Control Technology -2003 in Review," SAE 2004-01-0070. 2004.

30.) West Virginia University Challenge $X$ Team. "2006 Spring Technical Report." Submitted to General Motors 2006. < http://www.challengex.org>.

31.) "TerraCair Ultrapure Diesel Exhaust Treatment." Terra Industries. 15 May 2008.

$<$ http://www.terraindustries.com/our_products/urea/terracair/ terracair_brochure.pdf $>$.

32.) A.F. Mills. "Basic Heat and Mass Transfer." Prentice Hall. New Jersey. 1999.

33.) D. Young, B. Munson, and T. Okiishii. "A Brief Introduction to Fluid Mechanics.” John Wiley and Sons, Inc. New Jersey. 2004. 
Appendix A 
Terra Industries Ine.

Terra Centre - 600 Fourth Street

Urea Liquor

Sioux City, Iowa 51101

MSDS Number 2046 (Revised August 24, 2007)

6 Pages

\section{CHEMICAL PRODUCT and EMERGENCY TELEPHONE CONTACT}

\begin{tabular}{|c|c|}
\hline roduct Name:...... & Urea Liquor \\
\hline Chemical Family: & Amide \\
\hline Synonyms:................ & $\begin{array}{l}\text { Urea Solution; Urea Cattle Feed; Nitrogen } \\
\text { Solution for SCR NO Control Systems }\end{array}$ \\
\hline rmula: & $\mathrm{CH}_{4} \mathrm{~N}_{2} \mathrm{O}+\mathrm{H}_{2} \mathrm{O}$ \\
\hline
\end{tabular}

EMERGENCY TELEPHONE NUMBER

CHEMTREC (U.S.)

$800-424-9300$

CANUTEC (Canada): ............................ 613-996-6666

2. COMPOSITION/INFORMATION ON INGREDIENTS

Component Name Percentage by Weight CAS Number

\begin{tabular}{lll}
\hline Urea & $30-85 \%$ & $57-13-6$
\end{tabular}

Froe Ammonia $\quad 0.1-1,0 \% \quad 7664-41-7$

Biuret $\quad 0.1-0.5 \% \quad 108-19-0$

Ammonium Carbamate $\quad 0.1-0.5 \% \quad 1111-78-0$

Water $\quad 13-69.7 \% \quad 7732-18-5$

\begin{tabular}{|lllll|}
\hline \multicolumn{5}{|c|}{ Exposure Limits } \\
\hline Component & TWA & STEL & PEL & IDLH \\
\hline Ammonia & $25 \mathrm{ppm}$ & $35 \mathrm{ppm}$ & $50 \mathrm{ppm}$ & $300 \mathrm{ppm}$ \\
No limits established for urea liquor, biuret, or ammonium carbamate & \\
\hline
\end{tabular}

\section{HAZARDS IDENTIFICATION}

Colorless liquid. With slight ammonia (pungent) odor. Reacts with sodium hypochlorite or calcium hypochlorite to form the explosive nitrogen trichloride. When heated, urea releases ammonia and when heated to decomposition it emits toxic fumes of nitrogen oxides $\left(\mathrm{NO}_{\mathrm{x}}\right)$, ammonia, and cyanuric acid. Use water to control fires involving urea liquor if water is compatible with burning material. Urea liquor itself is non-flammable. 


\section{POTENTIALHEALTHEEEECTS}

Primary Routes of Entry: Skin contact/absorption, eye contact, and vapor inhalation.

General Acute Exposure: May cause irritation to eyes and skin. Ammonia and carbon dioxide vapors may accumulate in a confined space.

General Chronic Exposure: No test data available

Carcinogenicity:

NTP . . . . . Not Listed

IARC: ................................................... Not Listed

OSHA :................................................... Not Regulated

Medical Conditions Aggravated by Exposure: No test data available.

\section{FIRST AID MEASURES}

First Aid for Eyes: Flush eyes with copious amounts of tepid water for at least 15 minutes. If irritation, pain, swelling, excessive tearing, or light sensitivity persists, the patient should be seen in a health care facility.

First Aid for Skin: If irritation occurs, flush exposed area with copious amounts of tepid water for at least 15 minutes followed by washing area thoroughly with soap and water. The patient should be seen in a health care facility if irritation or pain persists.

First Aid for Inhalation: If irritation develops move patient to fresh air and monitor. If cough or difficulty in breathing develops, evaluate for respiratory tract irritation. If trained to do so, administer supplemental oxygen if needed. If irritation, coughing, or difficulty in breathing persists the patient should be seen in a health care facility.

First Aid for Ingestion: If conscious, give the patient large quantities of water to drink and induce vomiting. Seek medical attention.

\section{FIRE FIGHTING MEASURES}

Urea liquor is not flammable.

Extinguishing Media: Use water to extinguish a fire involving urea liquor if water is compatible with the burning material.

\section{Special Fire Fighting Procedures:}

a. Positive pressure self-contained breathing apparatus (SCBA) should be used when there is a potential for inhalation of vapors and/or fumes.

b. Wear full fire fighting protective equipment that is appropriate for conditions.

Caution:

a Runoff from fire control or dilution water may cause pollution.

b. At elevated temperature, urea liquor may decompose to form cyanuric acid, ammonia, biuret, and/or nitrogen oxides. 


\section{ACCIDENTAL RELEASE MEASURES}

Spill or Leak Measures: Keep unnecessary people away and isolate hazard area. Urea liquor may be toxic to cattle (ruminants) when ingested if amount ingested is not controlled properly.

Determining Spill Size: Generally, a small spill is one that involves a single, small package (i.e. up to a 55 gallon drum), small cylinder, or a small (non-continuing) leak from a large container.

\section{Small or Large Spill:}

a. Spilled urea liquor may cause slippery conditions.

b. Recover and use as fertilizer.

c. If disposal of product or contaminated by-products is necessary, follow guidelines set forth by local, state, and federal environmental agencies.

d. Runoff may cause pollution.

\section{HANDLING AND STORAGE}

No unusual storage precautions are necessary.

Handling Precautions: Use proper personal protective equipment when working with or around urea liquor. (See section 8).

\section{EXPOSURE CONTROLS, PERSONAL PROTECTION}

Respiratory Protection Requirements: Urea liquor may pose an inhalation hazard in confined areas due to its ability to produce ammonia and carbon dioxide vapors. If necessary to enter an area that contains urea liquor, monitor for ammonia and oxygen content. Oxygen levels should be maintained between $19.5 \%$ and $23.5 \%$, if outside of this range use appropriate precautions. If ammonia vapors are present, protect as follows:

$$
\begin{aligned}
25 \text { to } 35 \mathrm{ppm} \text { : } & \begin{array}{l}
\text { No protection required. } \\
35 \text { to } 50 \mathrm{ppm}:
\end{array} \\
50 \text { to } 250 \mathrm{ppm}: & \begin{array}{l}
\text { Protection required if the daily TWA is exceeded } \\
\text { ammonia canister(s) or cartridge(s). }
\end{array} \\
250 \text { to } 300 \mathrm{ppm}: & \begin{array}{l}
\text { Minimum of a full-face air-purifying respirator equipped } \\
\text { with ammonia canister(s) or cartridge(s). }
\end{array} \\
>300 \mathrm{ppm}: & \begin{array}{l}
\text { A fresh air supply system must be used (i.e. positive } \\
\text { pressure self contained breathing apparatus) }
\end{array}
\end{aligned}
$$


Engineering Controls: Adequate ventilation should be supplied.

Skin Protection Requirements: Impervious gloves should be worn. Urea liquor is shipped as a hot liquid (approximately $220^{\circ} \mathrm{F}$ ). Additional protection for hands and skin should be used to prevent contact of hot liquid.

Eye Protection Requirements: It is recommended that safety glasses or goggles be used and if there is a potential for splashing liquid, a face shield should be used in conjunction with the safety glasses or goggles.

Other Protective Equipment: Safety shower and eyewash fountain or at least 5 gallons of accessible clean water should be provided in a urea liquid handling area.

\section{PHYSICAL AND CHEMICAL PROPERTIES}

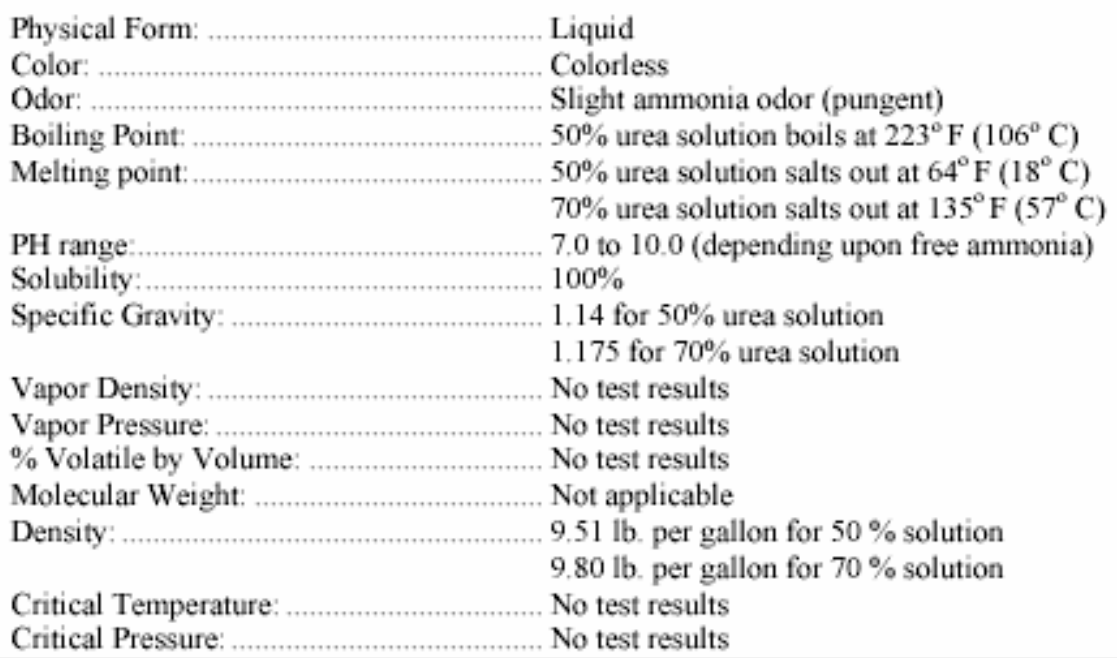

\section{REACTIVITY}

Stability: This is a stable material

Hazardous Polymerization Will not occur.

Decomposition: Urea liquor forms ammonia, cyanuric acid, biuret, and/or nitrogen oxides $\left(\mathrm{NO}_{\mathrm{x}}\right)$ upon decomposition.

Incompatibilities: Reacts with sodium hypochlorite or calcium hypochlorite to form nitrogen trichloride that may explode spontaneously in air. Incompatible with sodium nitrite, phosphorus pentachloride, and nitrosyl or gallium perchlorate. Urea will form urea nitrate when mixed with nitric acid at low $\mathrm{pH}$. Urea nitrate may become unstable and/or explosive under certain conditions. 


\section{TOXICOLOGICAL INFORMATION}

\section{Toxicity}

Acute Oral Toxicity

LD $\mathrm{L}_{50}$, Rat: ............................................... 14,300-15,000 mg/kg

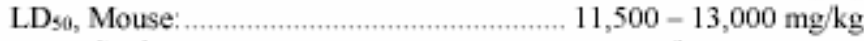

LD $D_{s 0}$, Cattle: …...................................... $510 \mathrm{mg} / \mathrm{kg}$

Repeated Dose Toxicity

Rat:

NOAEL $=40 \%$ in ointment $(24$ wks; dermal $)$

\section{Ecotoxicity}

Acute Toxicity to Fish

$\mathrm{LC}_{50} \quad$ Barillius barna ............................ 9,100 mg/L (96 hr)

Acute Toxicity to Aquatic Invertebrates

$\mathrm{EC}_{50} \quad$ Daphnia magna .......................... $>10,000 \mathrm{mg} / \mathrm{L}$ (DIN $38412 \mathrm{Part}$ II; $24 \mathrm{hr}$ )

Toxicity to Aquatic Plants

TT Scenedesmus quadracauda ........... $>10,000 \mathrm{mg} / \mathrm{L}$ (192 hr cell multiplication inhibition test)

Note: Data is for Urea

Source: TFI Product Testing Program April 2003

\section{ECOLOGICAL INFORMATION}

Notify local health and wildlife officials and operators of any nearby water intakes of contamination or discharge into or leading to waterways.

Note: See Ecotoxicitv information in section 11

\section{DISPOSAL CONSIDERATIONS}

Urea liquor is not listed by the Federal EPA as a hazardous waste. Consult state/provincial and local environmental agencies for acceptable disposal methods. Recover product for use as a fertilizer if possible.

\section{TRANSPORTATION INFORMATION}

Urea liquor is not listed by any U.S. or Canadian transportation authority as a hazardous material and as such, no specific information is available. 


\section{REGULATORY INFORMATION}

SARA TITLE III: Not Listed

CERCLA Hazardous Substances List: Not Listed

TSCA Inventory: Listed

\section{OTHER INFORMATION}

Nov, 5, 1996: The MSDS was rewritten to comply with ANSI Standard Z400,1-1993.

July 1, 2003: $\quad$ Added toxicity information from the TFI Product Testing Program 2003.

August 4, 2006: Reviewed and reissued without revisions.

Oetober 4, 2006: Revised Reactivity section to add information concerning the hazards of urea nitrate formation when urea is mixed with nitric acid

August 24, 2007: Added pH range.

The information and recommendations herein are taken from data contained in independent, industryrecognized references including but not limited to NIOSH, OSHA, CHRIS, the TFI Product Testing

Program, and SAX's Dangerous Properties of Industrial Materials - ninth edition. Terra Industries Inc. makes no guarantec, warranty or other representation concerning this substance, since conditions of its use are beyond the control of the company. Terra Industries Ine. disclaims any liability for loss or damage incurred in connection with the use of this substance. 